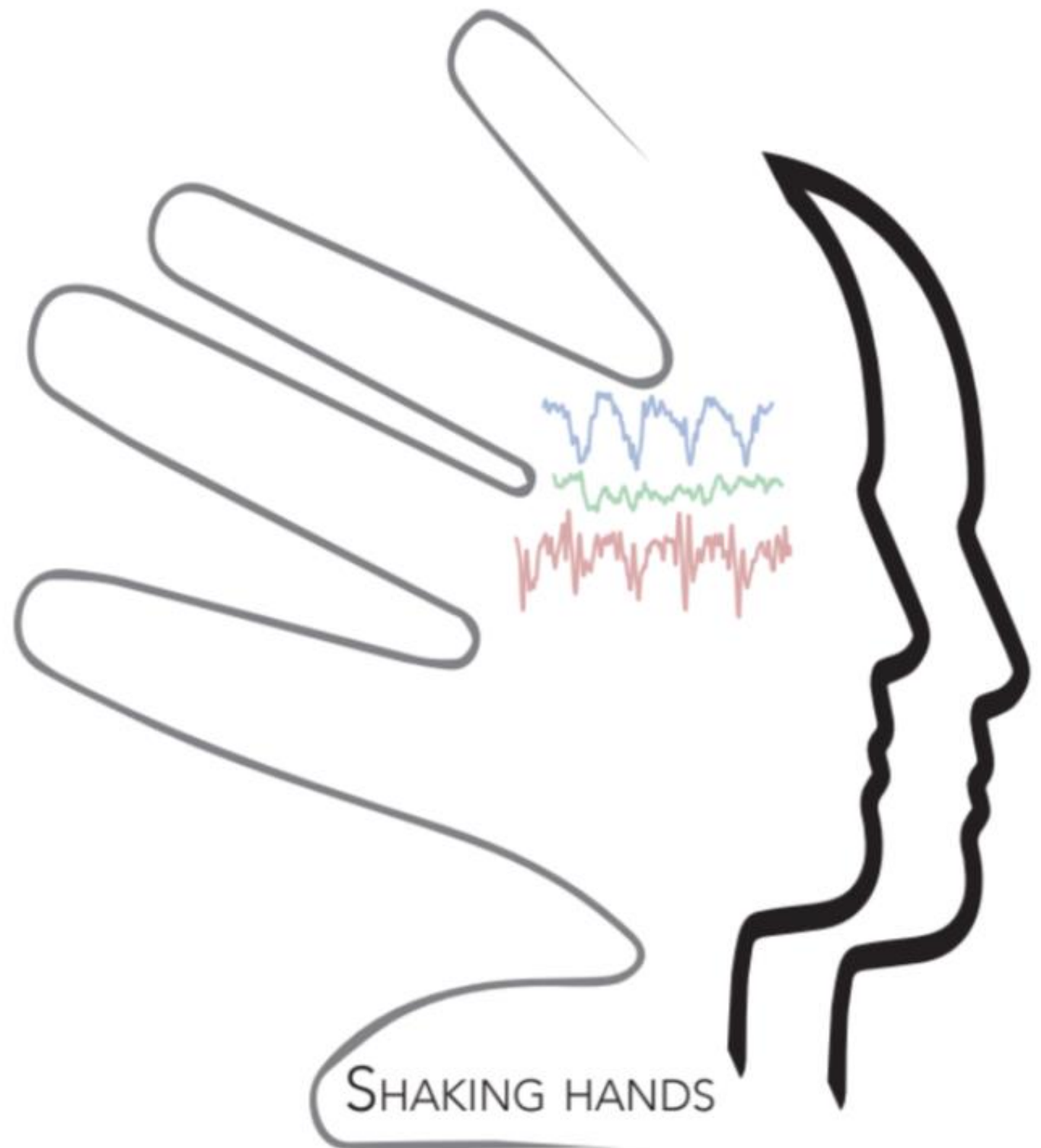

ESTABLISHING OBJECTIVE PARAMETERS TO DIFFERENTIATE BETWEEN ESSENTIAL TREMOR AND PARKINSON'S DISEASE

FraUke LufT 



\section{SHAKING HANDS}

ESTABLISHING OBJECTIVE PARAMETERS TO DIFFERENTIATE BETWEEN ESSENTIAL TREMOR AND PARKINSON'S DISEASE

Frauke Luft 


\section{UNIVERSITY OF TWENTE.}

Faculty of Electrical Engineering, Mathematics and Computer Science Department of Biomedical Signals and Systems

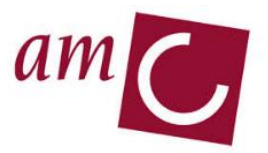

Amsterdam University Medical Centrum

P.O. 22660, 1100 DD Amsterdam Zuidoost

The Netherlands

TUDelft

Delft University of Technology

P.O. 5, 2600 AA Delft, The Netherlands

MOOG

Moog BV

2153 PJ Nieuw-Vennep, The Nederland

TMSi

Twente Medical Systems International B.V.

7575 EJ Oldenzaal, The Netherlands

The project was a cooperation between the Amsterdam University Medical Center, the Technical University Delft and the University of Twente. Technical partners in this project were MOOG and Twente Medical Systems (TMSI).

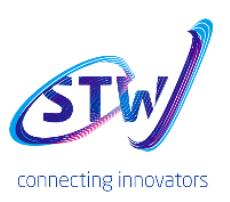

This research is supported by the Dutch Technology

Foundation (NeuroSIPE project number 10739), which is part of the Netherlands Organization for Scientific Research (NWO). 


\section{SHAKING HANDS}

ESTABLISHING OBJECTIVE PARAMETERS TO DIFFERENTIATE BETWEEN ESSENTIAL TREMOR AND PARKINSON'S DISEASE

\section{DISSERTATION}

to obtain

the degree of doctor at the University of Twente, on the authority of the rector magnificus, Prof. Dr. T.T.M. Palstra

on account of the decision of the graduation committee, to be publicly defended on Wednesday the $25^{\text {th }}$ of March 2020, at 14:45

by

Frauke Luft

born on the $16^{\text {th }}$ of January, 1987 in Münster, Germany 
This dissertation has been approved by:
Supervisor
Prof. Dr. Ir. P.H. Veltink
Co-supervisor
Dr. Ir. T. Heida

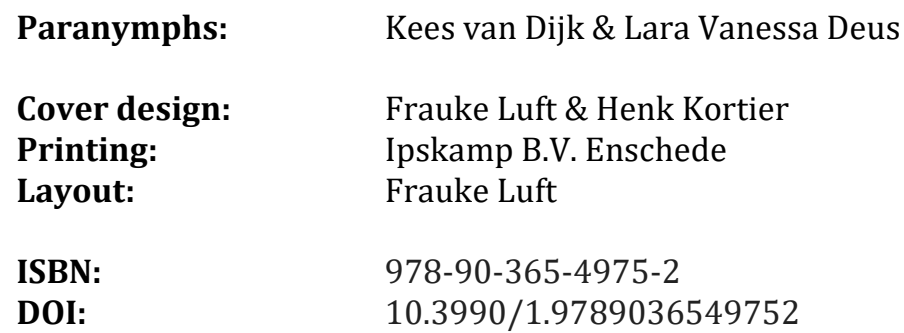

(C) Frauke Luft, 2020 - All rights reserved

No part of this publication may be reproduced or transmitted in any form or by any means, electronic or mechanical, including photocopy, recording or any information storage or retrieval system, without permission in writing from the author.

Alle rechten voorbehouden. Niets uit deze uitgave mag worden vermenigvuldigd, in enige vorm of op enige wijze, zonder voorafgaande schriftelijke toestemming van de auteur. 


\section{Composition of the graduation committee:}

Chairman \& secretary

Prof. Dr. J.N. Kok (Dean)

\section{Supervisor}

Prof. Dr. Ir. P.H. Veltink

\section{Co-supervisor}

Dr. Ir. T. Heida

\section{Members}

Prof. Dr. R.J.A. Richard van Wezel Prof. Dr. Ir. C.H. Slump

Prof. Dr. F.C.T. van der Helm

W.D. Hutchison, $\mathrm{PhD}$

Dr. R.C.G. Helmich
University of Twente

University of Twente

University of Twente

University of Twente University of Twente Delft University of Technology University of Toronto

Radboud University 



\section{Summary}

Movement disorders, such as essential tremor (ET) and Parkinson's disease (PD), are disabling and lower the quality of life of the affected patients. Despite their pathological differences, PD and ET can be difficult to distinguish from each other, due to overlapping symptoms, such as tremor or deficits during motor task performance. Common diagnostic tools, such as polymyography, movement disorder rating scales or single photon emission computed tomography (SPECT) scans are either invasive (SPECT), time consuming, subjective (rating scales), expensive and/or not widely available. Therefore, this thesis focusses on finding objective parameters to differentiate PD from ET that can be measured with commonly available tools.

The first objective, quantifying tremor occurrence in ET and PD subjects and identifying corresponding cortical activity, is the topic of chapters 2 and 3. The second objective, quantifying timing deficits of ET and PD subjects during voluntary movement under different conditions and identifying corresponding neuronal networks, is the topic of chapters 4 to 6 .

In chapters 2 through 5 movement was recorded using accelerometers and muscle activation by surface EMG electrodes. Cortical activity was recorded using EEG in chapters 3 and 5. In chapter 6 brain activation was also measured using functional magnetic resonance imaging (fMRI). Movement was recorded using 3D MRI compatible accelerometers.

Chapter 2 describes a new objective quantitative method to split surface electromyography and 3D accelerometer data into tremor and non-tremor windows. Afterwards, the tremor stability index was determined to indicate the advantage of detecting tremor windows prior to analysis. Subjects performed a resting, postural and movement task. Data was split into threesecond windows and the power spectral density was calculated for each window. The relative power around the peak frequency with respect to the power in the tremor band was used to classify the windows as either tremor or non-tremor. The method yielded a specificity of $96 \%$, sensitivity of $85 \%$ and accuracy of $91 \%$ of tremor classification. During tremor significant differences were found between groups in the tremor stability index. The results suggest that the introduced method could be used to determine 
under which conditions and to which extend undiagnosed patients exhibit tremor.

The aim of chapter 3 was to determine differences in cortical activity during the presence of tremor between PD and ET. For this purpose the method established in chapter 2 is used to split not only accelerometer and EMG data, but also electroencephalography (EEG) data into tremor and nontremor windows. Subjects performed the same tasks as in chapter 2. Data was split into tremor and non-tremor windows based on the relative power of the tremor frequency recorded with accelerometers placed on the hands. Regression analysis was used to determine significant correlations between tremor at the hands and cortical activity in the alpha and beta band recorded with EEG. Significant correlations were found at different cortical regions during tremor occurrence in both groups. The resting task revealed significant correlations between tremor and cortical activity in PD but not ET. During the postural task, significant correlations were found at the associate and primary visual cortex in ET suggesting that these patients rely on visual guidance for movement execution in contrast to PD patients.

The following chapters, chapters 4 through 6 , focus on the second objective of this thesis, quantifying the timing deficits of ET and PD subjects during voluntary movements. For this purpose subjects performed a bimanual tapping task. Chapter 4 describes the effect of external cues on the performance of a bimanual motor task in PD and ET patients. Providing external cues improves timing of these movements in PD, but its effect on ET has not yet been studied in depth. The aim of this study was to evaluate the usefulness of a bimanual tapping task as a tool during clinical decision making. Hand movements and tremor were recorded using accelerometers and EMG (m. extensor carpi ulnaris) from PD and ET patients and healthy controls during a bimanual tapping task as a way to distinguish PD from ET. All subjects performed the three minute tapping task at two different frequencies ( 2 and $4 \mathrm{~Hz}$ ) while an auditory cue was switched on and off every 30 seconds. No significant intra-group differences were found in the patient groups. Acceleration data revealed significantly less accurate and more variable tapping in PD than in ET and healthy controls (HC). ET subjects tapped less accurately and with a greater variability than healthy controls during the $4 \mathrm{~Hz}$ tapping task. Most interestingly, the ability to follow the cue frequency more accurately improved in PD patients ii 
when kinetic tremor occurred. Tremor was detected using EMG, while kinematic information was received from the accelerometer data. Chapter 4 concluded that providing ET and PD patients with an external cue results in different tapping performances between patient groups and healthy controls. Furthermore, the findings suggest that kinetic tremor in PD enables patients to perform the task with a greater accuracy. So far this has not been shown in other studies.

In chapter 5 the power spectral density was determined from the recorded EEG. From the spectrum, the cortical task related power (TRP) was calculated during the same bimanual tapping task as in chapter 4 for the HC, PD and ET group. Increased TRP was found in different areas in the three groups. In both patient groups areas of motor planning, movement initiation, maintenance and coordination were active. ET patients showed additional activity in areas responsible for proprioception and association between somatosensory, auditory and visual information. On the other hand, PD patients had additional activation of areas responsible for motor response inhibition, auditory priming and basic processing of auditory stimuli. In the HC group an increased TRP was found in the area of motor response inhibition, bilateral object manipulation and basic auditory processing.

In chapter 6 brain activation in PD and ET patients during a similar bimanual tapping task was studied with fMRI. Subjects had to perform a bimanual tapping task, consisting of 6 blocks. Each block started with one minute of rest followed by a minute of tapping at $2 \mathrm{~Hz}$. A visual cue, a blinking dot, was presented for half a minute each time (rest and tapping) and subjects were asked to synchronize their movement with the cue during the tapping phase. The results of this study showed large differences in activity patterns between patients with PD and ET and between the patient groups and HC. The contrast between cued movement and non-cued movement revealed the most notable differences between groups. In ET, cueing seemed to have almost no effect on activation, whereas in the PD group cross-modelling between different areas seemed to occur. Furthermore, reduced activation of the motor cortex was found in the ET group compared to the HC group supporting the findings of chapter 5 . 
The results of all three studies suggest that a simple tapping task could be useful during clinical decision making and might be a valuable tool in an objective diagnostic protocol. 


\section{Samenvatting}

Bewegingsstoornissen, zoals essentiële tremor (ET) en de ziekte van Parkinson (ZvP), verminderen de levenskwaliteit van een patiënt. Ongeacht de verschillen in de pathofysiologie blijft het in sommige gevallen lastig om de juiste diagnose te stellen. Dit komt vanwege het feit dat symptomen, zoals een tremor of problemen tijdens het uitvoeren van motorische taken, zowel in ET als in ZvP kunnen voorkomen. Diagnostische methoden, zoals polymyografie, classificatieschalen, of SPECT, zijn veelal invasief, duur (SPECT), vragen veel tijd, zijn gevoelig voor subjectieve interpretatie (classificatieschalen), of zijn beperkt beschikbaar. Dit proefschrift geeft hierop een betekenisvol antwoord door, gebruikmakend van breed beschikbare klinische meetapparatuur, objectieve parameters aan te wijzen die het verschil tussen ET en ZvP kunnen aantonen.

Het eerste doel, het kwantificeren van tremor in ET- en ZvP-patiënten en de identificatie van bijbehorende corticale activiteit, is het onderwerp van de hoofdstukken 2 en 3 . Het tweede doel, het kwantificeren en de identificatie van onderliggende neurale netwerken middels het aanbrengen van verschillende auditieve en visuele stimuli, wordt in hoofdstuk 4 tot en met 6 behandeld. Om deze doelen te bereiken zijn drie verschillende groepen, te weten de patiëntgroepen ET en Parkinsons, en gezonde proefpersonen geïncludeerd. In de hoofdstukken 2 tot en met 5 zijn versnellingsopnemers gebruikt en is elektromyografie (EMG) toegepast om beweging en tremor te meten. In de hoofdstukken 3 en 5 is de corticale activiteit met behulp van EEG gemeten. In hoofdstuk 6 is van functionele MRI en compatibele versnellingsopnemers gebruikt gemaakt om respectievelijk hersenactiviteiten en lichaamsbewegingen te meten in een MRI scanner.

Hoofdstuk 2 beschrijft een nieuwe methode waarmee een tremor door zowel EMG alsmede versnellingsopnemers objectief gedetecteerd kan worden. Het hoofdstuk kent twee uitkomsten. Allereerst, wordt er een objectieve methode aangedragen die data van zowel EMG alsmede versnellingsopnemers in een tremor en niet-tremor groep kan classificeren. Vervolgens is aangetoond dat de diagnostische nauwkeurigheid van parameters, zoals de tremor stabiliteitsindex, toeneemt indien de data vooraf in een tremor en niet-tremor groep wordt gescheiden. Daarbij is het 
relatieve vermogen rondom de piekfrequentie, in verhouding tot het vermogen binnen het tremorfrequentieband, gebruikt om tremor te classificeren. De geïntroduceerde methode behaalt een specificiteit van $96 \%$, een sensitiviteit van $85 \%$ en een nauwkeurigheid van $91 \%$. De resultaten laten zien dat de methode geschikt kan zijn om bij nog niet gediagnosticeerde patiënten de tremorintensiteit, en de condities waarbij de tremor optreedt, te bepalen.

In hoofdstuk 3 wordt de methode uit hoofdstuk 2 gebruikt om ook elektro-encefalografie (EEG) data in tremor en niet tremor te classificeren met daarbij als doel om verschillen in tremor-specifieke corticale activiteit tussen ZvP- en ET-patiënten te bepalen. Patiënten voerden 3 verschillende motorische taken uit, een rusttaak, een houdingstaak en een bewegingstaak. EEG-data werd, op basis van gemeten tremor in de handen, in een tremor en niet-tremor segment gescheiden. Vervolgens is een regressieanalyse toegepast om significante correlaties tussen de tremoractiviteit van de handen en de corticale activiteit in de alpha en beta banden te bepalen. De gebieden waarin een significante correlatie werd gedetecteerd verschilt voor $\mathrm{ZvP}$ en ET. Tijdens de rusttaak werden de meest significante correlaties in de ZvP groep gevonden, maar was de correlatie in de ET groep afwezig. Tijdens de houdingstaak werden er significante correlaties tussen de visuele cortex en handtremor in de ET-groep gevonden maar was deze in de ZvP groep afwezig. Dit suggereert dat ET-patiënten meer van de visuele input gebruik maken dan de $\mathrm{ZvP}$ patiënten voor de uitvoering van dergelijke taken.

De laatste drie hoofdstukken behandelen het tweede doel, het kwantificeren van de bewegingskwaliteit in ET en ZvP patiënten. Hiervoor voerden de patiënten een taak met beide handen uit waarin ze gevraagd werd om een auditief ritme met de handen mee te tikken. In hoofdstuk 4 is het effect van een extern auditief signaal op de nauwkeurigheid waarmee iemand ritmisch kan tikken geanalyseerd. Het effect van soortgelijke signalen op de bewegingen van ZvP patiënten is reeds in vele studies gedaan, echter geldt dit niet voor ET-patiëntgroepen. Het doel van dit onderzoek is de bepaling of patiënten verschillend met een extern signaal omgaan en daarmee vast te stellen of een soortgelijke taak een bruikbare toevoeging kan zijn tijdens het diagnostische proces. Handbewegingen van $\mathrm{ZvP}$, ET en gezonde proefpersonen werden met behulp van EMG en versnellingsopnemers gemeten. Aan de proefpersonen werd gevraagd om tijdens het uitvoeren van de taak het ritme zo goed mogelijk te synchroniseren met een auditieve stimulus. Iedere 30 seconden werd de stimulus onderbroken waarbij de proefpersonen gevraagd werd om het vi 
ritme, waarin men aan het tikken was, aan te houden. Er zijn geen intragroepsverschillen gevonden. De inter-groepsanalyse liet zien dat ZvP- en ET-patiënten met een grotere variabiliteit tikten vergeleken met gezonde proefpersonen. De nauwkeurigheid waarmee ZvP-patiënten de externe stimulus konden volgen is beter te zijn bij patiënten waarbij een actietremor optrad tijdens de taak, waarbij het optreden van actie-tremor bij ETpatiënten geen effect had. Een vergelijkbare taak zou toegepast kunnen worden in het diagnostische proces van een patiënt met actie-tremor.

In hoofdstuk 5 is de corticale activiteit tijdens eenzelfde taak als die in hoofdstuk 4 bekeken. Om groepsverschillen in kaart te brengen is het taak gerelateerde vermogen (TRP) in het EEG berekend. In beide patiëntgroepen werd een verhoogd TRP gemeten in de gebieden die betrokken zijn bij de motorische planning, het initiëren, het onderhouden en het coördineren van bewegingen. In de ET-groep werd hiernaast nog een verhoogde TRP in gebieden welke verantwoordelijk zijn voor proprioceptie en associatie tussen sensorische, auditieve en visuele informatie gevonden. In de $\mathrm{ZvP}$ groep daarentegen, lieten gebieden betrokken bij motorische inhibitie en verwerking van auditieve stimuli een verhoogde BOLD-responsie zien. Vergelijkbare gebieden werden eveneens in de groep van gezonde proefpersonen gevonden.

In hoofdstuk 6, voerden ZvP, ET en gezonde proefpersonen een tik-taak uit met behulp van een visuele stimulus. Hersenactiviteit is met behulp van fMRI gemeten door gebruik te maken van een blokdesign. Proefpersonen werden verzocht 1 minuut rustig in de MRI-scanner liggen, hierop volgde een minuut waarin ze gevraagd werd om met beide handen naast het bed te tikken en hierbij het ritme te synchroniseren aan de visuele stimulus die op een beeldscherm aan de achterkant van de scanner getoond werd. De gemeten activiteitspatronen verschilden tussen de groepen. Het tikken met en zonder visuele stimulus vertoonde de grootste verschillen in het activiteitenpatroon tussen de ET en ZvP groepen. In ET lijkt het erop dat de stimulus marginaal effect heeft op de hersenactiviteit, terwijl in de ZvPgroep activiteit in verschillende sensorische gebieden zichtbaar is. Dit doet vermoeden dat, voor het goed uitvoeren van een taak, er bij ZvP patiënten multimodale koppelingen tussen deze gebieden aanwezig zijn.

De resultaten uit de hoofdstukken 4 tot en met 6 doen suggereren dat het raadzaam is om een tik-taak met externe stimuli te includeren in een objectief diagnostische protocol. 


\section{Contents}

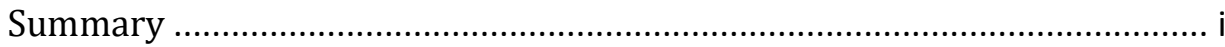

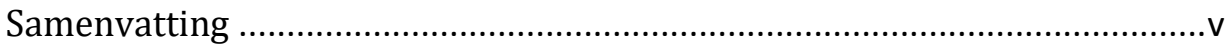

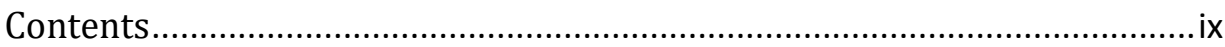

List of abbreviations ............................................................................

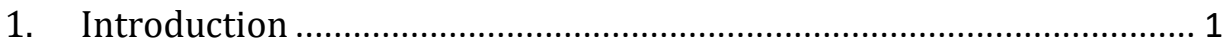

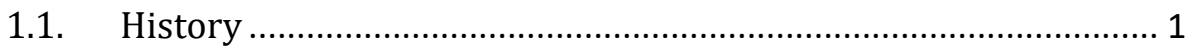

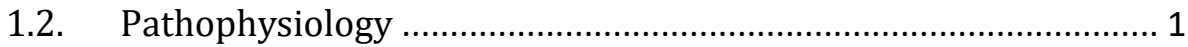

1.3. Quantitative measures of motor symptoms ………………......... 4

1.4. The Movement Diagnostic System project .................................... 8

1.5. Research objectives .............................................................. 11

1.6. Thesis outline ........................................................................... 11

PART I - TREMOR

2. Tremor detection in movement disorders ……................................ 15

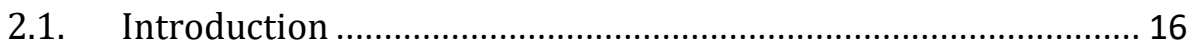

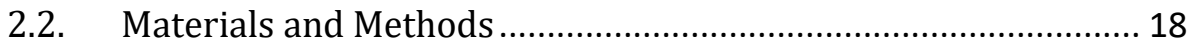

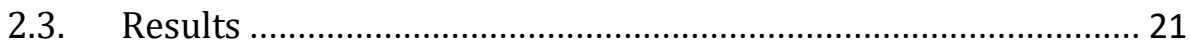

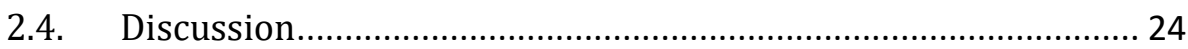

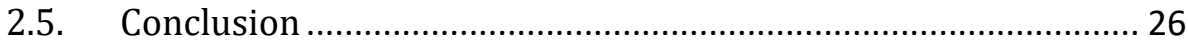

3. Cortical activity patterns during tremor windows ............................. 27

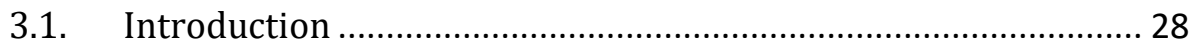

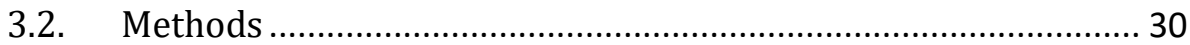

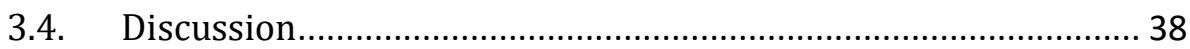

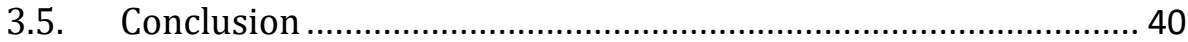

\section{PART II - CueING}

4. Movement analysis during cued and non-cued movement................. 43

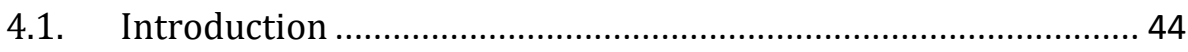




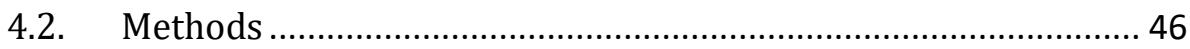

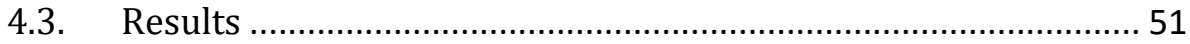

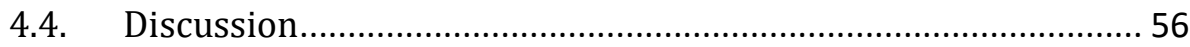

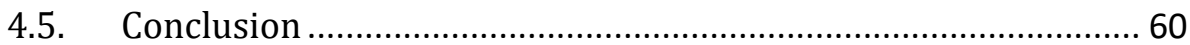

5. Cortical activity patterns during cued and non-cued movements...... 61

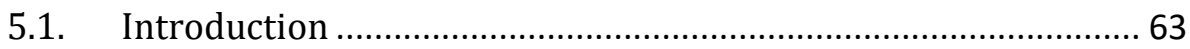

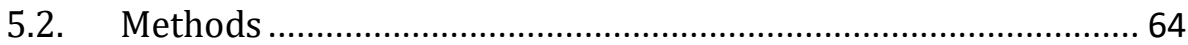

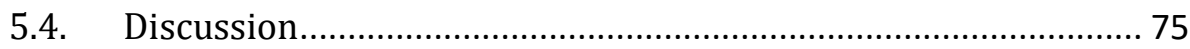

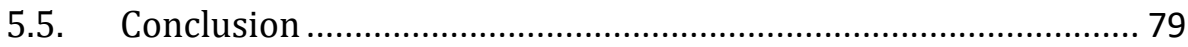

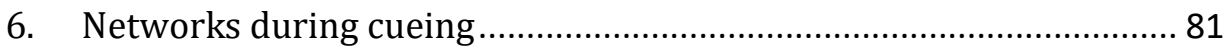

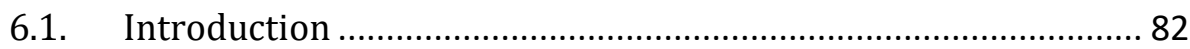

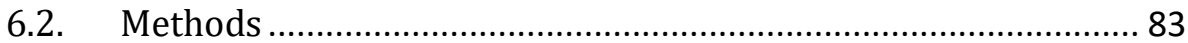

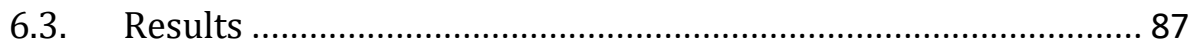

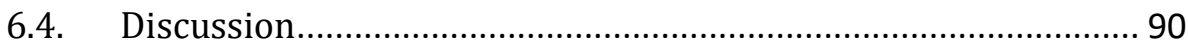

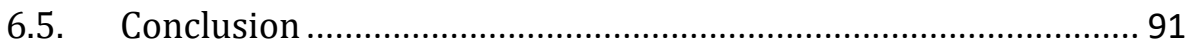

7. General discussion and conclusion .................................................... 93

7.1. Quantification of tremor severity and intermittency ................. 94

7.2. Quantification of timing ability ................................................... 95

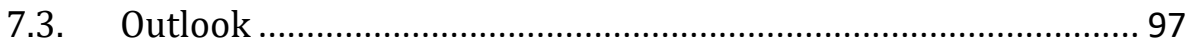

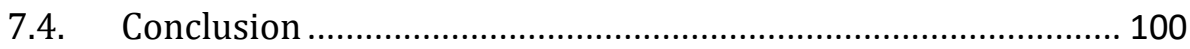

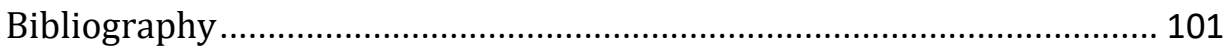

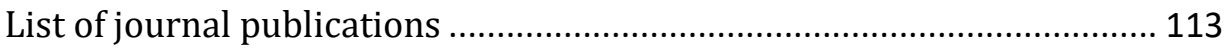

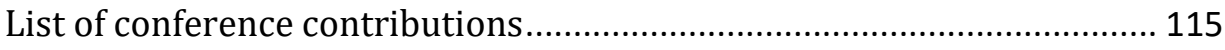

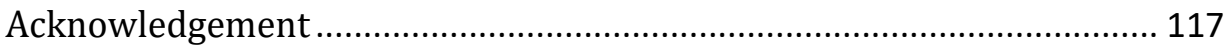




\section{List of abbreviations}

\begin{tabular}{ll} 
ACC & Accelerometer \\
ANOVA & Analysis of variance \\
BGTC & Basal ganglia-thalamo-cortical circuit \\
BOLD & Blood oxygenation level-dependent \\
C & Central \\
C2 & Cued movement at $2 \mathrm{~Hz}$ \\
C4 & Cued movement at 4 Hz \\
CMC & Cortical-muscular coherence \\
CTC & Cerebello-thalamo-cortical \\
DBS & Deep brain stimulation \\
EEG & Electroencephalography \\
EMG & Electromyography \\
EPI & Echoplanar imaging sequence \\
ET & Essential tremor \\
F & Female \\
F & Frontal \\
fMRI & Function Magnetic Resonance Imaging \\
FN & False negative \\
FP & False positive \\
GPi & Globus pallidus \\
HC & Healthy Controls \\
\hline
\end{tabular}




\begin{tabular}{ll} 
ICA & Independent component analysis \\
LC & Left central \\
LFP & Local field potential \\
M & Male \\
MDS & Movement diagnostic system \\
MT & Movement task \\
NC2 & Non-cued movement at $2 \mathrm{~Hz}$ \\
NC4 & Non-cued movement at $4 \mathrm{~Hz}$ \\
NTW & Non-tremor window \\
P & Posterior \\
PD & Parkinson's Disease \\
PSD & Power Spectral Density \\
PT & Postural task \\
RC & Right central \\
RelP & Relative Power \\
RT & Resting task \\
SPECT & Single Photon Emission Computed Tomography \\
STD & Standard deviation \\
STN & Subthalamic nucleus \\
TA & Tapping accuracy \\
TE & Echo time \\
TN & True negative \\
TP & True positive \\
\hline
\end{tabular}


TR Repetition Time

TRP Task related power

TRS Tremor rating scale

TSI Tremor stability index

TV Tapping variability

TW Tremor window

UPDRS Unified Parkinson's Disease Rating Scale

VIM Ventralis intermedius

VS Voxel size 



\section{Introduction}

\subsection{History}

In 1817, James Parkinson was the first physician to publish his observations about the shaking palsy (later: Parkinson's disease) and its differences compared to other tremulous disorders [2]. He described the motor symptoms surprisingly accurately and noticed that patients with other disorders experienced tremor during voluntary movement rather than during rest, as is the case most often described in Parkinson's disease (PD).

Nowadays, over 200 years later, a lot more is known about neurodegenerative disorders, such as PD. However, the exact pathophysiology is unknown. Furthermore, differentiation from other tremulous movement disorders, such as essential tremor (ET), probably the most common tremulous disorder [3], remains difficult. A delayed diagnosis and delayed targeted therapy have a marked impact on disease outcome and progression. Therefore, the studies described in this thesis focus on finding objective parameters to differentiate PD from ET.

\subsection{Pathophysiology}

Movement disorders, such as ET and PD are disabling and can lower the quality of life of the affected patients. From literature we know that ET and $\mathrm{PD}$ are diseases of the central nervous system, with pathological changes in different neuronal networks within the brain. In both disorders, changes in the cerebello-thalamo-cortical circuit are associated with tremor generation or regulation. However, the underlying cause of these changes is thought to be different between these disorders. PD is mainly associated with changes in the basal ganglia, with dopaminergic dysfunction of the pallidum causing an increase in activity in the cerebello-thalamo-cortical circuit. In ET, the most probable explanation of the increased activity in this circuit is a GABAergic dysfunction of the cerebellar dentate nucleus and the brain stem [1]. The basal ganglia and cerebellum project to the motor cortex via different nuclei of the thalamus, making the motor cortex the last common output for movement excitation. In Figure 1.1 a schematic 
overview of the approximate locations of the basal ganglia, cerebellum, thalamus and cortex are given. Figure 1.2 displays the tremor network (adapted from [1]).

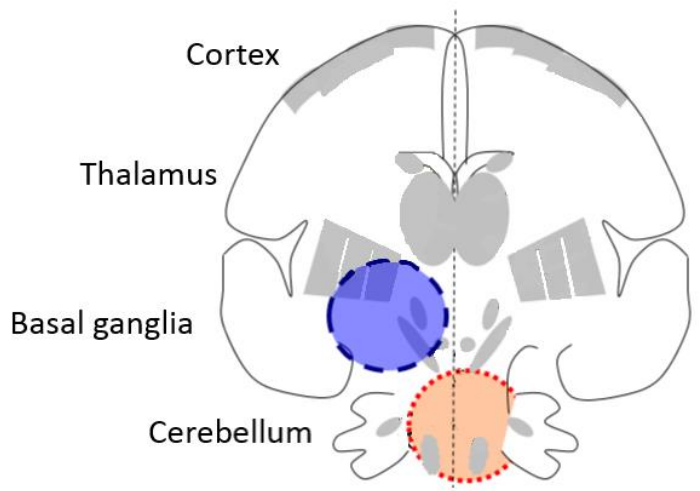

Figure 1.1. Schematic overview of areas that are affected: Basal ganglia (blue) and cerebellum (red).

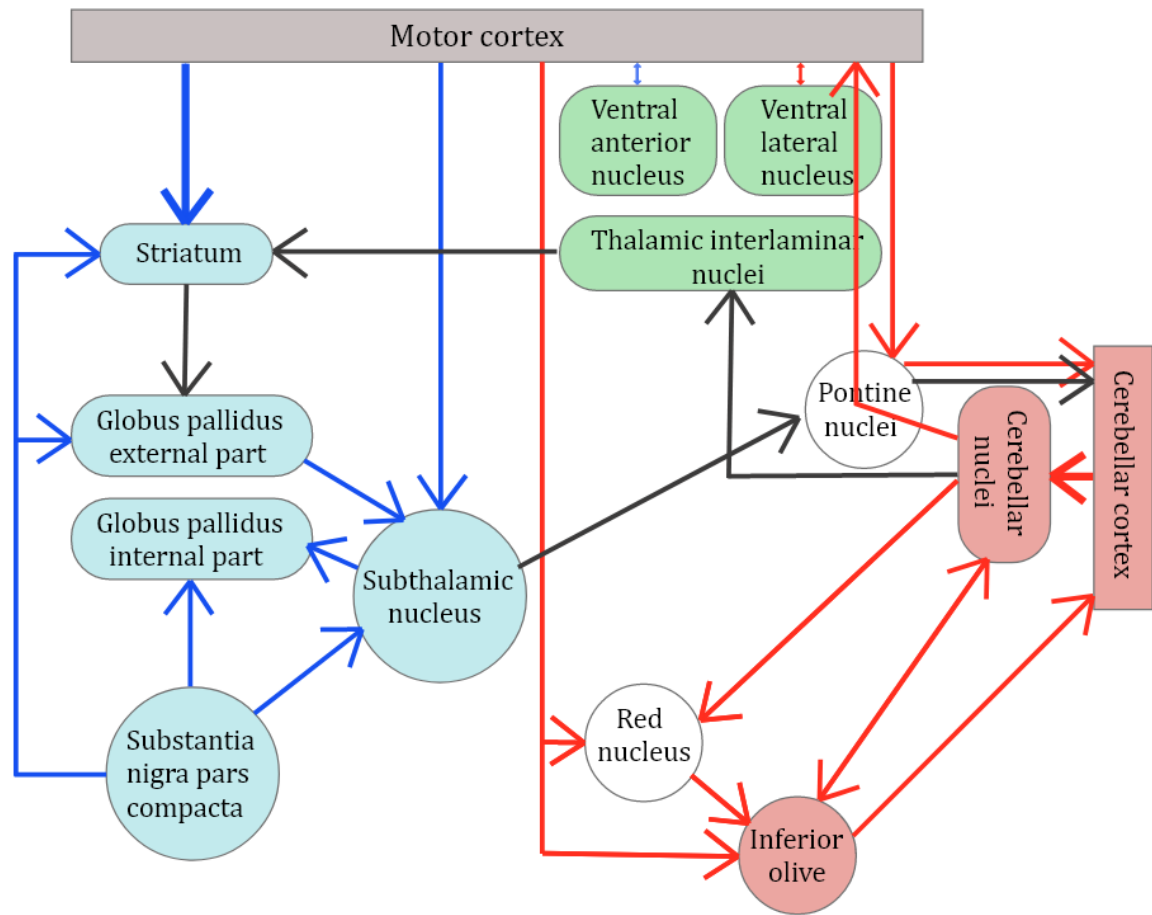

Figure 1.2. Schematic overview of tremor networks: basal ganglia (blue); cerebellum (red); thalamus (green); motor cortex (grey). Adapted from Helmich et al. [1]. 


\subsubsection{Parkinson's disease}

Parkinson's disease is a progressive neurodegenerative disorder affecting about $4 \%$ of the elderly population [4]. Motor manifestation of PD is defined as the occurrence of bradykinesia in combination with either or both resting tremor and rigidity.

PD is considered a disease of the basal ganglia. The cause or trigger of PD remains unclear, but the pathophysiology is associated with dopaminergic cell loss in the substantia nigra pars compacta. This causes a dopamine depletion in the striatum, especially in the dorsolateral putamen (see Figure 1.2).

The amount of cell loss is strongly linked to bradykinesia and rigidity. However, its relation to tremor remains unclear, making tremor the most intriguing symptom. Patients with tremor-dominant PD have substantially more cell loss in the retrorubral area of the midbrain and less in the substantia nigra [5]. Animal and other postmortem studies suggest that tremor might result from pallidal dysfunction triggered by loss of dopaminergic projections from the retrorubral area [6]. A PET study found a sensorimotor cortex, cerebellum and cingulate cortex tremor network [7], suggesting the cerebello-thalamo-cortical circuit being involved in tremor generation. These findings also support the dimmer-switch hypothesis, that suggests the basal ganglia as the trigger of tremor and the cerebellothalamo-cortical circuit as the modulator of tremor amplitude [6].

\subsubsection{Essential tremor}

ET is the most common tremulous movement disorder [8], most likely caused by pathological changes in the cerebellum. However, the exact pathophysiology is still unknown [9]. For quite a long time ET was considered a monosymptomatic disorder, characterized by a postural or kinetic tremor. However, due to marked clinical heterogeneity concerning the affected body parts, the site of tremor, the occurrence of non-tremulous symptoms, and the response of tremor to different drugs [1], ET was redefined. The current definition of tremor is (1) a bilateral, largely symmetric postural or kinetic tremor involving the hands and forearms that is visible and persistent, (2) additional or isolated tremor of the head may occur but in the absence of abnormal posturing, and (3) other causes for tremor must be excluded [10]. Up until today no specific markers of ET have 
been identified and therefore diagnosis is solely based on behavioral symptoms [11]. Neuroimaging studies show widespread structural and metabolic abnormalities in symptomatic patients, however there are large discrepancies in the results $[11,12]$. The structures most likely involved are the olivo-cerebellar system and the thalamus [13]. This is also supported by the fact that deep brain stimulation is most effective when the electrode is placed in the ventral intermediate nucleus of the thalamus, a region receiving input from the striatum (specifically the globus pallidus) and the cerebellum, and in turn projects to the motor cortex. No post mortem conclusive findings exist which makes it difficult to determine the real rate of misdiagnosis in this patient group. Some post mortem studies hint to a cerebellar neurodegenerative disorder and others found no differences compared to healthy controls.

\subsubsection{Clinical differentiation}

Currently, diagnosis, especially in early disease stages, is challenging due to limited objective diagnostic tools. Clinical rating scales, such as the Unified Parkinson's Disease Rating Scale (UPDRS) for PD, the Tremor rating scale (TRS) for ET and PD, and evaluation by clinical experts remain the gold standard for diagnosis [14], even though this leads up to $20-37 \%$ of misdiagnoses [15-17]. So far no neuroimaging technique or other objective diagnostic test is specifically recommended for diagnosing PD and ET. DaTSCAN technology has a rather high sensitivity (98\%) and specificity $(67 \%)$ to diagnose PD $[18,19]$, with increasing specificity up to $94 \%$, after the clinical diagnosis is established [19]. However, it is an invasive and expensive procedure that is not widely available.

\subsection{Quantitative measures of motor symptoms}

Finding objective parameters to differentiate between ET and PD has been the goal of many research studies. Two symptoms that can occur in both disorders and cause difficulties during the diagnostic process are tremor and a deficit in timing ability during voluntary movement.

\subsubsection{Tremor}

Mansur et. al [20] published a review about techniques for tremor recording and quantification. This review shows that each study has its own 
way of recording and signal processing for feature extraction. Most commonly electromyography and accelerometers are used to record tremulous movement (see Figure 1.3).

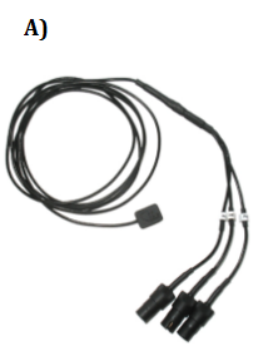

B)

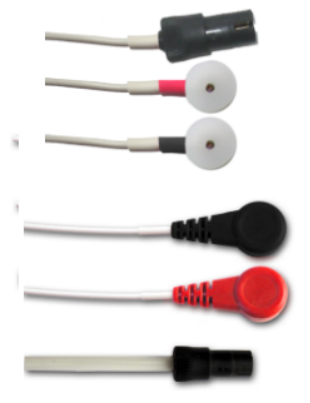

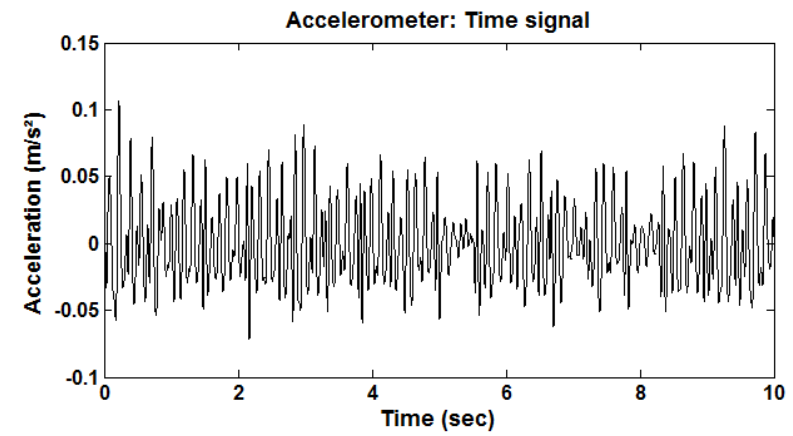

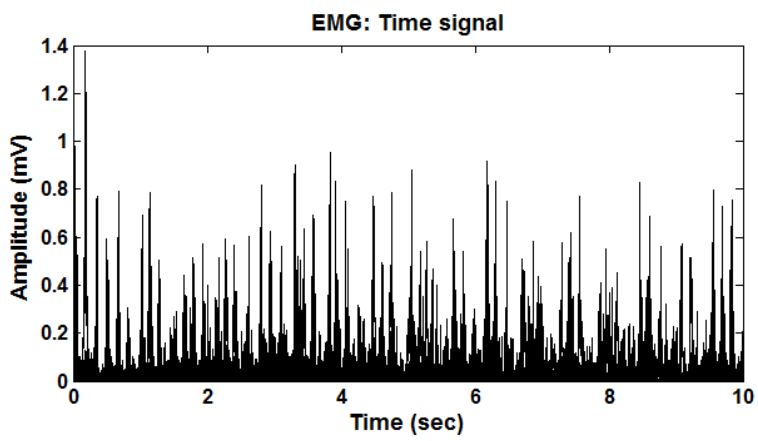

Figure 1.3. A) Accelerometer and signal of the dominant axis of tremor in the hand. B) EMG electrodes and envelope of the time signal of tremor in the m. extensor radialis. Sensors are from TMSi, Oldenzaal, The Netherlands.

Data analysis techniques used to extract parameters from recordings can be divided into two methods: time series analysis [21,22] and spectral analysis [23-25]. Time series analysis focuses on parameters such as tremor burst duration, timing of muscle contraction in antagonistic muscles (EMG) and the amplitude of the tremor (EMG, accelerometers). Parameters most often determined with spectral analysis are the peak frequency, amplitude of the peak frequency, peak width and the variation over time of these parameters. These parameters allow for a differentiation between physiological and pathological tremor, but not for a differentiation between pathological tremors [21]. Some studies show that differentiation between pathological tremors requires long-term (hours) recordings [26, 27], which makes these methods inadequate to implement in a clinical setting where 
examination times are rather short. A recent study by di Biase et al. [28] defined a new diagnostic parameter for differentiation between ET and PD: the tremor stability index. They used 100s of tremor recordings and determined the change in tremor frequency with respect to the instantaneous frequency. However, it is not mentioned how the presence of tremor in these recordings is determined. Furthermore, to acquire 100s of tremor recording long recording times might be necessary in some patients due to the intermittency of tremor. Additionally, the use of a tremor frequency band between $2-9 \mathrm{~Hz}$ could make it difficult to use the method to detect kinetic tremor during movement and the upper frequency cutoff of $9 \mathrm{~Hz}$ might not detect all ET patients.

Besides tremor analysis at the periphery, studies have also looked into tremor networks within the brain to determine differences in brain activity between ET and PD. Several imaging techniques have been used to study tremor networks with the most common ones being electroencephalography (EEG) and functional magnetic resonance imaging (fMRI). As already described, two central networks are believed to be involved in PD tremor generation: the cerebello-thalamo-cortical circuit and the basal ganglia-cortical motor loop [6]. Since hyperactivity has been found in the cerebellum in ET patients, the cerebello-thalamo-cortical circuit is also likely to be involved in ET. Using EEG, the most common analysis method is probably coherence analysis. Coherence analysis estimates the relative linearity between two stationary signals and has been used to estimate the coupling between tremor related activity in the cortex and muscles. In ET and PD cortico-muscular coherence was found in the primary motor cortex and the primary somatosensory cortex at tremor frequency and analysis of ET patients suggests a cortical drive of that frequency rather than kinesthetic feedback from the periphery [29, 30]. Since deep brain stimulation (DBS) electrodes are nowadays also used for recordings during surgery, coherences have also been estimated between deeper nuclei and cortical and muscle activity [31]. Coupling between the basal ganglia and the mesial cortical areas such as the SMA were found at $20-30 \mathrm{~Hz}$, whereas coupling between the lateral cortical motor areas and the basal ganglia were found at lower frequencies [32]. Furthermore, an increase in the gamma band was observed during movement, suggesting gamma activity to be prokinetic and decreased beta activity antikinetic [32, 
33]. Additionally, the decrease in beta power caused by levodopa intake or DBS has been linked to clinical improvement of the symptoms [34], except for tremor [35]. Concerning tremor, an increase of local field potential power around the tremor frequency, during parkinsonian resting tremor has been linked to a decrease in cortical power in the beta band after tremor onset. This increased subthalamic nucleus-cortex coherence has been shown to correlate with an increase in EMG power in the contralateral limb [36]. Furthermore, an increase in cortico-muscular coherence was found in the primary motor cortex, premotor cortex and the posterior parietal cortex contralateral to the tremulous limb [36]. Beudel et al. [35] found that a reduction in lower gamma band power $(31-45 \mathrm{~Hz})$ in the STN links to a reduction in resting tremor amplitude. Another method to analyze relations between neural and muscular signals is short-time Fourier analysis. Shorttime Fourier transform analysis is used to investigate the dynamic changes in transient neuromuscular events and functional correlation between neural and muscular signals in both the time and frequency domains [31].

\subsubsection{Deficits in timing ability}

Deficits in timing ability during voluntary movement has been observed in PD and in ET and may cause difficulties in the diagnostic process. The basal ganglia and the cerebellum are involved in movement preparation, timing and execution of movements. PD patients often suffer from a difficulty to initiate movements, including standing up or starting to walk, and to continue rhythmic cyclic motion, including walking and finger tapping $[37,38]$. It has been suggested that beta activity is modulated by internally and externally cued movement [34] and studies have shown that external cues enhance patients' ability to start and continue movements [38-40]. Rehabilitation studies found an improved gait when auditory cueing was applied [40, 41]: cues increased the cadence of PD patients. In addition, several studies have looked into patient's ability to perform finger tapping tasks when cueing was applied [37, 39]. During these experiments PD patients, in particular tremor dominant PD patients, tended to hasten movements when finger tapping tasks at lower frequencies had to be performed [39]. A pilot study by Espay et. al [42] found that patients with PD tapped with a smaller amplitude and reduced speed during an index finger to thumb tapping task compared to healthy controls (HC). Imaging 
studies, using functional magnetic resonance imaging (fMRI), show that PD patients exhibit an increased movement latency and increased involvement of the cerebello-thalamic pathway during rhythmic externally cued movements [43]. Furthermore, using a PET scan during unimanual and bimanual hand movement tasks, Samuel et al. [44] found evidence that in PD patients the parietal-lateral premotor circuits are activated instead of the striato-mesial frontal circuits to facilitate complex finger movements. Fewer studies have been conducted on the ability of ET patients to perform rhythmic cyclic movements. Farkas et. al [45] found an impairment of rhythm generation and an increased variability of hand movement during externally cued movements compared to HC. Furthermore, Avanzino et. al [46] found that $1 \mathrm{~Hz}-\mathrm{rTMS}$ over the ipsilateral cerebellum affected the performance during a finger movement task in patients with ET by reducing touch duration values and normalizing the inter touch interval. Hyperactivity in the cerebellum has been found in ET patients [12], and it is thought that tremor is caused by dysfunction of the cerebellum. In case an external trigger also activates the cerebellum, as suggested by studies in PD subjects, this could lead to a timing conflict in ET patients between cued voluntary movements and involuntary tremor movements when the difference in frequency (between the voluntary and involuntary movement) becomes larger.

In conclusion, no objective gold standard has yet been found to differentiate between PD and ET, although many of studies have been performed using multi-modal data to find quantitative, objective measures for such differentiation. Results of studies are often difficult to compare with each other because different types of signals and analysis methods, as well as different populations, were used.

\subsection{The Movement Diagnostic System project}

The Movement diagnostic system (MDS) project is a collaboration of the Academic Medical Center in Amsterdam, Delft University of Technology and the University of Twente. Furthermore, the companies Twente Medical Systems International B.V. (TMSi), and MOOG contributed to this project. The main objective of this project is to develop a diagnostic system to differentiate movement disorders and investigate pathological brain 
networks in movement disorders with tremor as one of the characteristic symptoms, using an EEG-EMG-accelerometer and a fMRI-EMGaccelerometer experimental setup. Using EEG and fMRI to capture abnormal brain activation patterns enables this project to study changes in cortical activity with a high temporal resolution (EEG) as well as changes in activity of networks located deep in the brain with a high spatial resolution (fMRI). To be able to identify pathological brain networks related to tremor, MR compatible kinematic sensors were developed together with TMSi. The experimental protocols used in these studies target parts of the human motor system that are likely to be involved in ET and PD. All parties are involved in either, or both, developing and testing the equipment and protocols used in this project.

The MDS setup

For kinematic recordings in this thesis EMG and 3D accelerometers were used. All EMG recordings reported used 6-channel bipolar surface EMG electrodes (TMSi, Oldenzaal, The Netherlands). Electrodes were placed on the wrist flexor (m. flexor carpi radialis), and on the wrist extensor (m. extensor carpi ulnaris). The accelerometers used for recording hand movement, are 3D accelerometers (TMSi, Oldenzaal, The Netherlands) and were placed on the back of each hand, approximately in the middle of the third metacarpal bone. For the orientation of the sensor see Figure 1.4. Sensor size is $13 \mathrm{mmx} 10 \mathrm{mmx} 5 \mathrm{~mm}$ and sensor weight is 2 grams.
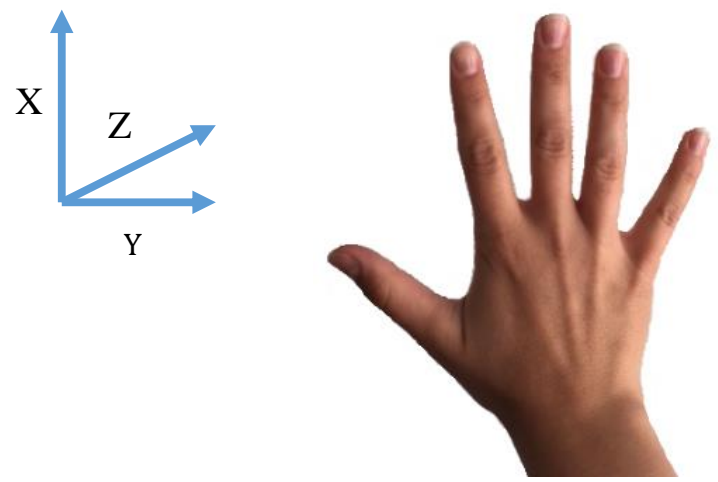

Figure 1.4. Orientation of the $x-, y$ - and $z$-axis of the 3D accelerometer. 
Brain activation patterns were captured with either EEG or fMRI depending on the experiment. During the research described in this thesis, EEG was recorded with a 72-channel Refa-system and a 64-channel low noise shielded EEG headcap (resistance $<30 \mathrm{kOhm}$ ) (TMSi, Oldenzaal, The Netherlands). The headcap (10-20 system) was connected to the Refa system using two EBA multiconnectors (TMSi, Oldenzaal, The Netherlands). See Figure 1.5 for the electrode arrangement.

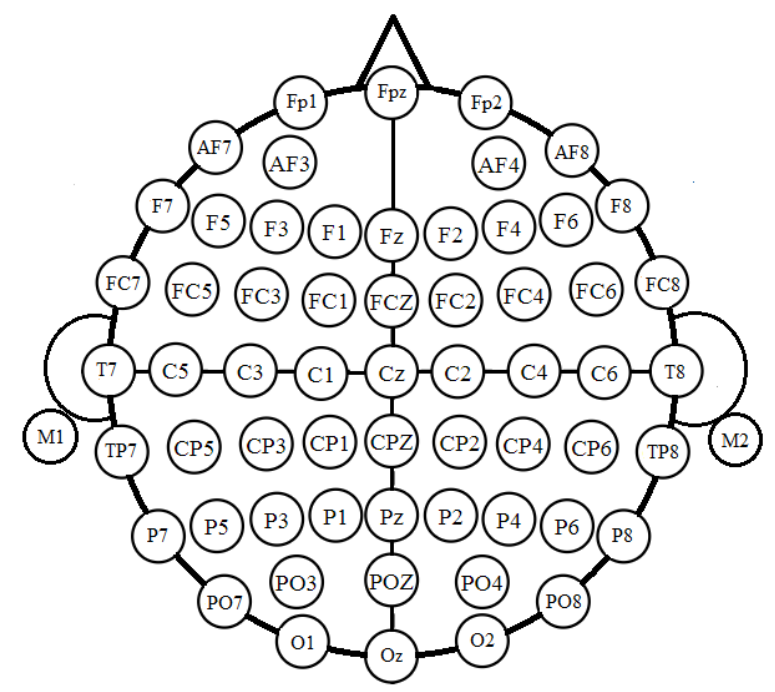

Figure 1.5. Overview of the EEG electrode placement used in this study.

For fMRI recordings a Philips 3T Magnetic Resonance scanner (Philips, Eindhoven, The Netherlands) with a standard head receiver coil was used. A structural contrast scan was obtained with a repetition time (TR) of $9 \mathrm{~ms}$, an echo time (TE) of $3.53 \mathrm{~ms}$ and a voxel size (VS) of $1 \mathrm{~mm}^{3}$. Blood oxygenation level-dependent (BOLD) function images are obtained using a gradient echoplanar T2*-weighted imaging (EPI) sequence (TR: $30 \mathrm{~ms}$; TE: $2000 \mathrm{~ms}$; VS: $3.5 \mathrm{~mm}^{3}$ ). Thirty-nine axial slices for a total of 180 volumes was obtained to cover the whole brain and the cerebellum. Head movement is minimized using foam padding inside the head coil.

In Figure 1.6 the experimental setup with EEG (A) and fMRI (B) are displayed. 
A)

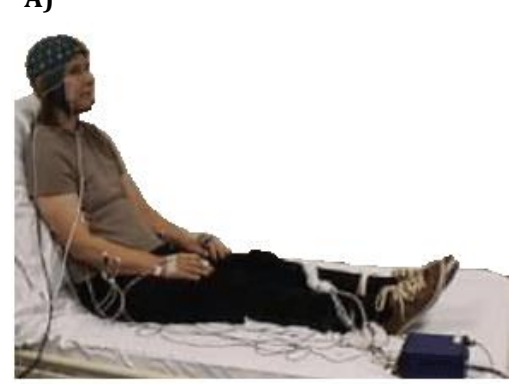

B)

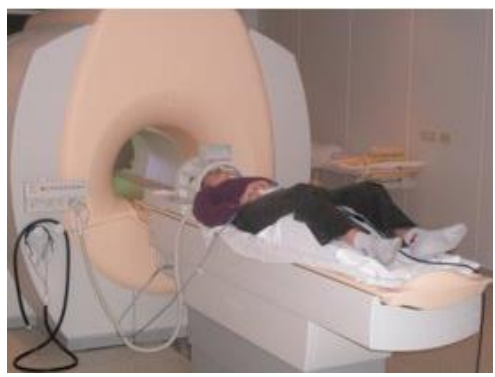

Figure 1.6. The MDS experimental setup. (A) EEG setup; (B) fMRI setup

\subsection{Research objectives}

This thesis has two objectives that were formulated within the Movement Diagnostic System project:

1) Quantifying tremor occurrence in ET and PD subjects and identifying corresponding cortical activity.

2) Quantifying the timing ability of ET and PD subjects during voluntary movement under different conditions and identifying corresponding neuronal networks.

\subsection{Thesis outline}

Based on the two research objectives this thesis is divided into two parts. Part one (research objective 1) consists of chapters 2 and 3 . In chapter 2 a new, straightforward method to detect tremor in movement disorder patients, independent of the underlying disorder, is introduced. Chapter 3 concerns the cortical phenomena occurring during tremor and non-tremor episodes in ET and PD patients. Whereas the goal of chapter 2 is the correct classification of tremor episodes independent of the underlying cause, the goal of chapter 3 is to determine differences between the patient groups. Part 2, consisting of chapters 4, 5 and 6, concerns the effect of external cues on the timing ability of voluntary movements and brain activity. In chapter 4 differences in kinematic movement characteristics between ET and PD subjects are described. Chapters 5 and 6 discuss the differences in brain activity as recorded by EEG and fMRI, respectively. 



\section{PART I}

TREMOR 



\section{Tremor detection in movement disorders ${ }^{1}$}

\section{ABSTRACT}

There is no objective gold standard to detect tremor. This concerns not only the choice of the algorithm and sensors, but methods are often designed to detect tremor in one specific group of patients during the performance of a specific task. Therefore, the aim of this study is twofold. First, an objective quantitative method to detect tremor windows in accelerometer and electromyography recordings is introduced. Second, the tremor stability index is determined to indicate the advantage of detecting tremor windows prior to further analysis.

Ten Parkinson's disease patients, ten essential tremor patients and ten healthy controls perform a resting, postural and movement task. Data is split into three-second windows and the power spectral density is calculated of each window. The relative power around the peak frequency with respect to the power in the tremor band is used to classify the windows as either tremor or non-tremor.

The method yielded a specificity of $96.45 \%$, sensitivity of $84.84 \%$ and accuracy of $90.80 \%$ of tremor detection. During tremor significant differences were found between groups in all three parameters.

The results suggest that the introduced method could be used to determine under which conditions and to which extend undiagnosed patients exhibit tremor.

\footnotetext{
${ }^{1}$ Published as:

Luft, F., Sharifi, S., Mugge, W., Schouten, A. C., van Rootselaar, A. F., Veltink, P. H., Heida, T., 'A Power Spectral Density-Based Method to Detect Tremor and Tremor Intermittency in Movement Disorders', Sensors 2019 (Basel), 19(19)
} 


\subsection{Introduction}

Tremors are the most common symptom in movement disorders [1]. The most common types of tremors are physiological $(8-12 \mathrm{~Hz}$, low amplitude), essential (4-12 Hz) [2], and parkinsonian (3-8 Hz) [2]. In contrast to a physiological tremor, essential and parkinsonian tremors are often disabling and lower the quality of life of patients. In clinical practice, diagnosis is based on family history and examination by a neurologist or movement disorder specialist, leading to a misdiagnosis in $20-37 \%$ of the patients [3-5]. Even though parameters, such as amplitude and presence of tremor, can be measured objectively and accurately using accelerometers and electromyography (EMG) [2,6-10], there is no objective gold standard to detect tremor episodes [11]. This involves the choice of the algorithm, as well as the choice of sensors. Furthermore, tremor detection methods are often used to detect tremors in one specific group of patients during the performance of a specific task. However, even within the same patient group, and certainly between different patient groups, tremors may appear at different frequencies, during different tasks, and with varying amplitudes $[7,12]$.

Studies show that differentiation between pathological tremors often requires long-term (hours) recordings [9,10], which makes these methods inadequate to implement in a clinical setting where examination times are rather short. Ghassemi et al. [13] used combined accelerometer and EMG measurements to differentiate between an essential tremor (ET) and a Parkinson's disease (PD) tremor, achieving an overall accuracy of differentiation of 83\%. Recently, di Biase et al. [14] introduced the tremor stability index (TSI) as a new promising tool for differentiation between tremor disorders. They used $100 \mathrm{~s}$ of tremor recordings and determined the change in tremor frequency with respect to the instantaneous frequency. However, it is not mentioned how the presence of tremor in these recordings is determined. Furthermore, to acquire $100 \mathrm{~s}$ of tremor recordings, long recording times might be necessary in some patients due to the intermittency of tremor. Additionally, the use of a tremor frequency band between 2-9 $\mathrm{Hz}$ could make it difficult to use the method to detect kinetic tremors, because ET patient can experience tremors of up to $12 \mathrm{~Hz}$. 
Heida et al., in 2013 [15], divided data into tremor windows (TWs) and non-tremor windows (NTWs) to determine the effect of deep brain stimulation on tremor during rest and movement in patients with PD. In that study, it was shown that, during a TW, almost all power is concentrated around the tremor frequency, and in an NTW, the power distribution is shifted to the movement $(0.25-3.5 \mathrm{~Hz})$ and physiological tremor $(7.5-20$ $\mathrm{Hz}$ ) frequency bands [15].

Therefore, the aim of this study was twofold. Firstly, we developed a transparent quantitative method to detect TWs in tremor disorder patients with a straightforward technical setup using only two accelerometers placed on the back of the hands and EMG recordings of the extensor carpi radialis muscles of both forearms. For the tremor detection method, we adopted the following criteria:

- Pathological tremors need to be detected and distinguished from physiological tremors.

- A large tremor frequency range needs to be adopted [16,17]. A frequency range of $3.5-12 \mathrm{~Hz}$ covers most pathophysiological tremors [18], including the most common ones: parkinsonian, essential and physiological tremors.

- Pathological tremors need to be detectable during various tasks.

We demonstrated that detection of tremors in accelerometer and EMG data is possible using a single method. The advantage of using both types of recordings is that different information is provided by them. EMG is related to motor unit recruitment and may be used to detect synchronization between the activation of (antagonistic) muscles, while accelerometer data is related to movements, which is the effective output resulting from the simultaneous (co-productive and counterproductive) activity of several muscles.

Secondly, the TSI was determined by the TW and NTW to indicate the importance of splitting data before further analysis was applied. 


\subsection{Materials and methods}

\subsubsection{Subjects and clinical evaluation}

Ten patients with ET (8 males), age $61.9 \pm 13.0$ years (mean \pm standard deviation), ten PD patients (7 males), age $64.6 \pm 12.4$ years, and ten healthy controls (HC) ( 7 male), age $59.7 \pm 6.5$ years participated in this study. Table 2.1 provides patient details. All subjects were right-handed according to the Edinburgh Handedness Inventory [19], and all patients were off tremorsuppressing medication (tapered on an individual basis). HC had no history of neurological disorders or tremor. Furthermore, PD patients were diagnosed according to the UK Brain Bank criteria for Parkinson's disease [20] and showed neither major fluctuation in symptoms nor suffered from severe dyskinesia. ET patients were diagnosed according to the criteria defined by the Tremor Investigation Group [21] and had a positive family history of ET. All subjects gave written informed consent in accordance with the Declaration of Helsinki prior to participation, and the study was approved by the medical ethics committee of the Academic Medical Center in Amsterdam, The Netherlands.

\subsubsection{Experimental protocol and data acquisition}

All subjects were seated comfortably on a bed, with the back elevated to an upright position. Voluntary and involuntary movements were recorded with two 3D accelerometers (ACC) (TMSi, Oldenzaal, The Netherlands), one placed on the back of each hand. Muscle activity was recorded from the m. extensor carpi radialis of both arms using surface EMG. Data acquisition was done using a custom-made program written in LabVIEW (National Instruments, Austin, TX, United States) with a sampling frequency of $2048 \mathrm{~Hz}$. Subjects were asked to perform three tasks to evoke either resting, postural, or kinetic tremors:

- Resting task (RT): Subjects sit with both hands in supine position resting in their lap; task duration: one min.

- Postural task (PT): Subjects stretch out both arms, unsupported against gravity, approximately parallel to the floor; task duration: one min.

- Movement task (MT): Subjects perform an elbow flexion-extension task (index finger from nose to knee) with the right arm at a self-paced speed, and the left arm remains rested in the lap; task duration: one min. 
Table 2.1. Overview of patients' details.

\begin{tabular}{|c|c|c|c|c|}
\hline Subject & Gender & Age & Disease onset & Medication \\
\hline *PD 1 & M & 58 & 50 & Levodopa, Trihexyphenidyl \\
\hline *PD 2 & M & 69 & 64 & Rasagiline, propranolol \\
\hline *PD 3 & M & 67 & 63 & Trihexyphenidyl \\
\hline *PD 4 & $\mathrm{~F}$ & 81 & 76 & Levodopa-Carbidopa, metoprolol tartrate \\
\hline *PD 5 & $\mathrm{~F}$ & 62 & 60 & Levodopa \\
\hline TPD 6 & M & 49 & 47 & $\begin{array}{c}\text { Levodopa-Carbidopa, ropinirole } \\
\text { hydrochloride }\end{array}$ \\
\hline TPD 7 & M & 71 & 71 & - \\
\hline TPD 8 & $\mathrm{~F}$ & 43 & 40 & Trihexyphenidyl, ropinirole hydrochloride \\
\hline T PD 9 & M & 78 & 76 & $\begin{array}{l}\text { Levodopa-Carbidopa, Rasagiline, } \\
\text { perindopril, omeprazole, pravastatin }\end{array}$ \\
\hline T PD 10 & M & 68 & 60 & Levodopa-Carbidopa \\
\hline *ET 1 & $\mathrm{M}$ & 45 & Childhood & - \\
\hline *ET 2 & $\mathrm{~F}$ & 81 & Childhood & - \\
\hline *ET 3 & M & 85 & Childhood & Propranolol \\
\hline *ET 4 & M & 65 & Teenager & - \\
\hline *ET 5 & $\mathrm{~F}$ & 51 & Childhood & - \\
\hline TET 6 & M & 49 & 40 & Propranolol \\
\hline TET 7 & M & 54 & Teenager & - \\
\hline TET 8 & M & 70 & Childhood & - \\
\hline TET 9 & M & 64 & Teenager & - \\
\hline TET 10 & M & 55 & Teenager & - \\
\hline
\end{tabular}

$(*)$ Training set. $(\mathrm{T})$ Validation group. $\mathrm{M}=$ Male; $\mathrm{F}=$ Female.

\subsubsection{Data analysis}

Data analysis was performed offline in MATLAB (MathWorks, Inc., Natick, Massachusetts, USA, R2013a). Prior to analysis the dominant tremor axis of the 3D accelerometers was determined using principle component analysis ( $p c a$ routine in MATLAB R2013a). Accelerometer data was bandpass filtered (non-causal, zero-phase, $0.5-20 \mathrm{~Hz}$, 2nd-order Butterworth filter). EMG data was filtered (non-causal, zero-phase, $20-400 \mathrm{~Hz}$, 4 th-order Butterworth), and the absolute value of the Hilbert transform was used as the envelope of the signal for further analysis. For the detection of TWs and NTWs, data was divided into 3-s windows with an overlap of $1.5 \mathrm{~s}$.

Prior to objective classification, each window (accelerometer and EMG) was classified as either TW or NTW by two raters (FL and TH), based on the power spectral density (PSD) of each 3-s window, which was estimated using the periodogram function in MATLAB (see Figure 2.1). Discrepant ratings were discussed until consensus was reached. 
The following steps were taken for further data analysis:

- Accelerometer recordings of ET patients 1-5, PD patients 1-5, and HC subjects 1-5 were used to evaluate the methods (Training set) and parameter settings.

- Accelerometer recordings of ET 6-10, PD 6-10, and HC 6-10 are used to validate the selected method (Validation Group 1).

- EMG recordings of all subjects were used to validate the selected method (Validation Group 2).

\subsubsection{Tremor classification}

The tremor classification method split the data into TW and NTW, based on the power distribution within the tremor frequency band. For each 3-s window, the PSD was estimated for the frequency range 3.5-12 Hz. Then, the relative power of the tremor frequency $\mathrm{P}_{\text {tremor,rel }}$ was calculated according to equation 2.1 :

$$
P_{\text {tremor, } r e l}=\frac{P\left(f_{\text {tremor }}\right)}{P(3.5-12 \mathrm{~Hz})}
$$

With $\mathrm{f}_{\text {tremor, }}$, the frequency range from $f_{\text {peak }}-0.5 \mathrm{~Hz}$ to $f_{\text {peak }}+0.5 \mathrm{~Hz}$. $f_{\text {peak }}$ was the detected peak within the tremor frequency range [3.5 12] Hz. A window was classified as a TW when the relative power within a $1 \mathrm{~Hz}$ range around the peak frequency exceeded or was equal to the thresholds defined in Table 2.2 .

$$
\begin{array}{ll}
\text { TW } & P_{\text {tremor,rel }} \geq \text { Threshold }_{\text {RelP }} \\
\text { NTW } & P_{\text {tremor,rel }}<\text { Threshold }_{\text {RelP }}
\end{array}
$$

In case an even power distribution existed within the tremor frequency band, the relative power around the peak frequency was approximately 0.11 . The thresholds to be tested were set to: $0.35,0.40,0.45$, and 0.50 to ensure that the power at the peak was at least three times higher compared to the rest of the frequency band $(3.5-12 \mathrm{~Hz})$.

\subsubsection{Outcome parameters}

The sensitivity, specificity and accuracy achieved with both methods were calculated with respect to this visual classification using a confusion matrix. For each task and hand, 36 windows were classified, resulting in a 
total of 3240 windows for the Training set and the same amount for Validation Group 1. For Validation Group 2, 6480 windows were available.

$$
\begin{aligned}
\text { Sensitivity } & =\frac{T P}{T P+F P} \\
\text { Specificity } & =\frac{T N}{T N+F N} \\
\text { Accuracy } & =\frac{T P+T N}{T P+F P+T N+F N}
\end{aligned}
$$

With TP, the correctly identified TW, FP, the windows falsely identified as TW, TN, the correctly identified NTW and FN the windows falsely identified as NTW. For the EMG data, 6480 windows were classified as either TW or NTW using the most suitable method determined with the accelerometer data. Furthermore, the following three parameters were determined for TW and NTW: TSI, tremor power, and tremor frequency.

Compared to di Biase et al. [14], the method to calculate the TSI was slightly adapted. Instead of calculating the instantaneous frequency from the time signal, we calculated the peak frequency between $3.5-12 \mathrm{~Hz}$ (periodogram routine in MATLAB 2013a) using a sliding window of $1 \mathrm{~s}$ over each 3-s window with $75 \%$ overlap. The large overlap was chosen to approximate the instantaneous frequency used by di Biase et al. [14]. The TSI was calculated as the difference between $f_{\text {peak }}$ of two successive windows.

\subsubsection{Statistical analysis}

To compare the TSI between groups during TW and NTW, the KruskalWallis test was used.

\subsection{Results}

A paired-sample t-test reveals no significant differences in age between groups ( $<$ < 0.05; PD - ET: $p=0.54 ;$ PD - HC: $p=0.22$; ET $-\mathrm{HC}: \mathrm{p}=0.42$ ). Gender is not considered to have any influence on the results.

Figure 2.1 shows ten seconds of the accelerometer signal (left) and the PSD of the 3-s windows of the whole signal (right). Data of a random tremor patient (grey) and a typical HC (black) are displayed. From top to bottom, data recorded during the RT, PT, and MT are visible. During the RT and PT, the amplitude and amplitude fluctuations are larger in the tremor patient 
compared to the HC. The power is several times smaller in the HC subject compared to the tremor patient. Therefore, an enlargement of the PSD of the HC subject in the tremor frequency band is given in the right column. During all three tasks, a clear peak around $5 \mathrm{~Hz}$ (and higher harmonics) is seen in the tremor patient but not in the HC. During the MT, a peak is visible in the lower frequency range in both groups, corresponding to the voluntary movement made by the subjects. In the tremor patient, additional peaks around 5 and $10 \mathrm{~Hz}$ are seen.
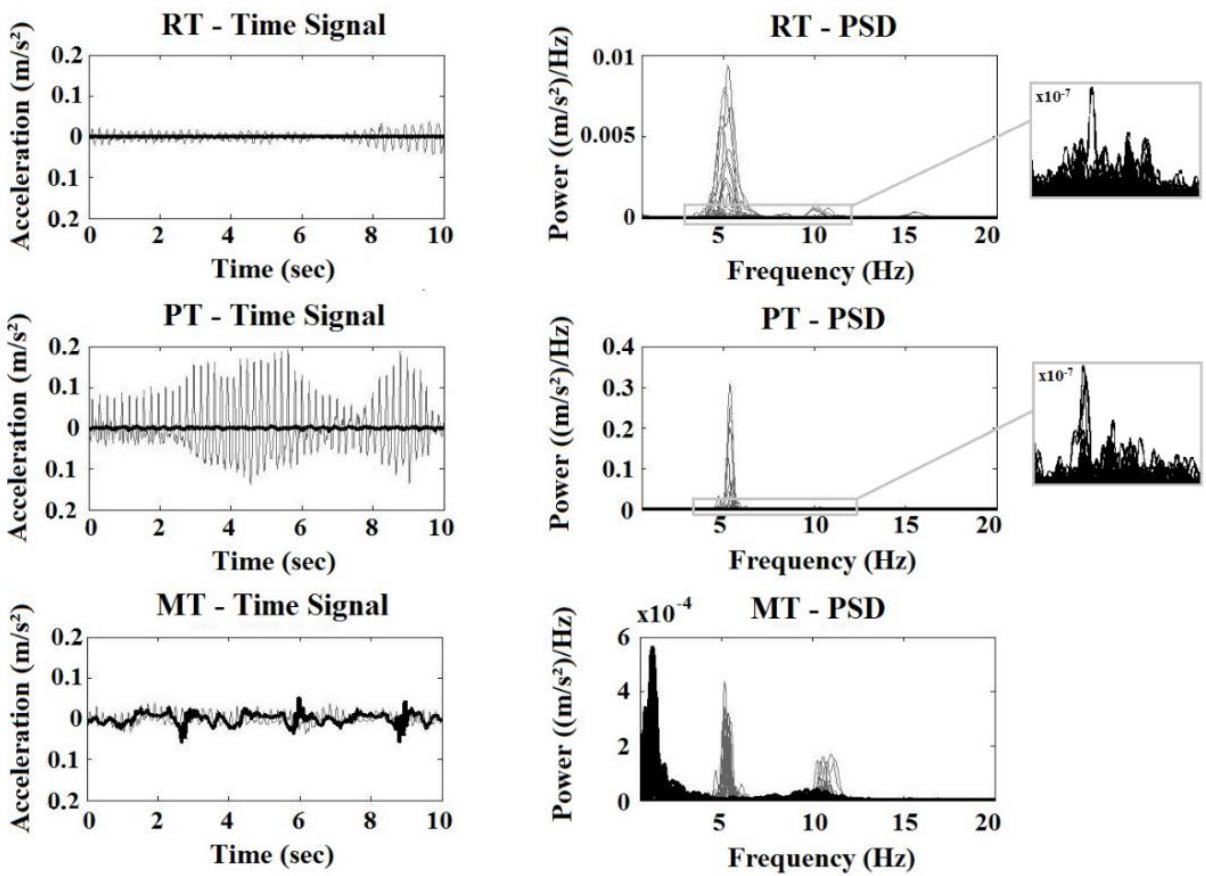

Healthy Subject

Tremor Patient

Figure 2.1. Time signals and corresponding power spectral densities (PSD) of a healthy control (black) and a tremor patient (grey). From top to bottom, data recorded during rest (RT), posture (PT), and movement (MT). On the right side, an enlargement of the PSD of the HC is given.

\subsubsection{Sensitivity, specificity, and accuracy}

In Table 2.2, the results of the method using the training and validation sets are given. In the training set, the highest accuracy (all three tasks combined) is achieved with a threshold of 0.40 for the tremor classification method, accuracy was $90.80 \%$ (Table 2.2. - mid column). Overall, the 
highest accuracy was achieved in Validation Group 2, at 94.38\% (Table 2.2. - right column).

Table 2.2. Tremor classification method - training and validation.

\begin{tabular}{|c|c|c|c|c|c|c|}
\hline \multirow[b]{2}{*}{ Threshold } & \multicolumn{4}{|c|}{ Threshold (Training Set) } & \multirow{2}{*}{$\frac{\text { ValGroup } 1}{0.40}$} & \multirow{2}{*}{$\frac{\text { ValGroup } 2}{0.40}$} \\
\hline & 0.35 & 0.40 & 0.45 & 0.50 & & \\
\hline Sensitivity (\%) & 92.64 & 84.84 & 76.09 & 66.20 & 78.31 & 92.12 \\
\hline Specificity (\%) & 87.13 & 96.45 & 99.10 & 99.70 & 95.00 & 95.00 \\
\hline Accuracy (\%) & 89.81 & 90.80 & 87.90 & 83.40 & 90.06 & 94.38 \\
\hline TW HC (\%) & 7.22 & 1.20 & 0 & 0 & 6.76 & 1.62 \\
\hline
\end{tabular}

Sensitivity, specificity, accuracy and tremor windows (TWs) detected in the Training set (middle column) for all threshold settings. The right column contains the results of the validation groups: accelerometer data of Validation Group 1 (marked with $\uparrow$ in Table I) and EMG data of all subjects (Validation Group 2). HC = healthy controls; TW = Tremor window; ValGroup 1 = Validation Group 1; ValGroup 2 = Validation Group 2.

\subsubsection{The Tremor Stability Index}

In Figure 2.2, the results of the TSI of each group (HC: left; ET: mid; PD: right) during tremor (black) and non-tremor (grey) windows are given. Results are displayed for the EMG (left side spider plot) and the ACC (right side spider plot) during all tasks.

The TSI was significantly different between the HC group and the two patient groups during the PT for TW (EMG) and NTW (ACC). An overview of all significant $\mathrm{p}$-values $(\mathrm{p}<0.05)$ is given in Table 2.3.

Table 2.3. Results of the statistical analysis.

\begin{tabular}{cccccc}
\hline \multirow{2}{*}{ Parameter } & Task & EMG & p-Value TW & \multicolumn{2}{c}{ p-Value NTW } \\
\hline TSI & RT & - & - & - & - \\
& PT & $<0.001^{\dagger}$ & - & $<0.001^{*}$ & $<0.001^{\dagger}$ \\
& MT & $0.004^{*}$ & - & - & $0.02^{*}$ \\
\hline
\end{tabular}

An overview of the results of the statistical analysis of the TSI. Only statistically significant results are given $(\mathrm{p}<0.05)$. The asterisk $\left(^{*}\right)$ marks the results in which the HC group was significantly different from the ET group. The $(\uparrow)$ denotes the tasks/parameters in which the HC group is significantly different from both patient groups. 

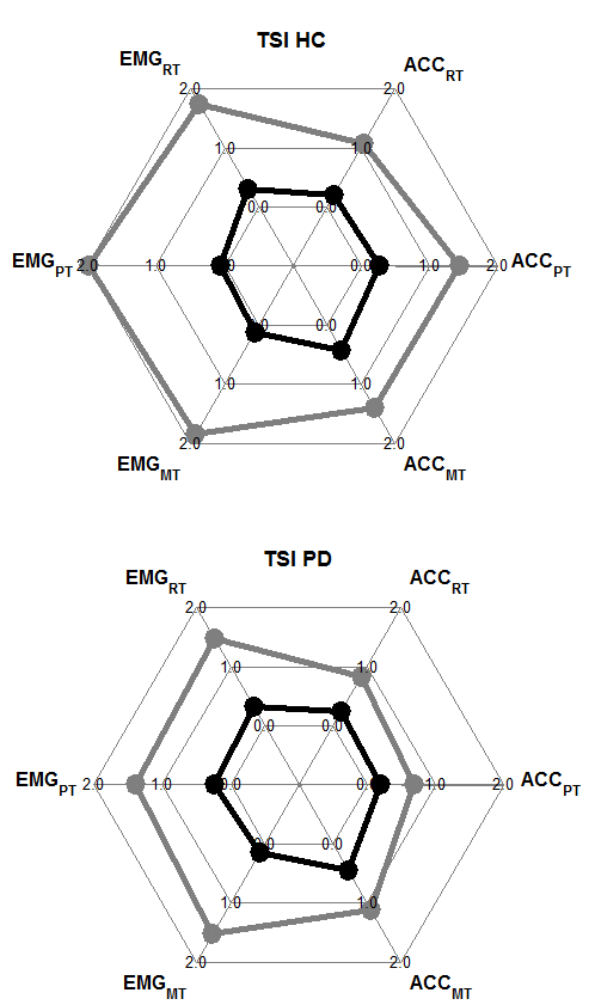

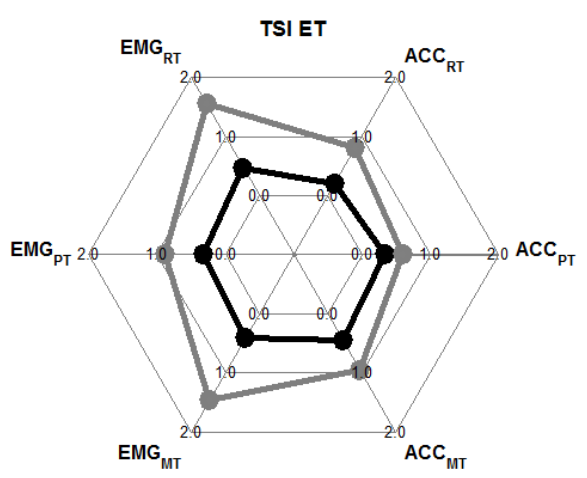

TW

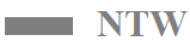

Figure 2.2. Group mean tremor stability index (TSI) of the healthy control (HC), essential tremor (ET), and Parkinson's disease (PD) groups. In each spider plot on the left side are the results of the EMG data (top to bottom: RT, PT, and MT), and on the right side are the results of the accelerometer data. In black, the TW results are displayed, and in grey, the results of the NTW.

\subsection{Discussion}

A transparent quantitative tremor detection method that reliably detects tremor in accelerometer and EMG data recorded under different movement conditions using a straightforward experimental setup was introduced. In literature, several methods have been used [11,15,22-25], but no objective golden standard has been determined yet. We showed that the same method can be used for several types of tremors during different tasks and for both EMG and accelerometer data. Second, we showed that splitting data into TW and NTW is desirable when determining parameters, such as the TSI. 


\subsubsection{Tremor classification method}

The presented tremor classification method depends on the power distribution within the tremor frequency band. It was found that the higher the chosen threshold, the higher the specificity and the lower the sensitivity. But with a threshold of 0.40 , both remain sufficiently high to classify TW and NTW. Some windows in the HC group are classified as TW (approximately 6.34\%). This is in accordance with a study of Elble [26], who found that up to $8 \%$ of young and elderly adults have an EMG-acceleration pattern which is indistinguishable from an essential tremor. Windows with a clear peak in the tremor frequency band were classified as TWs. The tremor classification method was able to classify 78.31-92.12\% of all TWs correctly, even those with a small amplitude. Low power physiological tremors were detected in HC but can be distinguished from pathological tremors based on their power distribution. The advantage of this method over others is that is can be used for EMG and accelerometers and has been tested in three different groups and during three different tasks. Misclassification is most often due to a second peak in the frequency band. Two reasons for a second peak are a slight shift in tremor frequency during the $3 \mathrm{~s}$ and the presence of higher harmonics of the tremor frequency. If these peaks have a high power, classification is difficult. Overall, small and large amplitude tremors could be well detected. Due to its robustness, the method could also be tested for ambulatory recording of tremors in a future study.

\subsubsection{Tremor measures}

For TWs and NTWs, the TSI were calculated (see Figure 2.2). The goal was to prove the advantage of splitting data into TWs and NTWs. Analysis of NTW showed that there are almost no significant differences between the groups. The TSI in the ET group was significantly smaller compared to the HC group (EMG data) during the PT, and it was significantly smaller in both patient groups compared to the HC group for the accelerometer data. During the MT, ET subjects also had a significantly smaller TSI during NTW compared to the HC group. The tremor frequency during the RT in NTW was significantly higher in the patient groups compared to the HC group. In the $\mathrm{HC}$ group, the mean frequency was around $3.5 \mathrm{~Hz}$. This was probably caused 
by decreasing power with increasing frequency $(3.5 \mathrm{~Hz}$ being the lowest frequency in the tremor band) and not by actual tremors.

During detected TWs, the only significantly different results found were for the EMG data during the PT and MT. This is in contrast to the good results of di Biase et al. [14], who were able to distinguish between ET and PD using receiver operating characteristic analysis (area under the curve: 0.916). Differences might be the result of the definition of TWs and the length of the recording. Di Biase et al. [14] used $100 \mathrm{~s}$ of tremor recordings, and we used $60 \mathrm{~s}$ in total, splitting those $60 \mathrm{~s}$ into TWs and NTWs. This resulted in a total of 2262 (ACC) and 1529 (EMG) TW over all subjects. Another cause of the discrepancy might be that di Biase et al. [14] used the instantaneous frequency determined from the time signal instead of the frequency of a 3-s window determined from the periodogram. However, the results also show that the differences between groups in TSI is a lot larger in the TW compared to the NTW. This suggests that without splitting of the data prior to determining tremor parameters, in this case the TSI, the differences between groups would be even smaller. Furthermore, the results showed that the value of the TSI, and probably other tremor parameters as well, is sensor-type and task-dependent.

\subsection{Conclusion}

Overall, the method used is suitable to split data into TWs and NTWs using EMG and accelerometer data streams. Splitting data into TWs and NTWs proved useful for the analysis of the TSI. During TWs, the differences in parameters between groups was larger compared to NTWs. Furthermore, the postural task is the most useful task to differentiate between groups. For future analysis longer data sets should be used to be able to compare the results of the TSI better to the results of di Base et al. [14]. However, this study also shows the importance of reliable tremor detection for parameters, such as the TSI. Especially in the early stages of the disorders, tremor detection can be challenging and classification of TWs difficult. The method used here proved reliable in detecting even small amplitude pathological tremors. 


\section{Cortical activity patterns during tremor windows ${ }^{2}$}

\section{ABSTRACT}

Parkinson's disease (PD) and essential tremor (ET) can present with tremor during rest, posture and/or voluntary movement. However, identifying the underlying disorder may not be straight forward. From pathological findings it is known that PD and ET involve different neural networks in the brain. The purpose of this study is to determine differences in cortical activity during the presence of tremor in PD and ET.

Sixteen ET and sixteen PD patients performed a resting, postural and movement task. Data was split into tremor and non-tremor windows based on the relative power of the tremor frequency recorded with accelerometers placed on the hands. Regression analysis was used to determine significant correlations between tremor of the hands and cortical activity in the $\alpha$ - and $\beta$-band recorded with EEG.

Significant correlations were found at different cortical regions during the occurrence of tremor in both groups. The resting task revealed significant correlations between tremor and cortical activity in PD but not ET. During the postural task, significant correlations were found at the associate and primary visual cortex in ET suggesting that these patients rely more on visual guidance for movement execution compared to PD patients.

The results of the resting task showed the clearest difference in cortical activity between PD and ET. As the occurrence of resting tremor is one of the causes for misdiagnosis, analysis of the correlation between hand tremor and cortical activity in the $\alpha$ - and $\beta$-band might be a tool for the diagnostic process of PD and ET.

\footnotetext{
2 Under review:

Luft, F., Sharifi, S., Mugge, W., Schouten, A. C., van Rootselaar, A. F., Veltink, P. H., Heida, T. "Identifying tremor patterns in EEG of patients with Parkinson's disease and essential tremor"
} 


\subsection{Introduction}

Tremor is the most common symptom in movement disorders [47]. Since it occurs in several movement disorders, the diagnosis of the underlying cause of tremor can be difficult. Parkinson's disease (PD) and essential tremor (ET) can present with a heterogeneous phenotype, especially in the early stages of the disorder, with tremor occurring during rest, posture and/or voluntary movement [6]. Identifying tremor mechanisms in movement disorders is important for diagnostic purposes, as well as for understanding the underlying pathological changes.

Several studies proposed objective methods to determine differences between parkinsonian and essential tremor [48-50]. These studies investigated kinematic parameters, such as the peak detected in the power spectral density of EMG or accelerometer data within the tremor range, the amplitude of this peak, tremor amplitude, time of occurrence and tremor burst duration. The results of these studies have indicated that there is too much overlap in the values of tremor parameters to find distinct markers for either parkinsonian tremor or essential tremor [48-50].

Di Biase et al. [28] recently defined the tremor stability index (TSI). The TSI is a measure of the variability of the tremor frequency. Based on this index ET and PD patients could be classified with a sensitivity, specificity and accuracy of up to $95 \%, 95 \%$ and $92 \%$, respectively. Luft et al. [51] introduced a method, RelP, to split EMG and accelerometer data automatically into tremor (TW) and non-tremor (NTW) windows. The introduced method is able to detect tremor between $3.5-12 \mathrm{~Hz}$ and is independent of the underlying disorder. Tremor characteristics, such as the TSI, result in an even better differentiation between PD and ET when calculated after splitting data into TW and NTW [51].

Besides kinematic tremor analysis at the hands and arms, studies have looked into tremor networks within the brain [52]. Networks involved in PD tremor are the cerebello-thalamo-cortical (CTC) circuit and the basal ganglia-thalamo-cortical motor loop[6]. In ET patients hyperactivity was found in the cerebellum [12], indicating that the CTC circuit is also involved in essential tremor. To link specific neural activity to tremor occurrence, several studies [30-32, 36, 53] used coherence analysis. Cortico-muscular coherence (CMC) analyses in ET and PD found significant coherence 
between muscle activity recorded with EMG and activity of the primary motor and primary somatosensory cortex at the tremor frequency [30].

Deep brain stimulation (DBS) electrodes have been used for postoperative recordings, and coherences were estimated between local field potentials (LFP) in deeper nuclei, at the cortical level and recorded muscle activity [31]. In PD, an increase of LFP power in the subthalamic nucleus (STN) around the tremor frequency during parkinsonian resting tremor has been linked to a decrease in cortical power in the $\beta$-band $(13-30 \mathrm{~Hz})$ after tremor onset [32]. This increased STN-cortex coupling correlates with an increase in EMG power in the contralateral limb [36]. Furthermore, a negative correlation has been found between the increase in $\alpha$-power ( 8 $12 \mathrm{~Hz}$ ) and PD resting tremor at the centro-parietal cortex [54]. In ET the thalamus, specifically the ventralis intermedius (VIM), is a more common target for DBS. Kane et al. [53] found an increased coherence between the $\theta$-band ( $4-7 \mathrm{~Hz}$ ) for the LFP's in the VIM and tremor activity at the hands recorded with accelerometers. Another study found desynchronization of $\alpha$ and $\beta$ activity during tremor in the primary motor and sensorimotor cortex in ET [55]. Wang et. al [31] used regression analysis to prove a coupling between tremor intermittency and LFP power in the STN in PD patients. As DBS locations of recording and stimulation are different in ET and PD, comparing DBS findings is difficult.

Comparing cortical or subcortical activity of ET and PD patients, recorded at the same location and with the same method is desirable and might be a useful tool to determine differences between parkinsonian and essential tremor. Therefore, the aim of this study is to identify differences in cortical activity during TW in PD and ET. As other studies have found significant correlations and coherences between parkinsonian and essential tremor and the $\alpha$ - and $\beta$-band at the cortical level, these frequency bands will also be the focus in this study. Furthermore, since the sensorimotor cortex is the final common pathway of voluntary and involuntary movements [30], EEG seems to be a suitable tool to study and compare cortical involvement in essential and parkinsonian tremor non-invasively. For this purpose statistical significance of correlations between hand tremor and cortical activity were assessed using regression analysis. 


\subsection{Methods}

\subsubsection{Subjects}

Sixteen ET patients (12 male), age $59 \pm 18$ years (mean \pm standard deviation) and 16 PD patients ( 9 male), age $64 \pm 10$ years, were included in this study. A two-sampled t-test determined no significant differences in age between the two groups. An overview of patient details is given in Table 3.1. All patients were right-handed according to the Edinburgh Handedness Inventory [56] and all patients were off tremor-suppressing medication according to an individual scheme established by an experienced neurologist. PD patients were diagnosed with Parkinson's disease according to the UK Brain Bank criteria for Parkinson's disease [57] and showed neither major fluctuation in symptoms due to medication, nor suffered from severe dyskinesia. ET patients were diagnosed according to the criteria defined by the Tremor Investigation Group [58] and had a positive family history of ET. All patients gave written informed consent prior to participation in accordance with the Declaration of Helsinki. The study was approved by the medical ethics committee of the Amsterdam UMC, The Netherlands.

\subsubsection{Experimental setup and data acquisition}

Patients were seated comfortably on a hospital bed with the back elevated to a sitting position. Movement was recorded using a 3D accelerometer (TMSi, Oldenzaal, The Netherlands) placed on the back of each hand, approximately in the middle of the third metacarpal bone with the $\mathrm{x}$-direction pointing towards the fingertips and the $y$-direction pointing towards the thumb. Sensor size was $13 \mathrm{mmx} 10 \mathrm{~mm} \times 5 \mathrm{~mm}$ and sensor weight was 2 grams. Simultaneously, EEG was recorded with a 72-channel Refasystem and a 64-channel low noise shielded EEG head cap (TMSi, Oldenzaal, The Netherlands) (resistance $<30 \mathrm{k} \Omega$ ). Data acquisition was done using a customized program written in LabVIEW (National Instruments, Austin, Texas, United States) with a sampling frequency of $2048 \mathrm{~Hz}$. 
Table 3.1. Patient details

\begin{tabular}{|c|c|c|c|c|}
\hline Gender & Age [years] & Duration [years] & Medication & Group \\
\hline $\mathrm{M}$ & 58 & 8 & levodopa, trihexyfenidyl & PD \\
\hline M & 69 & 5 & $\begin{array}{l}\text { Monoamino-oxidase-B inhibitor, } \\
\text { propranolol }\end{array}$ & PD \\
\hline M & 67 & 4 & trihexyfenidyl & PD \\
\hline $\mathrm{F}$ & 81 & 5 & Levodopa, carbidopa, metoprolol & PD \\
\hline $\mathrm{F}$ & 62 & 2 & levodopa & PD \\
\hline M & 49 & 2 & Levodopa, carbidopa, ropinirol & PD \\
\hline M & 71 & 2 & - & PD \\
\hline $\mathrm{F}$ & 54 & 12 & Levodopa, benserazide & PD \\
\hline $\mathrm{F}$ & 43 & 3 & ropinirol & PD \\
\hline M & 78 & 2 & $\begin{array}{c}\text { Levodopa, carbidopa, rasagiline, } \\
\text { perindopril }\end{array}$ & PD \\
\hline M & 68 & 14 & Levodopa, carbidopa & PD \\
\hline M & 64 & 10 & Levodopa, carbidopa, benserazide & PD \\
\hline $\mathrm{F}$ & 72 & 2 & - & PD \\
\hline M & 67 & 8 & $\begin{array}{l}\text { Levodopa, carbidopa, amantadine, } \\
\text { entacapon, levothyroxine }\end{array}$ & PD \\
\hline $\mathrm{F}$ & 56 & 5 & levodopa, ropinirol & PD \\
\hline $\mathrm{F}$ & 64 & 6 & Levodopa, benserazide, & PD \\
\hline M & 50 & 50 & - & ET \\
\hline $\mathrm{F}$ & 81 & 21 & - & ET \\
\hline M & 54 & 4 & propranolol & ET \\
\hline M & 85 & $>40$ & propranolol & ET \\
\hline M & 65 & $>40$ & - & ET \\
\hline $\mathrm{F}$ & 51 & $>30$ & - & ET \\
\hline M & 65 & 45 & propranolol & ET \\
\hline $\mathrm{F}$ & 23 & $>5$ & - & ET \\
\hline M & 49 & 9 & propranolol & ET \\
\hline M & 54 & 38 & - & ET \\
\hline $\mathrm{M}$ & 70 & $>40$ & - & ET \\
\hline $\mathrm{M}$ & 64 & $>40$ & - & ET \\
\hline $\mathrm{M}$ & 55 & $>30$ & - & ET \\
\hline $\mathrm{M}$ & 72 & 12 & - & ET \\
\hline $\mathrm{M}$ & 27 & 27 & - & ET \\
\hline $\mathrm{F}$ & 81 & 61 & - & ET \\
\hline
\end{tabular}


Patients were asked to perform three tasks with eyes open to evoke either resting, postural or kinetic tremor:

1. Resting task (RT): Patients sat with both hands in supine position resting in their lap. Three minutes of data were recorded during the resting task.

2. Postural task (PT): Patients stretched out the right arm, unsupported against gravity, approximately parallel to the floor. They performed the task 3 times for one minute, while the left arm remained rested in the lap.

3. Movement task (MT): Patients performed an elbow flexion-extension task (index finger from nose to knee) with the right arm at a self-paced speed and the left arm remained rested in the lap. Task duration was one minute.

\subsubsection{Signal pre-processing and analysis}

Data analysis was performed off-line in MATLAB (MathWorks, Inc., R2013, Natick, Massachusetts, USA). The dominant tremor axis of the 3D accelerometers was determined using principle component analysis, and this signal was used for further analysis. Afterwards accelerometer data was band-pass filtered between $0.5 \mathrm{~Hz}$ and $20 \mathrm{~Hz}$ (non-causal, $4^{\text {th }}$ order Butterworth). EEG data was band-pass filtered between $0.5 \mathrm{~Hz}$ and $45 \mathrm{~Hz}$ (non-causal, zero-phase, $4^{\text {th }}$ order Butterworth). Eye movement artefacts in the EEG data were removed using independent component analysis and a local average montage was used to minimize reference and volume conduction effects at distances of approximately the inter-electrode spacing [59]. The montage is described by (3.1).

$$
V_{\text {ref }, i}=V_{i}-\frac{1}{N} \sum_{j=1}^{N} V_{i j}
$$

With $V_{i}$ is the potential at electrode i, $V_{i j}$ are the potentials of the neighbouring electrodes and $\mathrm{N}(\mathrm{N}=8)$ the number of neighbouring electrodes for non-border electrodes. Border electrodes were excluded from analysis as they often contain EMG artefacts and have fewer neighboring electrodes to calculate the local average.

All data was resampled to $512 \mathrm{~Hz}$ and split into 3-second windows with $50 \%$ overlap to detect TW. Each window was classified as a TW using the 
accelerometer signal and the RelP method of Luft et. al [51]: a window is classified as a TW when the relative power within a $1 \mathrm{~Hz}$ range around the peak frequency within the tremor frequency band $(3.5-12 \mathrm{~Hz})$ is equal to or greater than $40 \%$ of the total power (P) within the frequency band, described by (3.2).

$$
\mathrm{TW} \stackrel{\text { def }}{=} \frac{P\left(f_{\text {tremor }}\right)}{P(3.5-12 \mathrm{~Hz})} \geq 0.40
$$

With $f_{\text {tremor }}$ the frequency range between $f_{\text {peak }}-0.5 \mathrm{~Hz}$ and $f_{\text {peak }}+$ $0.5 \mathrm{~Hz} . f_{\text {peak }}$ is the detected peak within the tremor frequency range of 3.5$12 \mathrm{~Hz}$. The relative tremor power was calculated using (3.3):

$$
P_{\text {rel }}=\frac{P\left(f_{\text {tremor }}\right)}{P(3.5-12 \mathrm{~Hz})}
$$

From the EEG data the relative power of the $\alpha-(8-12 \mathrm{~Hz})$ and $\beta$-band $(13-30 \mathrm{~Hz})$ with respect to the power over all frequencies was calculated $(0.5-45 \mathrm{~Hz})$.

\subsubsection{Outcome parameters}

To analyze the relation between tremor at the periphery and cortical activity a regression analysis was used comparable to the method of Wang et. al [31]. Regression analysis was performed on the windows classified as TW, between the relative power in each frequency band of the EEG electrodes and the relative peak power of the accelerometer of the dominant hand. The dominant hand was not based on tremor severity, but handedness. As this was done for both groups the effect was approximately the same and no mirroring of the results was necessary for the analysis. This was done for each subject, task and electrode. Afterwards, the significance of the correlation was calculated using a t-distribution with n-2 degrees of freedom [60], according to (3.4).

$$
t=r \cdot \frac{\sqrt{n-2}}{\sqrt{1-r^{2}}}
$$

With $r$ the correlation coefficient and $n$ the number of tremor windows. For $t$ equal to or larger than 2 the correlation is considered to be significant.

For calculating inter-group differences, the EEG electrodes were grouped into 5 areas (see Figure 3.1): frontal, left central, central, right 
central and posterior. The t-values in these areas were compared between groups using the non-parametric Kruskal-Wallis test due to varying standard deviation and post-hoc analysis using Bonferroni correction for multiple comparison. A p-value smaller than 0.05 was considered significant.

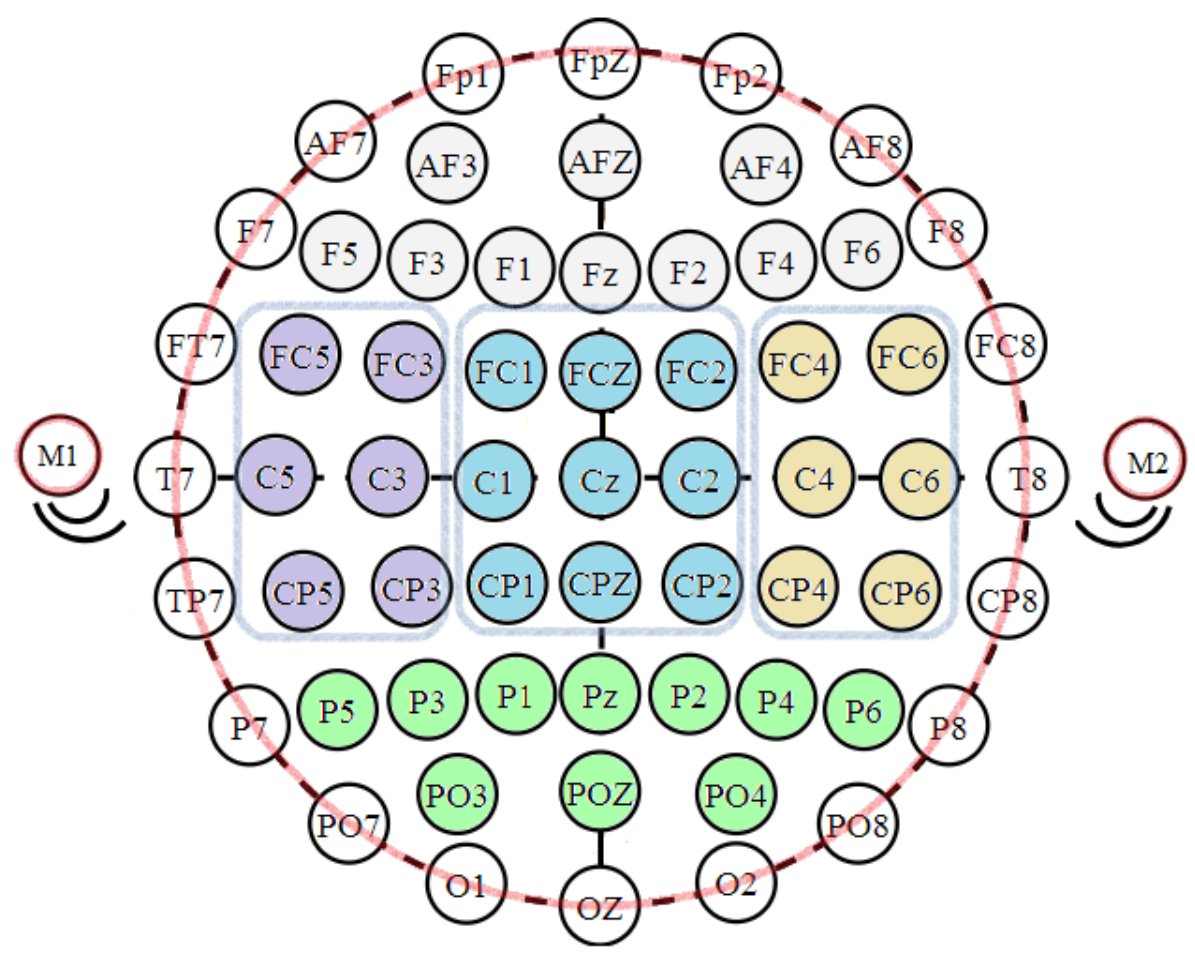

Figure 3.1. Overview of the EEG electrodes. Red regions indicate the border electrodes which were excluded during analysis. Blue and non-circled regions indicate the 5 defined areas for statistical analysis. Grey = frontal area; purple = central left area; beige = central right area; blue = central area and green $=$ posterior area .

\subsection{Results}

Tremor windows were detected in both groups during all three tasks (Table 3.2). Therefore, regression analysis between relative tremor power and the power in EEG could be performed. 
Table 3.2. Overview of the number of detected tremor windows

\begin{tabular}{|c|c|c|c|}
\hline Subject & RT (\%) & PT (\%) & MT (\%) \\
\hline$\overline{\mathrm{PD}}$ & 7.6 & 100 & 33.3 \\
\hline PD & 93.2 & 99.0 & 92.7 \\
\hline PD & 55.6 & 18.3 & 5.6 \\
\hline PD & 78.6 & 86.5 & 32.4 \\
\hline PD & 100 & 91.3 & 100 \\
\hline PD & 2.6 & 22.1 & 20.5 \\
\hline PD & 5.1 & 6.7 & 8.1 \\
\hline PD & 97.1 & 94.2 & 16.2 \\
\hline PD & 3.1 & 2.9 & 2.8 \\
\hline PD & 100 & 95.2 & 67.6 \\
\hline PD & 1.7 & 9.6 & 8.3 \\
\hline PD & 34.5 & 33.7 & 2.8 \\
\hline PD & 5.1 & 8.7 & 13.5 \\
\hline PD & 100 & 54.8 & 7.5 \\
\hline PD & 95.7 & 41.3 & 16.2 \\
\hline PD & 98.3 & 100 & 30.6 \\
\hline ET & 7.6 & 19.2 & 8.1 \\
\hline ET & 50 & 71.2 & 27.0 \\
\hline ET & 0.9 & 0 & 0 \\
\hline ET & 36.8 & 35.6 & 15.8 \\
\hline ET & 78.0 & 52.9 & 10.5 \\
\hline ET & 69.6 & 94.6 & 10.5 \\
\hline ET & 12.7 & 9.7 & 7.9 \\
\hline ET & 3.4 & 2.9 & 23.7 \\
\hline ET & 0 & 4.8 & 15.8 \\
\hline ET & 94.1 & 72.1 & 63.2 \\
\hline ET & 3.4 & 23.1 & 0 \\
\hline ET & 21.2 & 24.0 & 63.2 \\
\hline ET & 100 & 100 & 2.6 \\
\hline ET & 10.2 & 19.2 & 8.3 \\
\hline ET & 1.8 & 4.8 & 2.8 \\
\hline ET & 100 & 100 & 36.1 \\
\hline
\end{tabular}

The mean group results of the regression analysis during TW for the ET and PD group are displayed in Figure 3.2. The RT revealed no significant correlation within the $\alpha$ and $\beta$-band in the ET group. In the PD group significant correlations were found in both bands. In the $\alpha$-band significant correlations with the dominant hand were found within the dorsolateral prefrontal, intermediate frontal and associative visual cortex and the angular gyrus ipsilateral to the dominant hand. Contralateral to the dominant hand significant correlations within the somatosensory 
association cortex were found. Inter-group analysis revealed significant differences in almost all areas in the $\alpha$-band and three areas in the $\beta$-band (Table 3.3).

\section{Essential tremor Parkinson's disease \\ Resting task}
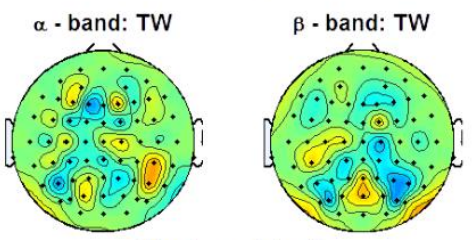

Postural task
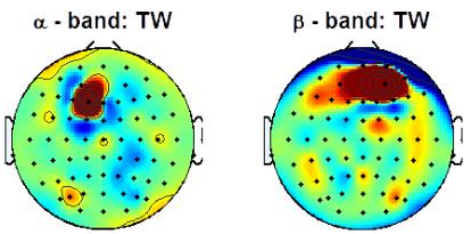

Movement task
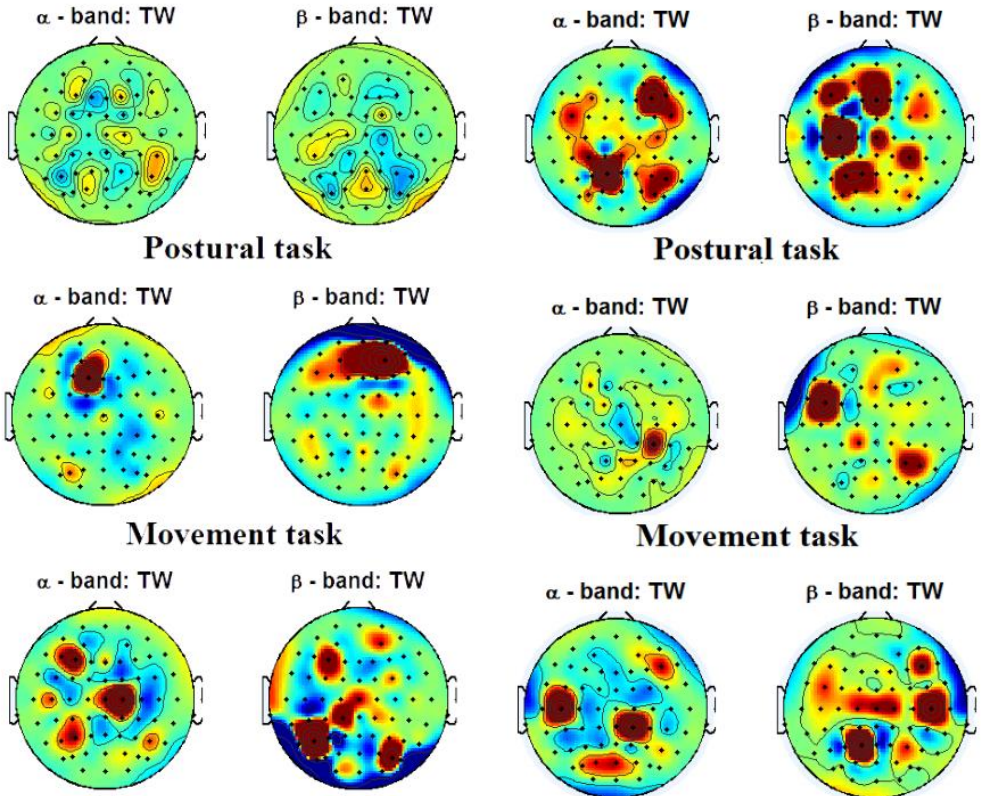

\section{Postural task}
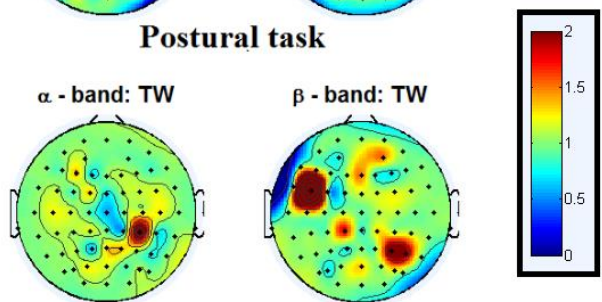

Movement task
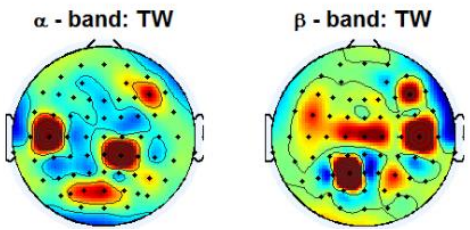

Figure 3.2. Topo-plots of the group results of the significant correlations between tremor at the dominant hand and cortical activity. From top to bottom the group results of the correlation between EEG and accelerometer data during TW for the three tasks, resting, postural and movement are presented, for both ET (left) and PD (right). Correlation is displayed between the relative power of the alpha and beta band and the relative tremor power of the right hand. The color map indicates the t-value at each electrode. Dark red areas are statistically significant $(t>2)$. 
Table 3.3. Results of the inter-group analysis

\begin{tabular}{cccc}
\hline & & \multicolumn{3}{c}{ Frequency band } \\
\hline Task & Area & $\boldsymbol{\alpha}$ & $\boldsymbol{\beta}$ \\
\hline RT & Frontal & $0.031^{*}$ & $0.022^{*}$ \\
& Left central & $0.011^{*}$ & - \\
& Central & $0.004^{*}$ & - \\
& Right central & - & $0.043^{*}$ \\
& Posterior & $0.002^{*}$ & $<0.001^{*}$ \\
\hline PT & Frontal & - & $0.0054^{\ddagger}$ \\
& Left central & - & - \\
& Central & - & - \\
& Right central & $0.037^{*}$ & - \\
& Posterior & $0.014^{*}$ & - \\
\hline MT & Frontal & - & - \\
& Left central & - & - \\
& Central & - & - \\
& Right central & - & - \\
\hline
\end{tabular}

Superscripts indicate which group showed a higher correlation between tremor and cortical activity. ${ }^{*}$ PD higher than ET; ${ }^{¥}$ ET higher than PD; RT = resting task; $\mathrm{PT}$ = postural task; $\mathrm{MT}=$ movement task; $\mathrm{LC}=$ central left, $\mathrm{RC}=$ central right.

During the PT a significant correlation with tremor was found in the EEG of both groups in both frequency bands. In the ET group significant correlations were found at the contralateral intermediate frontal and dorsolateral prefrontal cortex in the $\alpha$-band. The $\beta$-band showed significant correlations at the intermediate frontal and dorsolateral prefrontal cortex. In PD significant correlations were found at the ipsilateral supramarginal gyrus in the $\alpha$-band and the ipsilateral angular gyrus and contralateral premotor cortex in the $\beta$-band. Inter-group analysis revealed significant differences in the central right and posterior area in the $\alpha$-band and frontal area in the $\beta$-band.

The MT revealed a significant correlation between the contralateral intermediate frontal, ipsilateral primary motor and somatosensory association cortex in the $\alpha$-band and tremor in ET. In the $\beta$-band similar areas were found with a slight shift towards the associative visual cortex contralateral to the dominant hand. In PD significant correlations were found in the posterior transverse temporal cortex contralateral in the $\alpha$ - 
band and ipsilateral in the $\beta$-band. Furthermore, the ipsilateral supramarginal gyrus in the $\alpha$-band and in the contralateral somatosensory association cortex in the $\beta$-band showed a significant correlation with tremor. However, inter-group analysis revealed no significant differences.

\subsection{Discussion}

Until now, tremor analysis of short (couple of minutes) EMG or accelerometer data has not been sufficient to differentiate between ET and PD due to similarities in the features and parameters retrieved from this type of data. In this study we showed that adding EEG recordings to these short-term recordings and splitting data into TW and NTW periods, prior to further analysis, results in distinct cortical activity patterns during tremor. These activity patterns were significantly different during rest and posture between the two patient groups. In a future study, it should be tested whether these patterns are already present in an early stage of the disease and whether they can provide a tool for the diagnostic process.

Even though TW were found in both groups during the RT, no significant correlations between EEG and accelerometer data were found in the $\alpha$ and $\beta$-band for the ET group, whereas in the PD group significant correlations were found in both frequency bands. From literature it is known that up to $50 \%$ of the ET patients present with resting tremor and that the appearance of resting tremor seems to depend on the setting in which the patients are evaluated [61]. Resting tremor in ET is often associated with longer disease duration [62], but the underlying mechanism is still unclear. Other studies have found cortical involvement in tremor genesis in ET, but these studies focused on postural or grip force tasks $[63,64]$. The results of this study suggest no cortical involvement in ET with regard to resting tremor. The dimmer-switch model of Helmich et al. [6] suggests that in PD resting tremor is caused by malfunction of the basal ganglia, but its amplitude is regulated by malfunction of the cerebellar-thalamo-cortical loop. It is suggested that in PD the connection between the two circuits and final output path of the tremor lies within the motor cortex [65]. Our results support that the cortex is involved in the generation, or at least the facilitation, of parkinsonian resting tremor, but not in ET, indicating different mechanisms being responsible for resting tremor in ET and PD. Intermittent cortical involvement in postural tremor generation in ET has 
been found by several studies $[63,66]$. The findings in this paper suggest that resting tremor involves other circuits than postural tremor in ET. In the PD group significant correlations were found in areas responsible for movement execution and initiation and eye movement during the RT. The involvement of these areas would be expected during a movement task but not a resting task, indicating that the tremor network in PD might involve the same regions as voluntary movement. This may also explain the fact that tremor in some cases disappears during voluntary movement as a result of a selection process to facilitate one or the other.

During the PT ET patients showed significant correlation not only within areas of motor planning and execution but also within areas of eye movement. All patients were able to see their arm and hand during the task. Finding significant correlations within areas of eye movement in the ET group supports findings of other studies suggesting that patients with cerebellar disorders might rely more on visual guidance for movement execution [67]. The PD group showed significant correlation with the angular gyrus, which is involved in processing visual information and processing a sequence of actions. This may indicate that patients with PD also need to rely on visual information to maintain a posture in the presence of tremor. Furthermore, deficits in visuospatial perception in PD patients have been related to freezing of gate [68]. The lateral activation of the ipsilateral premotor area in PD could be a result of malfunction of the basal ganglia [44].

During the MT more central areas are involved in ET compared to PD. Since the cerebellum projects via the thalamus to the central areas of the motor and premotor cortex, the findings suggest an involvement of the cerebello-thalamo-cortical circuit in the ET group. In both groups areas involved in processing and controlling movement guided by visuospatial information are seen. Furthermore, in the ET group the primary motor cortex, which is also involved in hand and wrist movement and rhythmic motor tasks, is involved in tremor. However, activation patterns found during the MT were not significantly different between the patient groups.

A concern with EEG data is that it often contains large artefacts caused by muscle activity and electrode movement. We used ICA to remove these artefacts. All regions, in which significant correlation has been found between EEG and accelerometers with respect to tremor, are involved in 
movement initiation, planning or execution, or visual and sensory processes. All regions are expected to be involved in a movement task and, therefore, we believe artefact reduction was successful as otherwise a more widespread correlation or none at all could be expected. Another limitation of the study is that only group results are presented. ET is known to be a heterogeneous group and individual differences might have been smoothed out. In this study we chose to select the patients so that the groups were approximately age-matched and not matched based on disease duration. This was done because age is also known to affect movement performance and we wanted to minimize this bias. The next step would be to focus on the evaluation of individual subjects. The group analysis could also explain the different findings in ET in other studies $[12,69]$. However, in PD and in ET specific locations were found that showed significant correlations with the tremor recorded at the dominant hand of each subject. Therefore, the findings of this study show that regression analysis on short term EEG and accelerometer recording could be a valuable tool in the differentiation of ET and PD tremor. A future study should also look at EMG of proximal and distal arm muscles. This would provide more detailed information about tremor origin (at the muscular level) and might provide even more localized coherent activity at the cortical level.

\subsection{Conclusion}

In conclusion the findings of this study suggest that especially resting tremor involves different tremor networks in ET and PD. To determine the underlying differences and identify the exact network more studies are necessary. However, for differentiation between the two disorders the RT is a promising task and regression analysis a promising tool in clinical practice when the underlying cause of the occurring tremor is unclear. 


\section{PART II}

Cueing 



\section{Movement analysis during cued and non-cued movement ${ }^{3}$}

\section{ABSTRACT}

Parkinson's disease (PD) and essential tremor (ET) are neurodegenerative diseases characterized by movement deficits. Especially in PD, maintaining cyclic movement can be disturbed due to pathological changes in the basal ganglia and the cerebellum. Providing external cues improves timing of these movements in PD and also affects ET. The aim of this study is to determine differences in cortical activation patterns in PD and ET patients during externally and internally cued movements.

Eleven PD patients, twelve ET patients and nineteen age-matched healthy controls were included and asked to perform a bimanual tapping task at two predefined cue frequencies. The auditory cue was an metronome beat alternately switched on or off every 30 seconds. Cortical activity was recorded using a 64-channel EEG cap. To establish the cortical activation pattern in each group, the task related power (TRP) was calculated for each subject. For inter-groups analysis, EEG electrodes were divided into 5 different areas.

Inter-group analysis revealed significant differences in areas responsible for motor planning, organization and regulation and involved in initiation, maintenance, coordination and planning of complex sequences of movements. Within the area of the primary motor cortex the ET group showed a significantly lower TRP than the HC group. In the area responsible for combining somatosensory, auditory and visual information both patient groups had a higher TRP than the HC group.

Different neurological networks are involved during cued and non-cued movements in ET, PD and HC. Distinct cortical activation patterns were revealed using task related power calculations. The results suggest that including a cued/non-cued tapping task during clinical decision making could be a valuable tool in an objective diagnostic protocol.

\footnotetext{
3 Published as:

Luft, F., Sharifi, S., Mugge, W., Schouten, A. C., van Rootselaar, A. F., Veltink, P. H., Heida, T.; Deficits in tapping accuracy and variability in tremor patients. J Neuroeng Rehabil, 2019. 16(1): p. 54
} 


\subsection{Introduction}

Movement disorders can affect all phases of movement, i.e. the preparation, timing, execution and termination. Two of the most common movement disorders are Parkinson's disease (PD) and essential tremor (ET) $[70,71]$. PD is considered a disease of the basal ganglia, and for ET, literature suggests pathological changes in the cerebellum [12]. However, the classifications of the two disorders have been revised in recent years. Classic PD is diagnosed based on bradykinesia and at least one of the following symptoms: rigidity or resting tremor $[14,72]$. ET is clinically defined as a disorder presenting with a bilateral postural or/and kinetic tremor [73-75]. However, it has been shown that ET is a rather heterogeneous disorder making the diagnosis difficult when patients present with a resting tremor as well as a postural or kinetic tremor [62, $74,75]$. On the other hand, PD patients may express a postural tremor, similar to the one seen in ET and no resting tremor [76]. Furthermore, rigidity and postural instability are two symptoms usually associated with PD, but are also common in elderly [77], complicating the diagnosis of elderly PD (most people with idiopathic PD develop symptoms at 50 years of age or older [78]) and late-onset ET patients (late disease onset at age 46 and older [79]). Since tremor is a common disease characteristic, many studies have attempted to distinguish PD and ET based on quantitative characteristics of tremor such as tremor amplitude and frequency [20]. However, the ranges of these tremor characteristics show significant overlap despite the pathological differences and differences in classic clinical presentation [80]. Therefore, the rate of misdiagnosis in ET is up to $37 \%$ with the most common true diagnosis either PD (15\%) or dystonic tremor $[17,81]$.

The Unified Parkinson's Disease Rating scale (MDS-UPDRS), commonly used to rate the severity of PD, includes various finger and hand movement tasks. The parameters of interest are the speed, amplitude and regularity of these movements. These parameters have also been studied quantitatively in several studies [37, 42]. PD patients often suffer from a difficulty to initiate movements, including standing up or starting to walk, and to continue rhythmic cyclic motion, including walking and finger tapping $[37,38]$. Other studies have shown that external cues 
enhance PD patients' ability to start and continue movements [38-40]. Several studies have looked into patients' ability to perform finger tapping tasks when cueing was applied [37, 39]. During these experiments, PD patients, in particular tremor dominant PD patients, tended to hasten movements when finger tapping tasks at lower frequencies $(<3 \mathrm{~Hz})$ had to be performed. At higher frequencies $(4-5 \mathrm{~Hz})$ patients tapped slower than the cue frequency [39]. Furthermore, studies using a synchronization-continuation task also showed that PD patients hastened movements at lower frequencies and that this deficit was greater in PD patients with freezing of gait episodes [82]. A pilot study by Espay et. al [42] found that patients with PD tapped with a smaller amplitude and reduced speed during an index finger to thumb tapping task compared to healthy controls (HC).

Fewer studies have been conducted on ET patients and rhythmic cyclic movements. Farkas et. al [45] found an impairment of rhythm generation and an increased variability of hand movement during externally cued movements compared to HC. Furthermore, Avanzino et. al [46] found that $1 \mathrm{~Hz}$-rTMS over the ipsilateral cerebellum affected the performance during a finger movement task in patients with ET by reducing touch duration values and normalizing the inter touch interval values.

The ability to perform a rhythmic cyclic movement has been evaluated for both patient groups in comparison with healthy controls, but not in comparison with each other or other neurological disorders. Additionally, such a task is not included in any rating scale (MDS-UPDRS and Tremor rating scale), even though differences between patients and healthy controls are known and adding such a task might be useful during clinical decision making or analyzing disease progression. Furthermore, the occurrence of kinetic tremor during such a movement has not been evaluated, even though kinetic tremor has been reported in both disorders and is the primary symptom in ET. Therefore, the aim of this study is to evaluate and compare the performance of ET and PD patients in performing a bimanual synchronization-continuation tapping task to determine the usefulness of such a task as a tool during clinical decision making. For this purpose we evaluated movement characteristics during rhythmic cyclic movements at different frequencies. Furthermore, we evaluated the effect of kinetic tremor on these movement characteristics. An additional group of $\mathrm{HC}$ was 
included to evaluate overall deficits in both groups compared to HC. We expected to find greater deficits in timing ability in the PD group and more frequent occurrence of kinetic tremor in the ET group compared to PD and HC.

\subsection{Methods}

\subsubsection{Participants}

Eleven PD patients (3 Female (F); Age: $66 \pm 11$ ), seventeen ET patients (4 F; Age 58 \pm 17 ) and nineteen HC (9 F; Age: $59 \pm 15$ ) (mean \pm std (years)) participated in the study. An overview of the patient details is given in Table 4.1. HC subjects were matched in age as good as possible to both groups (see Table 4.1). No significant differences in age between the three groups was found (PD - ET: $\mathrm{p}=0.29$; PD - HC: $\mathrm{p}=0.28$; ET - HC: $\mathrm{p}=0.98$ ). Gender was not considered to have any influence on the results. For the patient groups an overview of the tremor frequencies, recorded with accelerometers, of resting, postural and kinetic tremor are given in Table 4.2. All subjects were right-handed according to the Edinburgh Handedness Inventory [56] and patients were willing to stop medication according to an individual scheme prior to the experiment. Furthermore, the PD patients were diagnosed with Parkinson's disease according to the UK Brain Bank criteria for Parkinson's disease [57] and showed neither major fluctuations in symptoms nor suffered from severe dyskinesia. Additionally, all PD patients presented with a resting tremor during the intake. ET patients had essential tremor according to the criteria defined by the Tremor Investigation Group [58], and had a positive family history of ET. HC had no record of neurological or other diseases affecting the motor system. The study was conducted in accordance with the Declaration of Helsinki and was approved by the Medical Ethical Committee of the Academic Medical Center, Amsterdam, The Netherlands. All subjects signed written informed consent prior to the experiment.

\subsubsection{Experimental setup}

Subjects were seated on a bed, with head and back supported for a sitting posture. They performed a bimanual, in-phase, tapping task at two predefined cue frequencies, 2 and $4 \mathrm{~Hz}$ (equivalent to an inter-tap interval of $500 \mathrm{~ms}$ and $250 \mathrm{~ms}$, respectively). The forearm and proximal part of the 46 
wrist joint were supported against gravity by the bed and tapping movements were made by wrist flexion. At each frequency, subjects had to tap on the bed next to their legs continuously with both hands for three minutes. The three minutes were split into blocks of thirty seconds, with the auditory cueing switched on and off, alternately. Instructions were given verbally prior to the experiment and all subjects were able to perform the task without further practice. During cued movement, subjects were able to hear a metronome beat via computer speakers. Prior to the experiment subjects were asked whether they were able to hear the sound clearly. The three-minute tapping task was performed at both cue frequencies.

Hand movement was recorded with 3D accelerometers (TMSi, Oldenzaal, The Netherlands - see Introduction for specifications). Muscle activity was recorded from the m. extensor carpi ulnaris of both arms using surface electromyography (EMG) electrodes. All signals were connected to a physiological amplifier system (Porti, TMSi, Oldenzaal, The Netherlands) to synchronize the data streams. Data acquisition was done with a sampling frequency of $2048 \mathrm{~Hz}$ using a customized program written in LabVIEW (National Instruments, Austin, Texas, USA).

In this study EMG and accelerometers were used to record movement and tremor as they may provide complementary information.

\subsubsection{Data pre-processing}

First the norm of the accelerometer vectors was calculated, giving one acceleration signal for each hand. The acceleration signal for each hand was filtered off-line (non-causal, $0.25-20 \mathrm{~Hz}$ bandpass, $4^{\text {th }}$ order Butterworth). Afterwards the data was split into cued and non-cued movement, the first and last $2 \mathrm{~s}$ of each block were removed to avoid transition effects, giving 3 blocks of $26 \mathrm{~s}$ for each condition. This was done for the $2 \mathrm{~Hz}$ and for the 4 $\mathrm{Hz}$ tapping task. EMG data was filtered off-line (non-causal, $20-400 \mathrm{~Hz}, 4^{\text {th }}$ order Butterworth). Then the absolute value of the Hilbert transform was used as the envelope of the EMG signal for further analysis. 
Table 4.1. Overview of included subjects

\begin{tabular}{|c|c|c|c|c|}
\hline Subject & Gender & Age & Duration (Years) & Medication \\
\hline PD 1 & $\mathrm{M}$ & 69 & 5 & Levodopa, Trihexyphenidyl \\
\hline PD 2 & M & 67 & 4 & Propranolol, Rasagilin \\
\hline *PD 3 & $\mathrm{~F}$ & 81 & 5 & Trihexyphenidyl \\
\hline *PD 4 & M & 62 & 2 & Levodopa, Metoprolol succinat \\
\hline PD 5 & M & 71 & 2 & Levodopa \\
\hline PD 6 & $\mathrm{~F}$ & 43 & 3 & - \\
\hline PD 7 & M & 68 & 8 & Levodopa, Rasagilin, perindopril, omeprazole \\
\hline PD 8 & M & 64 & 15 & - \\
\hline PD 9 & M & 67 & 11 & Levodopa, Benserazid \\
\hline *PD 10 & $\mathrm{~F}$ & 56 & 9 & Levodopa, Carbidopa, Amandatin \\
\hline PD 11 & M & 64 & 7 & - \\
\hline ET 1 & $\bar{M}$ & 50 & 50 & - \\
\hline ET 2 & $\mathrm{~F}$ & 81 & 21 & - \\
\hline * ET 3 & M & 54 & 4 & Propranolol \\
\hline ET 4 & M & 85 & Childhood & Propranolol \\
\hline *ET 5 & M & 65 & Childhood & - \\
\hline ET 6 & $\mathrm{~F}$ & 51 & Childhood & - \\
\hline * ET 7 & M & 65 & 45 & Propranolol \\
\hline ET 8 & $\mathrm{~F}$ & 23 & Childhood & - \\
\hline ET 9 & M & 49 & 9 & Propranolol \\
\hline ET 10 & M & 54 & Childhood & - \\
\hline ET 11 & M & 70 & Childhood & - \\
\hline ET 12 & M & 64 & Childhood & - \\
\hline ET 13 & M & 55 & Childhood & - \\
\hline *ET 14 & M & 72 & 12 & Propranolol \\
\hline ET 15 & M & 27 & Childhood & - \\
\hline ET 16 & $\mathrm{~F}$ & 81 & Childhood & - \\
\hline ET 17 & M & 45 & Childhood & - \\
\hline
\end{tabular}

PD = Parkinson's Disease; ET = essential tremor; $\mathrm{M}=$ Male and F = Female. The asterisk ${ }^{*}$ marks the subjects that were either excluded (essential tremor) due to technical failure or false execution of the task or not able to perform the $4 \mathrm{~Hz}$ tapping task (Parkinson's disease). 
Table 4.2. Overview tremor frequencies

\begin{tabular}{cccc}
\hline Subject & Rest (Hz) (R/L) & Posture (Hz) (R/L) & Tapping (Hz) (R/L) \\
\hline PD 1 & $5 / 5$ & $6 / 5$ & $6 / 6$ \\
PD 2 & $5 / 5$ & $7 / 8$ & $-/ 6$ \\
*PD 3 & $6 / 4$ & $5 / 7$ & $-/ 5$ \\
*PD 4 & $6 / 6$ & $7 / 7$ & $7 / 7$ \\
PD 5 & $9 / 8$ & $6 / 6$ & $-/ 6$ \\
PD 6 & $8 / 8$ & $9 / 8$ & $-/-$ \\
PD 7 & $4 / 5$ & $5 / 6$ & $6 / 6$ \\
PD 8 & $6 / 6$ & $6 / 7$ & $-/-$ \\
PD 9 & $7 / 6$ & $6 / 7$ & $5 /-$ \\
*PD 10 & $6 / 6$ & $5 / 5$ & $-/-$ \\
PD 11 & $6 / 7$ & $6 / 8$ & $-/-$ \\
\hline ET 1 & $6 / 7$ & $6 / 6$ & $-/-$ \\
ET 2 & $5 / 5$ & $7 / 6$ & $6 / 5$ \\
* ET 3 & - & - & - \\
ET 4 & $8 / 6$ & $5 / 6$ & $-/-$ \\
* ET 5 & - & - & - \\
ET 6 & $7 / 6$ & $7 / 7$ & $7 / 7$ \\
* ET 7 & - & - & - \\
ET 8 & $8 / 7$ & $7 / 8$ & $-/ 8$ \\
ET 9 & $7 / 7$ & $5 / 6$ & $7 /-$ \\
ET 10 & $6 / 6$ & $6 / 7$ & $6 / 6$ \\
ET 11 & $5 / 9$ & $7 / 7$ & $-/-$ \\
ET 12 & $7 / 4$ & $7 / 7$ & $9 /-$ \\
ET 13 & $8 / 8$ & $8 / 8$ & $8 / 7$ \\
* ET 14 & - & - & - \\
ET 15 & $6 / 6$ & $5 / 7$ & $-/ 7$ \\
ET 16 & $5 / 5$ & $5 / 10$ & $6 / 6$ \\
ET 17 & $7 / 7$ & $6 / 7$ & $-/-$ \\
\hline PDD Parkin & 5 & - \\
\hline
\end{tabular}

$\mathrm{PD}=$ Parkinson's disease; ET = essential tremor; $\mathrm{R}=$ Right hand; $\mathrm{L}=$ Left hand. The tremor frequencies are given for each individual patient. For the postural tremor patients had both arms outstretched.

\subsubsection{Data analysis}

Acceleration and EMG data were split into 3 second epochs with $50 \%$ overlap. The power spectral density (PSD) of each epoch was estimated using a periodogram with a rectangular window to maximize frequency resolution. For each epoch the tapping frequency was calculated as the highest peak in a range $+/-1 \mathrm{~Hz}$ of the cue frequency, resulting in the spectrum between $1-3 \mathrm{~Hz}$ and between $3-5 \mathrm{~Hz}$ for the $2 \mathrm{~Hz}$ and $4 \mathrm{~Hz}$ tapping tasks, respectively. These narrow frequency bands were chosen after visual inspection of all epochs and subjects. To test the timing ability and the consistency of tapping we used two measures that were retrieved 
from the acceleration data, the tapping accuracy (TA) and tapping variability (TV).

$$
\mathrm{TA}_{\text {Subject }}=\frac{\sum_{\mathrm{n}=1}^{\mathrm{N}}\left(\mathrm{f}_{\text {cue }}-\mathrm{f}_{\text {tap }, \mathrm{n}}\right)}{\mathrm{N}}
$$

With $f_{\text {cue }}$ the predefined cue frequency, $f_{\text {tap }, n}$ the tap frequency per epoch, $n$ the epoch number and $N$ the total number of epochs. A TA of 0 resembles perfect synchronization with the cue frequency.

$$
\mathrm{TV}_{\text {Subject }}=\frac{\sum_{\mathrm{n}=1}^{\mathrm{N}}\left|\left(\mathrm{f}_{\text {mean }}-\mathrm{f}_{\text {tap }, \mathrm{n}}\right)\right|}{\mathrm{N}}
$$

With $f_{\text {mean }}$ the mean tapping frequency during cued and non-cued movement, $f_{\text {tap }, n}$ the tapping frequency in epoch $\mathrm{n}$, and $\mathrm{N}$ the total number of epochs. TV $=0$ indicates a perfectly constant tapping frequency. The variability was calculated in addition to the accuracy to see whether subjects tapped a constant rhythm independent of the predefined cue frequency. TA and TV were also calculated from the EMG data. This was done to determine whether the measurement signals provided complementary information about movement characteristics.

The EMG data was analyzed with respect to the occurrence of kinetic tremor. For this purpose a tremor frequency band was chosen between 5 $14 \mathrm{~Hz}$ [83]. The presence of kinetic tremor was determined quantitatively using a straight forward threshold method and by visual inspection of the PSD of the EMG data of each subject. An epoch was classified as kinetic tremor if the ratio of the average power in the tremor band $(5-13 \mathrm{~Hz})$ and the average power in the movement band $(1-4 \mathrm{~Hz})$ exceeded a threshold level of 0.8 , according to equation 4.3:

$$
\text { Kinetic Tremor: } \frac{\sum_{\mathrm{f}=5}^{\mathrm{f}<14} \operatorname{Pxx}(\mathrm{f}) / \mathrm{N}_{\mathrm{TF}}}{\sum_{\mathrm{f}=1}^{\mathrm{f}<5} \operatorname{Pxx}(\mathrm{f}) / \mathrm{N}_{\mathrm{MF}}} \geq 0.8
$$

With Pxx(f) the power at each frequency f, $N_{T F}$ the number of samples in the tremor frequency band and $N_{M F}$ the number of samples in the movement band. The threshold of 0.8 was chosen based on the data of the $\mathrm{HC}$ assuming that they did not show kinetic tremor. The mean ratio of the power in the tremor band and the movement band was 0.41 in the HC, 0.86 in the ET and 1.01 in the PD group. The threshold was chosen as 
approximately twice the mean ratio of the HC group. Kinetic tremor was only determined using the EMG data, because the occurrence of high-power higher harmonics of the movement in the accelerometer data (see Figure 4.1) made the use of a straight forward threshold condition difficult.

All parameters were calculated for cued and non-cued movement during the 2 and $4 \mathrm{~Hz}$ tapping task and for the left and the right hand.

\subsubsection{Statistical analysis}

To determine differences in accuracy and variability during cued and non-cued movements (movement condition) with the left and right hand (hand) a multiway analysis of variance (ANOVA) is used. A p-value smaller than 0.05 was considered significant. The following intra-group differences were analyzed for the $2 \mathrm{~Hz}$ and the $4 \mathrm{~Hz}$ tapping task:

- Difference in TA and TV between the left hand cued, right hand cued, left hand non-cued and right hand non-cued movement.

- Difference in TA and TV: main factor hand

- Difference in TA and TV: main factor movement condition

The inter-task difference between the $2 \mathrm{~Hz}$ and the $4 \mathrm{~Hz}$ tapping task (left and right hand separately) was determined. In addition, the following inter-group differences were analysed for the $2 \mathrm{~Hz}$ and the $4 \mathrm{~Hz}$ tapping task:

- Difference in TA and TV: main factor group.

- Difference in TA and TV: main factor group and interaction factor movement condition

- Difference in TA and TV: main factor group and interaction factors movement condition and hand.

\subsection{Results}

After visual inspection of the data $2 \mathrm{HC}$ and $1 \mathrm{ET}$ patient were excluded due to technical failure of one or more accelerometers or EMG electrodes. 3 ET patients performed the tapping task by only using their index finger and not their whole hand. These subjects were also excluded from further analysis to prevent errors due to differences in task execution. 3 PD patients (marked in Table 4.1) were not able to perform the $4 \mathrm{~Hz}$ tapping task due to 
fatigue or other reasons. Eventually, $17 \mathrm{HC}, 12 \mathrm{ET}$ subjects, $11 \mathrm{PD}$ subjects ( $2 \mathrm{~Hz}$ tapping task) and $8 \mathrm{PD}$ subjects ( $4 \mathrm{~Hz}$ tapping task) were included in the analysis.

In Figure 4.1, data of a HC (A), and a tremor patient ET (B) is given (Figure 4.1 has been slightly adapted compared to publication). At the top, 10 seconds of the pre-processed EMG data and the corresponding PSD plots are shown. The figure below shows the accelerometer data and corresponding PSD plots for the same time frame of 10 seconds. In the PSD plot (EMG and accelerometer) of the ET and PD patient two main peaks are visible. One is located around the cue frequency of $2 \mathrm{~Hz}$, the tapping frequency, and the other around $6 \mathrm{~Hz}$, the kinetic tremor frequency. In the accelerometer data also a peak at $4 \mathrm{~Hz}$ is visible. This peak is most likely a higher harmonic of the tapping frequency.

\subsubsection{Tapping accuracy}

No significant intra-group differences in TA were found. Therefore, the inter-group analysis was only done for the main factor "group" and interaction factor "movement condition". In Figure 4.2 the results that showed significant inter-group differences are displayed: the results of the accelerometer data for the $2 \mathrm{~Hz}(\mathrm{~A})$ and the results of the EMG data for the $4 \mathrm{~Hz}$ tapping task (B). The bar plots give the absolute value of the deviation from the cue frequency of each group and the error bars indicate the standard deviations of the groups.

Inter-group differences for the $2 \mathrm{~Hz}$ tapping task were found in the accelerometer data. The PD group tapped significantly less accurate than the other two groups (PD: 0.12 and 0.08; ET: 0.02 and 0.08; HC: 0.01 and 0.02 , for the $2 \mathrm{~Hz}$ and $4 \mathrm{~Hz}$ tapping task respectively) (indicated by asterisks). Considering only cued movement, they tapped less accurate than the HC group.

EMG data revealed significant differences between the patient groups and the HC group (indicated by asterisks) during the $4 \mathrm{~Hz}$ tapping task. The HC group tapped with greater accuracy than the two patient groups. Both patient groups tapped slower (mean \pm std: $3.99 \pm 0.19 \mathrm{~Hz}$ and $3.98 \pm 0.16$ $\mathrm{Hz}$ for PD and ET, respectively) than the predefined cue frequency of $4 \mathrm{~Hz}$, whereas the HC group either tapped accurately at the cue frequency or tended to tap faster than that (mean \pm std: $4.02 \pm 0.10 \mathrm{~Hz}$ ). 
A) Time signals and PSD of a healthy control: $2 \mathrm{~Hz}$ Tapping Task

EMG: Time signal
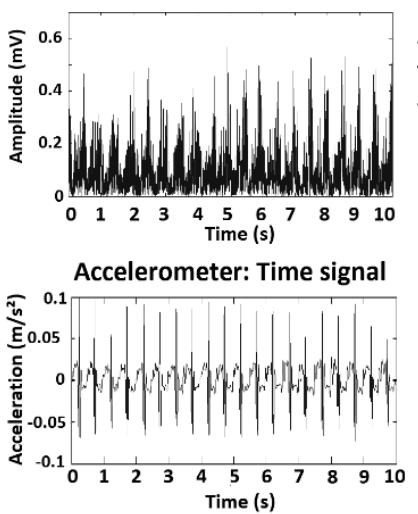

EMG: PSD
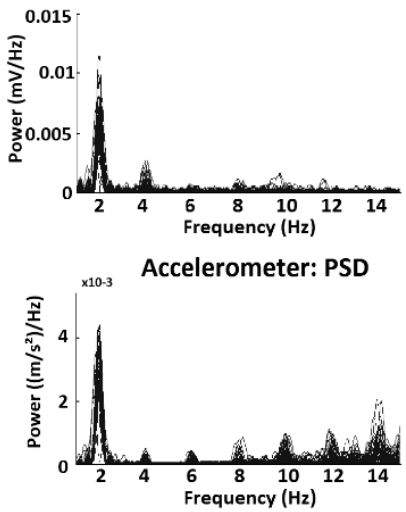

B) Time signals and PSD of an essential tremor patient: $2 \mathrm{~Hz}$ Tapping task
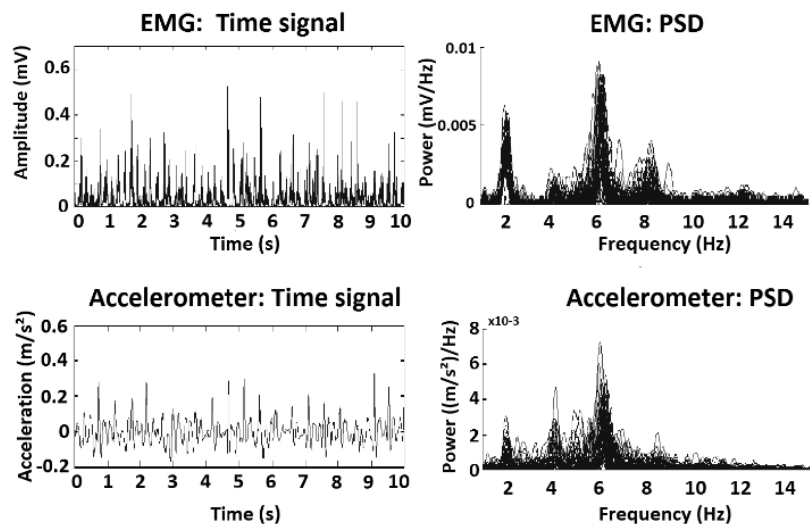

Accelerometer: PSD

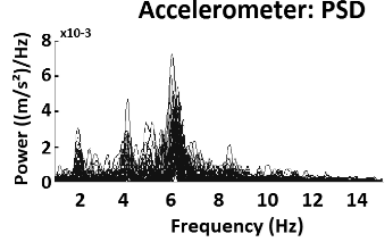

Figure 4.1. Example of the time signal ( 10 seconds) and corresponding power spectral density (PSD) (of all epochs) of the EMG (top) and accelerometer (bottom) data. Time signals are presented in the left figure and the PSD in the right figure. A) Data are of a representative healthy subject. B) Data are of a tremor patient with high power kinetic tremor at $6 \mathrm{~Hz}$.

\subsection{2. $\quad$ Tapping variability}

In Figure 4.3 the significant results concerning the tapping variability are displayed. The only significant intra-group difference found was in the $\mathrm{HC}$ group between the right (dominant) and left hand during the $4 \mathrm{~Hz}$ tapping task in the EMG data (see bottom part of Figure 4.3). Significant differences were only found during the $4 \mathrm{~Hz}$ tapping task. The accelerometer data found significant inter-group (main factor "group") differences during the $4 \mathrm{~Hz}$ task between all three groups. 
PD patients tapped with a significantly higher variability than the other two groups. ET patients tapped with a greater variability than the HC group (indicated by asterisks).

EMG data showed significant differences during the $4 \mathrm{~Hz}$ tapping task as well (Figure 4.2). PD group tapped with greater variability than the other two groups (indicated by asterisks). ET tapped with a greater variability than the HC group.

\subsubsection{Kinetic tremor}

Kinetic tremor was detected electrophysiologically in nine of the thirteen ET patients using our tremor detection method. In three subjects tremor occurred during both tasks, at both hands and during both tapping conditions. In six subjects (46\%) kinetic tremor was detected during the cued movement at $2 \mathrm{~Hz}$. During non-cued movement five ET patients (38\%) showed a kinetic tremor at the right and six at the left hand. During the $4 \mathrm{~Hz}$ tapping task four subjects (31\%) showed tremor at the right hand, during the cued and non-cued movement. Five subjects presented with tremor at their left hand.

In eight of the eleven PD patients tremor was detected electrophysiologically during at least two of the eight hand-condition-task combinations. Three subjects (27\%) presented with a tremor in the right hand during the $2 \mathrm{~Hz}$ tapping task. At the left hand one subject (9\%) showed a tremor during cued movement and three subjects during non-cued movement. During the $4 \mathrm{~Hz}$ tapping task (only eight subjects) three subjects (38\%) experienced tremor during cued movement. Non-cued movement caused a kinetic tremor in one subject (13\%) at the right and in two subjects $(25 \%)$ at the left hand.

In Figure 4.4 it is shown that during the $2 \mathrm{~Hz}$ tapping task (A), the PD subjects experiencing tremor tapped more accurate and with a smaller variability compared to ET subjects with kinetic tremor. During the $4 \mathrm{~Hz}$ tapping task (B) both groups tend to tap with a high variability when tremor occurs. A trend is visible indicating that PD patients tend to tap slower than the predefined frequency during non-cued movement, whereas the presence of tremor does not seem to have an effect on the variability in the ET group. 
A) Accelerometers - Tapping Accuracy: 2 Hz Tapping Task

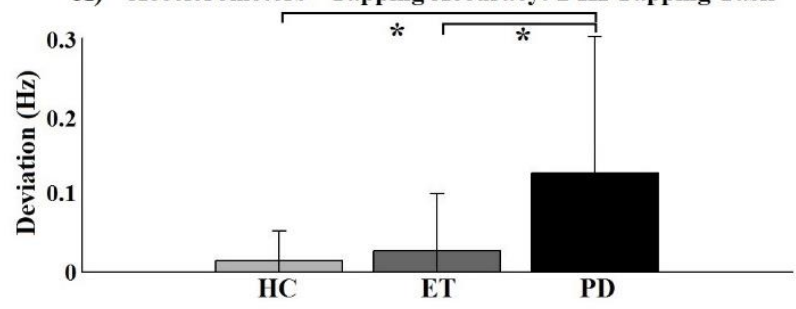

B) EMG - Tapping Accuracy: 4 Hz Tapping Task

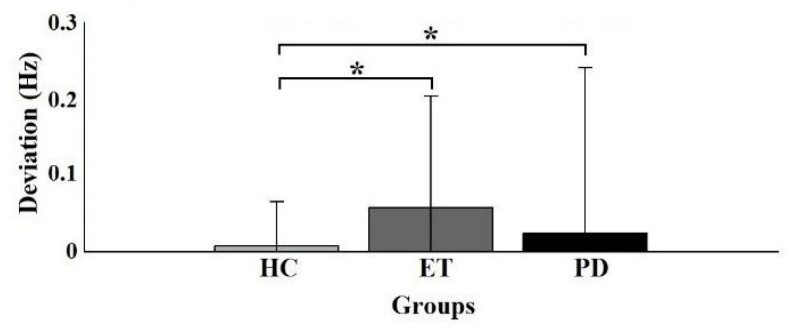

\begin{tabular}{lll}
$\square$ HC & $\square$ ET \\
\hline
\end{tabular}

Figure 4.2. Tapping accuracy determined with the accelerometers for the $2 \mathrm{~Hz}$ (top) and $4 \mathrm{~Hz}$ (bottom) tapping task. Significant differences between individual task/hand combination are indicated by asterisks. HC = Healthy controls; ET = essential tremor; PD = Parkinson's disease.

A) Accelerometers - Tapping Variability: 4 Hz Tapping Task

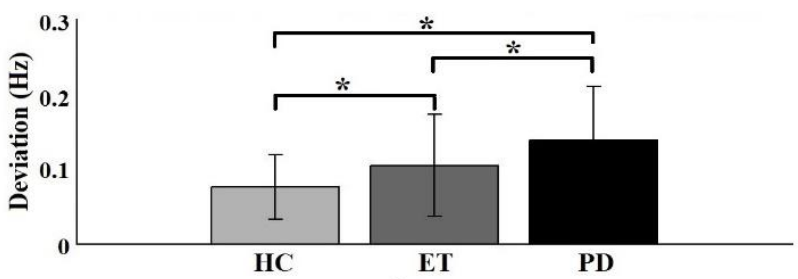

B) EMG - Tapping Variability: 4 Hz Tapping Task

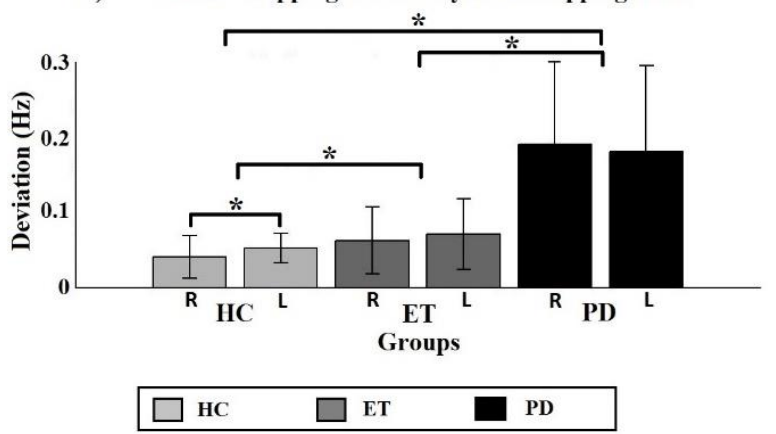

Figure 4.3. Tapping variability determined with the accelerometers for the $4 \mathrm{~Hz}(\mathrm{~A})$ and EMG data of the $4 \mathrm{~Hz}$ (B) tapping task. Inter-group differences between individual task/hand combination are indicated by asterisks. $\mathrm{HC}=$ Healthy controls; ET = essential tremor; $\mathrm{PD}=$ Parkinson's disease; R = Right hand; L = Left hand. 
A) Effect of kinetic tremor on tap frequency: $2 \mathrm{~Hz}$ Tapping Task
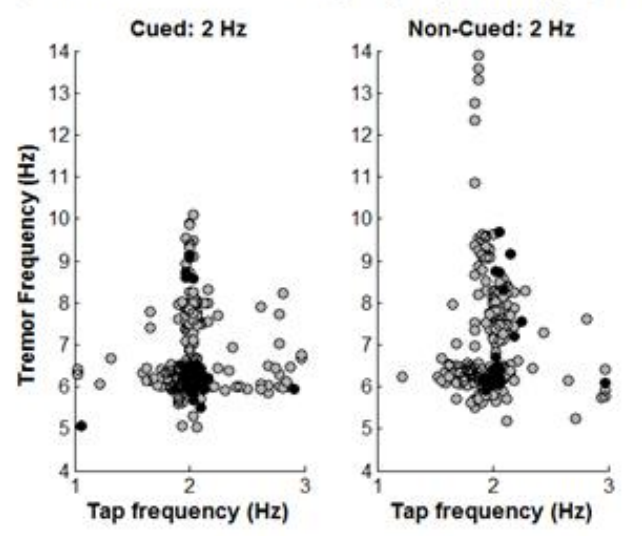

B) Effect of kinetic tremor on tap frequency: $4 \mathrm{~Hz}$ Tapping Task

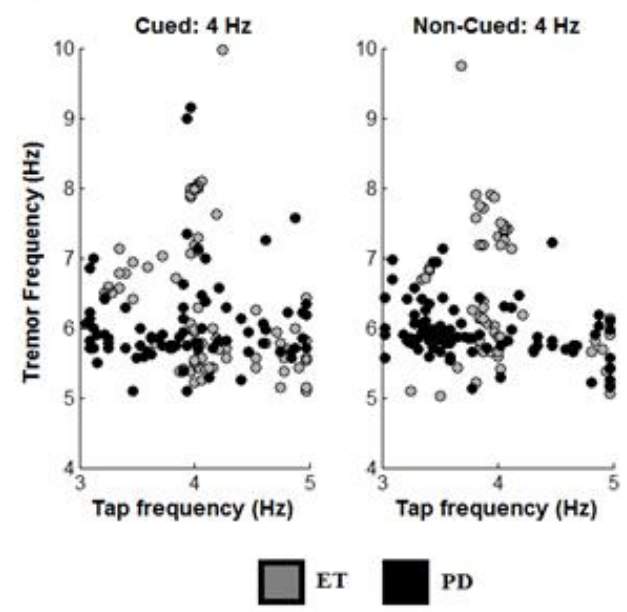

Figure 4.4. Effect of kinetic tremor on the tapping frequency determined from EMG data, during the 2 $\mathrm{Hz}(\mathrm{A})$ and $4 \mathrm{~Hz}$ (B) tapping task. In black the results of the PD group are given and in grey the results of the ET group.

\subsection{Discussion}

We hypothesized that kinetic tremor would occur more frequently in ET patients compared to the other two groups. However, kinetic tremor occurred in both patient groups to the same extent. The second hypothesis that PD patients suffer greater deficits in TA and TV compared to the other two groups is accepted. There are differences between PD and ET patients in performing rhythmic cyclic movements under cued and non-cued conditions. First, the mean tapping frequency during the $4 \mathrm{~Hz}$ tapping task 
is significantly lower in the PD group than in the ET group. Second, acceleration data revealed significantly less accurate tapping in the PD group than in the ET group during the $2 \mathrm{~Hz}$ tapping task. Third, acceleration and EMG data revealed a greater tapping variability in the PD group during the $4 \mathrm{~Hz}$ tapping task compared to the ET group. Fourth, occurrence of kinetic tremor had a different effect on TA and TV in the ET group compared to the PD group.

\subsubsection{Tapping accuracy and variability}

Overall, the PD group tapped less accurate than the other two groups. This was the case for the cued and non-cued movement during the $2 \mathrm{~Hz}$ tapping task and consistent with the findings of Freeman at. al [39]. These findings are consistent with the hypothesis that the basal ganglia play mainly a role in the internal timing of voluntary repetitive movements, and that to a certain extent, this dysfunction can be compensated for by external cues. The PD group tapped at a lower frequency than the cue frequency during the $4 \mathrm{~Hz}$ tapping task. This is in accordance with the findings of Freeman et. al [14] and could be due to bradykinesia affecting these patients.

In general, the ET subjects also tapped slower than the cue frequency of $4 \mathrm{~Hz}$. Therefore, it can be concluded that ET as well as PD patients experience a timing problem during rhythmic, cyclic movements. Other studies have shown that patients with cerebellar dysfunction or lesion show a larger variability in rhythmic movement as was seen in the ET group [84]. The cerebellum is involved in the timing of movement. It acts as an internal timing system and this system is disturbed in ET patients [9]. Furthermore, differences in activity in the cerebellum exist during a finger tapping task in ET compared to healthy controls as has been shown by Buijink et. al [27]. In this study ET patients showed decreased activation in widespread areas of the cerebellar cortical regions compared to healthy controls. On the other hand, altered activity in the cerebellum is thought to be the cause of kinetic tremor. Therefore, these widespread changes might lead to a timing problem in the cerebellum in ET patients, a timing problem between executing voluntary movement (tapping) and causing involuntary movement such as tremor. In PD external cueing is thought to take over the function of the basal ganglia as an internal 
clock by activating the cerebellum as a compensatory pathway. However, the activation of the cerebellum due to the cue also causes an increased kinetic tremor in some patients. Helmich et al [6] introduced the dimmerswitch model for parkinsonian resting tremor in which it is suggested that the basal ganglia activates tremor (switch), and the cerebello-thalamocortical circuit modules tremor amplitude (dimmer). This concept might also be applicable for kinetic tremor in case of cued movement. As a compensatory mechanism the PD group can tap more accurately by bypassing the basal ganglia, while this activation of the cerebellar circuit also affects tremor. In the ET group the tapping frequency seemed unaffected by the occurrence of tremor. This could explain the differences in TA between PD and ET during the $2 \mathrm{~Hz}$ task. Cueing affects the activity in the cerebellum, which in case of ET may have an adverse effect on motor output due to the dysfunction of the cerebellum. In a future study we hope to further explore these theories with the use of imaging data. The differences seen between the $2 \mathrm{~Hz}$ and the $4 \mathrm{~Hz}$ tapping task is most likely simply a consequence of the tempo subjects had to follow. At $2 \mathrm{~Hz}$ subjects are able to react to each single cue as a separate event, whereas at $4 \mathrm{~Hz}$ a pattern generator is most likely activated.

\subsubsection{Kinetic tremor}

Kinetic tremor is commonly found in ET, but also in some PD patients [85] which can cause confusion between the two, especially in early stages of the disease when other symptoms of PD are not as distinctive as in the later stages. Our results support the findings of others that kinetic tremor is also found in PD patients, even though it is less common than in the ET group. However, our findings show that the occurrence of tremor influences the TA and TV of the patient groups differently. Where it did not appear to affect the ET group, it affected the PD group during the $2 \mathrm{~Hz}$ task. This is rather intriguing because the group analysis shows that overall the PD group taps less accurate than the ET group, even though, Figure 4.4 indicates that PD subjects with kinetic tremor tap more accurate than subjects with ET showing tremor. To our knowledge these finding have not been reported in other studies and suggests that different tremor mechanisms exist in these two disorders.

Four ET patients did not suffer from kinetic tremor during the 
repetitive movements. Louis et al. [61] showed that the occurrence of resting tremor in ET depends on the study setting. Our results suggest that the same could be true for kinetic tremor in ET. Furthermore, the ET and PD patients presenting with tremor during the tapping task had asymmetric and symmetric tremor presentation (Table 4.2). This indicates that tremor symmetry is not a good indicator for differentiation between PD and ET.

\subsubsection{Study limitations}

Due to malfunctioning of the basal ganglia in PD patients the external cue is thought to replace the missing internal cue [29]. However, no differences were found between the two tapping conditions, neither at $2 \mathrm{~Hz}$ nor at 4 $\mathrm{Hz}$. It could be that the paradigm used in this study was not suitable to detect such differences. Thirty seconds of cued movement were immediately followed by thirty seconds of non-cued movement. It is possible that cueing has a wash-out effect which has a positive influence on the TA during the non-cued movement task.

Another study [38] concerning the effect of cueing during physiotherapy has found indications for such an effect. Therefore, it is suggested to slightly adapt the paradigm of this study to yield a larger intra-group effect by including a resting period between cued and noncued movement. This might also result in a larger inter-group difference as not only the continuation of cyclic movement would be included in the analysis but also the effect of initiating a cyclic movement without an external cue. To determine differences between the dominant and nondominant hand in subjects, tapping with the left and right hand should be separated into two different tasks. Furthermore, the current setup and choice of sensors is based on a clinical setup in which the way of executing the movement is known. Induced kinetic tremor was expected in the extensor muscles and could therefore be measured by choosing these muscles to record from. This allowed us to measure kinetic tremor from the EMG data.

Movement was recorded using accelerometers placed on both hands and EMG recordings from the $\mathrm{m}$. extensor carpi radialis of the left and right forearm. Accelerometers record the start of movement of an extremity whereas EMG records the activation of a muscle that could result in movement but not necessarily has to. Results were in no case 
contradicting each other. Differences could be caused by the activation of additional or other muscles, not measured here with surface EMG, influencing the net movement of the hand. Therefore, in addition to the extensor muscle the flexor muscle might also be of interest. It could show if the flexion movement of the hand, necessary for tapping, is caused by activation of the flexor muscle or rather by the relaxation of the extensor muscle. The results of this study show that the measurement techniques can provide supplementary information as also shown in other disciplines, such as prosthetics [86]. Especially in case of kinetic tremor, EMG might be able to detect it earlier and locate its origin more accurate than accelerometers. In some cases kinetic tremor was only visible in the EMG data and not in the accelerometer data. This indicates that the occurrence of a tremor in a muscle does not always have to cause visible tremor in an extremity. It might be though that this tremor in the muscle leads to fatigue of the muscle due to this overactivity [87] and therefore to less or no movement. Another possibility is that the occurrence of tremor inhibits the movement by inhibiting movement selection whenever the power in the tremor frequency band is larger than in the movement band [88].

The results suggest that this method might be useful in a classifier model for movement disorders. In this model step one would be to separate patients from healthy controls. And the second step would be to separate patient groups from one another using the mean tapping frequency during a $4 \mathrm{~Hz}$ tapping task and the effect of kinetic tremor on TA and TV during a 2 Hz tapping task.

\subsection{Conclusion}

This study showed that with a straightforward experimental setup consisting of two accelerometers and two surface EMG electrodes, differences between PD and ET patients can be revealed during a bimanual tapping task. Furthermore, differences between both patient groups and HC were found. Especially the finding that the occurrence of kinetic tremor did not affect tapping accuracy of PD patients while it decreased tapping accuracy in ET could be used in a classifier model to support clinical decision making during the diagnostic process of PD and ET. 


\section{Cortical activity patterns during cued and non- cued movements ${ }^{4}$}

\section{ABSTRACT}

Parkinson's disease and essential tremor are neurodegenerative diseases characterized by movement deficits. Especially in PD, maintaining cyclic movement can be significantly disturbed due to pathological changes in the basal ganglia and the cerebellum. Providing external cues improves timing of these movements in PD and also affects ET. The aim of this study is to determine differences in cortical activation patterns in PD and ET patients during externally and internally cued movements.

Eleven PD patients, twelve ET patients, OFF tremor suppressing medication, and nineteen age-matched healthy controls (HC) were included and asked to perform a bimanual tapping task at two predefined cue frequencies. The auditory cue, a metronome sound presented at 2 or $4 \mathrm{~Hz}$, was alternately switched on and off every 30 seconds. Tapping at two different frequencies was used, since it is expected that different brain networks are involved at different frequencies as has been shown in previous studies. Cortical activity was recorded using a 64-channel EEG cap. To establish the cortical activation pattern in each group, the task related power (TRP) was calculated for each subject. For inter-group analysis, EEG electrodes were divided into 5 different areas.

Inter-group analysis revealed significant differences in areas responsible for motor planning, organization and regulation and involved in initiation, maintenance, coordination and planning of complex sequences of movements. Within the area of the primary motor cortex the ET group showed a significantly lower TRP than the HC group. In the area responsible for combining somatosensory, auditory and visual information both patient groups had a higher TRP than the HC group.

\footnotetext{
${ }^{4}$ Published as:

Luft, F., Sharifi, S., Mugge, W., Schouten, A. C., van Rootselaar, A. F., Veltink, P. H., Heida, T. “Distinct cortical activity patterns in Parkinson's disease and Essential tremor during a bimanual tapping", Journal of NeuroEngineering and Rehabilitation
} 
Different neurological networks are involved during cued and non-cued movements in ET, PD and HC. Distinct cortical activation patterns were revealed using task related power calculations. Different activation patterns were revealed during the 2 and $4 \mathrm{~Hz}$ tapping task indicating different strategies to execute movements at these rates. The results suggest that including a cued/non-cued tapping task during clinical decision making could be a valuable tool in an objective diagnostic protocol. 


\subsection{Introduction}

The basal ganglia and the cerebellum are brain structures involved in the preparation, timing and execution of timed movements. In movement disorders, such as Parkinson's disease (PD) and essential tremor (ET), these structures can be affected. PD is considered a disease of the basal ganglia, and ET a disorder related to changes in the cerebellum [12]. Despite their pathological differences, PD and ET can be difficult to distinguish from each other, due to overlapping symptoms. Common diagnostic tools, such as polymyography, movement disorder rating scales or SPECT scans are either invasive (SPECT), time consuming, subjective (rating scales), expensive and/or not widely available.

Several studies have investigated movement parameters and cortical and subcortical changes in patients and healthy controls during hand and finger movements. In a previous study [89] we showed that PD patients tap significantly less accurately during a $2 \mathrm{~Hz}$ tapping task and with a greater variability during a $4 \mathrm{~Hz}$ tapping task than ET patients and healthy controls (HC). Furthermore, ET patients tapped less accurately and with a greater variability than $\mathrm{HC}$ during a $4 \mathrm{~Hz}$ tapping task. Findings were similar for cued and non-cued conditions. Most interestingly, the occurrence of kinetic tremor during a tapping task did not seem to affect or even improve the performance of PD patients, but seemed to decrease performance in ET. Gerloff et. al [90] showed that different cortical activation patterns can be recorded in healthy subjects during internally and externally cued finger movements using task-related power calculations of two frequency bands: part of the alpha $(9-11 \mathrm{~Hz})$ and part of the beta band $(20-22 \mathrm{~Hz})$. These bands have previously been shown to be sensitive to movement-related changes in cortical activity [90]. Changes in activation pattern were found in the supplementary motor areas, primary sensory motor area and lateral premotor cortex during internally timed and externally cued movements. The mesial frontocentral cortex and the ipsilateral sensorimotor cortex were primarily activated during internally cued movements. Another frequency that is altered in PD is the gamma band [91]. Activity in the gamma band is known to represent engaged networks and facilitate movement [91].

Samuel et al. [44] found evidence that in PD patients the parietal-lateral premotor circuits are activated instead of the striato-mesial frontal circuits 
to facilitate complex finger movements. A functional MRI study [43] showed that PD patients exhibited an increased activation in the cerebellum and the frontostriatal circuit during externally cued movements and a greater involvement of the cerebello-thalamic circuit compared to $\mathrm{HC}$ during internally timed movements.

In ET patients, a study has shown impairment of rhythm generation and increased variability of rhythmic hand movements during cued movements [45]. Furthermore, Avanzino et. al [46] found that $1 \mathrm{~Hz}-\mathrm{rTMS}$ over the ipsilateral cerebellum affected the performance during a finger movement task in patients with ET, by reducing touch duration values and normalizing the inter touch interval values.

However, comparing the cortical activation patterns of PD and ET patients during cueing has not yet been done, let alone used for clinical decision making. Therefore, the aim of this study is to determine if there are differences in cortical activation patterns in PD and ET patients and HC during cued and non-cued movements. For this purpose, all participating subjects performed a bimanual tapping task at two frequencies, i.e. they tapped with both hands simultaneously and in synchrony with the cue frequency. The subjects were asked to continue movement at approximately the same pace after the cue was turned off. It is hypothesized that PD patients show increased activation of the lateral cortical areas instead of the striato-mesial frontal area during non-cued, internally timed movements due to increased activity in the parietal-lateral premotor circuits as a compensatory strategy using the cerebello-thalamic circuit [44]. In ET patients, reduced activation of the motor cortex is expected during cued movements as hyperactivity of the cerebellum increases the inhibitory output of the thalamus to the motor cortex.

\subsection{Methods}

\subsubsection{Participants}

11 PD patients (3 Female (F); Age: $66 \pm 11$ (mean \pm std (years)), 12 ET patients (4 F; Age: $58 \pm 20$ ) and 19 age-matched HC (9 F; Age: 59 \pm 15 ) were included in the study. Gender was not considered to be of influence on the results. Therefore, due to a higher incidence rate in men than in women in both patient groups [92-94], more males were included than females, but 
the HC group was not gender matched. See Table 5.1 for an overview of patient details. Tremor rating scores and tremor severity are not included in this table as both, occurrence and severity, can be very task dependent. Instead the tremor presence per task will be calculated. All subjects were right-handed according to the Edinburgh Handedness Inventory [56] and patients were willing to stop medication according to a personalized scheme, established by an experienced neurologist, prior to the experiment. Additionally, PD patients were diagnosed with Parkinson's disease according to the UK Brain Bank criteria for Parkinson's disease [57] and showed neither major fluctuations in symptoms due to medication nor suffered from severe dyskinesia. ET patients had essential tremor according to the criteria defined by the Tremor Investigation Group [58], expressed moderate to severe tremor (Tremor Rating Scale Part A2 UE > 2) and had a positive family history of ET. Healthy subjects had no record of a neurological or other disorder. All subjects gave written informed consent prior to participation and the study was approved by the Medical Ethical Committee of the Academic Medical Center, Amsterdam, The Netherlands.

\subsubsection{Experimental setup}

Subjects were seated on a bed, with head and back supported for a sitting posture. Prior to the tapping task resting state EEG was recorded for 3 minutes. Afterwards, subjects performed a bimanual wrist flexion tapping task at two cue frequencies, 2 and $4 \mathrm{~Hz}$ (equivalent to an inter-tap interval of $500 \mathrm{~ms}$ and $250 \mathrm{~ms}$, respectively). The cue was a metronome sound set to the predefined cue frequencies. The forearm and proximal part of the wrist joint were supported against gravity by the bed. At each frequency, subjects had to tap the bed next to their legs continuously and in-phase with the cue with both hands for three minutes. The three minutes were split into blocks of thirty seconds, with the auditory cueing switched on and off alternately. Instructions were given verbally prior to the experiment and all subjects were able to perform the task without practice. During cued movements, subjects were able to hear a metronome beat through computer speakers. Prior to the experiment, subjects were asked whether they were able to hear the sound clearly. The three-minutes tapping task was first performed at $2 \mathrm{~Hz}$ and then at $4 \mathrm{~Hz}$, with several minutes rest in between. A schematic overview of the task is given in Figure 5.1. In addition to the tapping task, subjects performed a three-minutes resting task with hands resting comfortably in their lap, palms up. 
Hand movement was recorded with 3D accelerometers (TMSi, Oldenzaal, The Netherlands - see Introduction for specifications). Muscle activity was recorded from the $\mathrm{m}$. extensor carpi ulnaris of both arms using surface electromyography (EMG) electrodes. EEG was recorded with a 72channel Refa-system and a 64-channel low-noise shielded EEG head cap (TMSi, Oldenzaal, The Netherlands) (resistance $<30 \mathrm{kOhm}$ ). Data acquisition was done using a customized program written in LabVIEW (National Instruments, Austin, Texas, United States) with a sampling frequency of $2048 \mathrm{~Hz}$.

\subsubsection{Data pre-processing}

To minimize transition effects (from cued to non-cued movement and vice versa), the first and last 5 seconds of each block were excluded from analysis (see Figure 5.1). Voluntary movement was analysed using the norm of the accelerometer vectors, giving one acceleration signal for each hand. The acceleration signal for each hand was filtered off-line (non-causal, zerophase, $0.25-20 \mathrm{~Hz}$ bandpass, $4^{\text {th }}$ order Butterworth). EMG data was filtered off-line (non-causal, zero-phase, $20-400 \mathrm{~Hz}$, $4^{\text {th }}$ order Butterworth). Then the absolute value of the Hilbert transform was used as the envelope of the EMG signal for further analysis.

The second minute of the resting state EEG data, recorded prior to the tapping tasks, was used for further analysis and analyzed using the same pre-processing steps as described below for the tapping task. The EEG data recorded during the tapping tasks was split into cued and non-cued movement segments. To minimize transition effects (from cued to non-cued movement and vice versa), the first and last 5 seconds of each block were excluded from analysis (see Figure 5.1). Each segment of the tapping task and the resting state was filtered digitally off-line with a band-pass filter (non-causal, zero-phase, 1-45 Hz; $4^{\text {th }}$ order Butterworth). Eye movement artefacts were removed prior to further analysis using independent component analysis. To minimize reference and volume conduction effects at distances of approximately the inter-electrode spacing [59], a local average reference was used after artefact removal. The montage is described by equation 5.1.

$$
V_{r e f, i}=V_{i}-\frac{1}{N} \sum_{j=1}^{N} V_{i j}
$$


with $V_{i}$ is the potential at electrode i, $V_{i j}$ are the potentials of the neighbouring electrodes and $\mathrm{N}(\mathrm{N}=8)$ the number of neighbouring electrodes for non-border electrodes. Border electrodes were excluded from analysis as they often contain EMG artefacts and have fewer neighbouring electrodes to calculate the local average, leaving 42 electrodes for analysis (see Figure 5.2). Furthermore, the mean and the standard deviation of the power of the entire time signal (time signal squared $=$ P) was calculated. Afterward the data was divided into $500 \mathrm{~ms}$ epochs with $50 \%$ overlap. Only epochs with a mean power, $P_{\text {epoch }}$, according to equation 5.2 were included:

$$
\operatorname{mean}\left(P_{\text {epoch }}\right)<\operatorname{mean}(P)+3 * \operatorname{std}(P)
$$

\subsubsection{Data analysis}

The presence of kinetic tremor during each task was calculated using the EMG data and equation 5.3 [89].

$$
\text { Kinetic Tremor: } \frac{\sum_{\mathrm{f}=5}^{\mathrm{f}<14} \operatorname{Pxx}(\mathrm{f}) / \mathrm{N}_{\mathrm{TF}}}{\sum_{\mathrm{f}=1}^{\mathrm{f}<5} \operatorname{Pxx}(\mathrm{f}) / \mathrm{N}_{\mathrm{MF}}} \geq 0.8
$$

After preprocessing, the mean power at each electrode in the frequency domain was calculated for frequencies, up to $45 \mathrm{~Hz}$, using the power spectral density (PSD). The PSD of all epochs was averaged per subject and per task

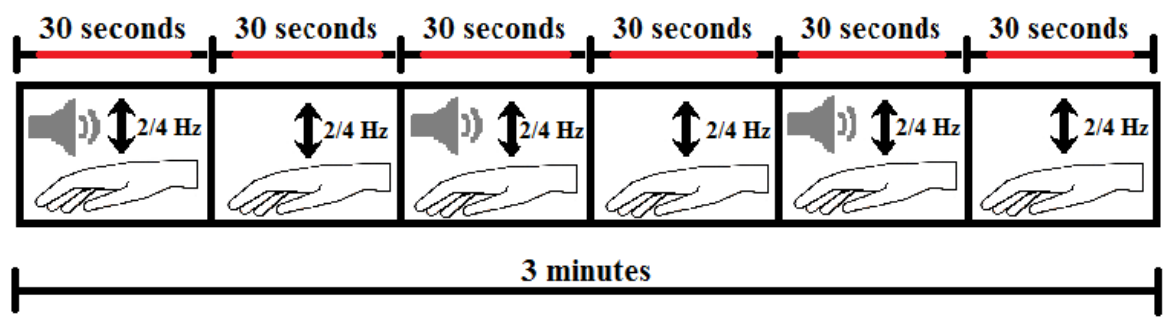

Figure 5.1. Schematic presentation of the bimanual tapping task. 30 seconds of cued movements were followed by 30 seconds of non-cued movements. This was repeated 3 times in total and at two and four $\mathrm{Hz}$ as cueing frequencies. The red line indicates the data segment used for analysis. 
Table 5.1. Overview of patient details

\begin{tabular}{|c|c|c|c|c|}
\hline Subject & Sex & Age & Duration (years) & Medication \\
\hline ET & $\mathrm{M}$ & 50 & Since birth & - \\
\hline ET & $\mathrm{F}$ & 81 & 21 & - \\
\hline ET & M & 85 & Unknown & Propranolol \\
\hline ET & $\mathrm{F}$ & 51 & Childhood & - \\
\hline ET & $\mathrm{F}$ & 23 & Childhood & - \\
\hline ET & M & 49 & 9 & Propranolol \\
\hline ET & M & 54 & 38 & - \\
\hline ET & M & 70 & Unknown & \\
\hline ET & M & 64 & Unknown & \\
\hline ET & M & 55 & Childhood & - \\
\hline ET & M & 27 & Birth & - \\
\hline ET & $\mathrm{F}$ & 81 & 61 & - \\
\hline PD & $\mathrm{M}$ & 69 & 5 & $\begin{array}{l}\text { Monoamino-oxidase-B inhibitor, } \\
\text { propranolol }\end{array}$ \\
\hline PD & M & 67 & 4 & Trihexyfenidyl \\
\hline PD & $\mathrm{F}$ & 81 & 5 & Levodopa, carbidopa, metoprolol \\
\hline PD & $\mathrm{F}$ & 62 & 2 & Levodopa \\
\hline PD & M & 71 & 2 & - \\
\hline PD & $\mathrm{F}$ & 43 & 3 & Ropinirol \\
\hline PD & M & 68 & 14 & Levodopa, carbidopa \\
\hline PD & M & 64 & 10 & Levodopa, carbidopa, benserazide \\
\hline PD & M & 67 & 8 & $\begin{array}{c}\text { Levodopa, carbidopa, amantadine, } \\
\text { entacapon, levothyroxine }\end{array}$ \\
\hline PD & $\mathrm{F}$ & 56 & 5 & levodopa, ropinirol \\
\hline PD & M & 64 & 7 & Levodopa, benserazide \\
\hline
\end{tabular}

$\mathrm{PD}=$ Parkinson's disease; ET = essential tremor; $\mathrm{M}=$ male; $\mathrm{F}$ = female 


\subsubsection{Outcome parameters}

The percentage of tremor presence during each task was calculated for each subject. From the accelerometer data the tapping accuracy [89] was calculated for each task and tapping condition according to (5.4).

$$
\mathrm{TA}_{\text {Subject }}=\frac{\sum_{\mathrm{n}=1}^{\mathrm{N}}\left(\mathrm{f}_{\mathrm{cue}}-\mathrm{f}_{\text {tap }, \mathrm{n}}\right)}{\mathrm{N}}
$$

The task related power (TRP) was calculated according to equation 5.5 for cued and non-cued movement.

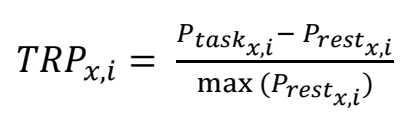

For each of the following bands, $\mathrm{x}$, the TRP was calculated for each electrode, i, 9-11 Hz, 20-22 $\mathrm{Hz}$ and 30-45 Hz. TRP $<0$ indicates a desynchronization, a decrease in activity, during movement compared to rest and TRP $>0$ indicates synchronization, an increase in activity, compared to rest.

\subsubsection{Statistical analysis}

Statistical analysis was performed to determine differences between groups. Differences in tapping accuracy were determined using multivariate ANOVA analysis. To determine differences in cortical activity EEG electrodes were grouped into 5 groups (see Figure 5.2): frontal, left central, central, right central and posterior. TRP in these areas was compared between groups (inter-group analysis) and within groups (intragroup analysis) using the non-parametric Kruskal-Wallis test due to varying standard deviation and post-hoc analysis using Bonferroni correction for multiple comparison. A p-value smaller than 0.05 was considered significant. 


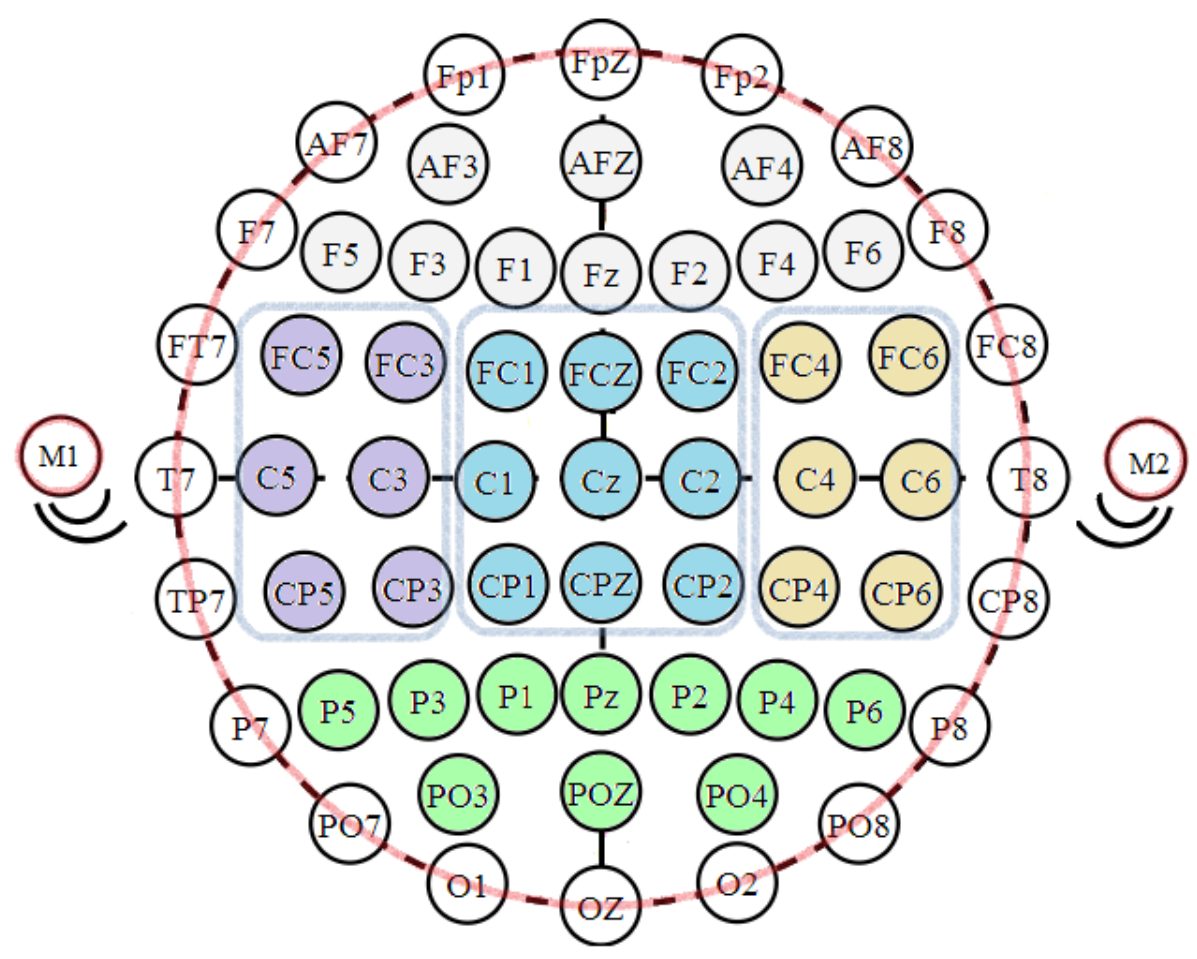

Figure 5.2. Overview of the EEG electrodes. Red regions indicate the border electrodes which were excluded during analysis. Blue and non-circled regions indicate the 5 defined areas for statistical analysis. Grey = frontal area; purple = central left area; beige = central right area; blue = central area and green $=$ posterior area .

\subsection{Results}

The percentage of tremor windows per task and subject are given in Table 5.2.

In Figure 5.3 the results of the tapping accuracy are given. Significant differences were only found during the non-cued $2 \mathrm{~Hz}$ tapping task (NC2), indicated by the asterisk. PD patients tapped significantly less accurate than the other two groups. 
Table 5.2. Tremor presence during tasks

\begin{tabular}{ccccc}
\hline Subject & C2 (\%) & NC2 (\%) & C4 (\%) & NC4 (\%) \\
\hline ET & 1 & 0 & 0 & 0 \\
ET & 5 & 82 & 6 & 21 \\
ET & 0 & 0 & 0 & 0 \\
ET & 27 & 52 & 7 & 12 \\
ET & 31 & 0 & 3 & 0 \\
ET & 0 & 0 & 0 & 17 \\
ET & 99 & 90 & 19 & 12 \\
ET & 0 & 1 & 0 & 0 \\
ET & 0 & 18 & 0 & 0 \\
ET & 37 & 78 & 17 & 13 \\
ET & 8 & 0 & 12 & 0 \\
ET & 21 & 37 & 0 & 0 \\
\hline PD & 2 & 86 & 20 & 91 \\
PD & 0 & 0 & 46 & 0 \\
PD & 2 & 0 & 10 & 0 \\
PD & 0 & 0 & 0 & 0 \\
PD & 6 & 15 & 0 & 0 \\
PD & 0 & 0 & 0 & 0 \\
PD & 0 & 2 & 0 & 6 \\
PD & 0 & 0 & 0 & 0 \\
PD & 3 & 0 & 0 & 0 \\
PD & 2 & 7 & 0 & 0 \\
PD & 0 & 0 & 0 & 0 \\
\hline PD Par & 0 & & & 0 \\
\hline
\end{tabular}

$\mathrm{PD}=$ Parkinson's disease; ET = essential tremor; $\mathrm{C} 2$ = cued tapping task at $2 \mathrm{~Hz}$; NC2 = non-cued tapping task at $2 \mathrm{~Hz}$; $\mathrm{C} 4=$ cued tapping task at $4 \mathrm{~Hz}$; NC4 = non-cued tapping task at $4 \mathrm{~Hz}$. 


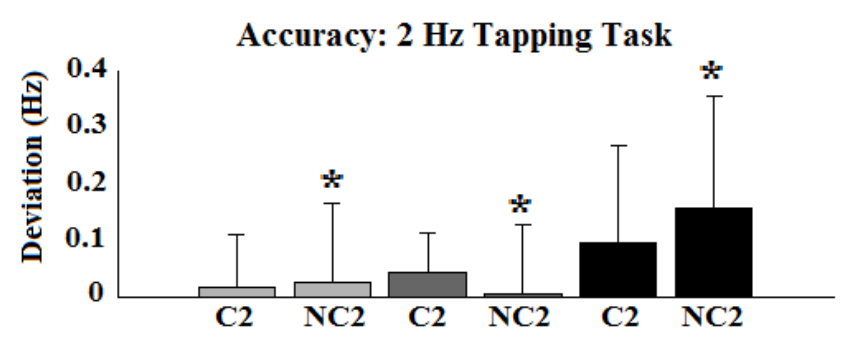

Accuracy: $4 \mathrm{~Hz}$ Tapping Task

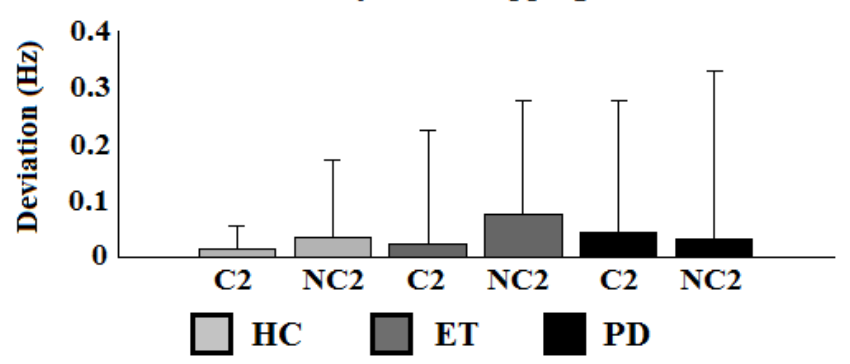

Figure 5.3. Group results of the tapping accuracy during the 2 and $4 \mathrm{~Hz}$ tapping task with and without cue. Statistical differences are marked by an asterisk. HC = Healthy controls; ET = essential tremor; PD = Parkinson's disease; $\mathrm{C} 2$ = cued tapping task at $2 \mathrm{~Hz}$; NC2 = non-cued tapping task at $2 \mathrm{~Hz} ; \mathrm{C} 4=$ cued tapping task at $4 \mathrm{~Hz}$; NC4 = non-cued tapping task at $4 \mathrm{~Hz}$.

In Figure 5.4 the results of the TRP per task and frequency band are given in topoplots for the HC (A), ET (B) and PD (C) group, respectively. Results represent the mean group result.

In the HC group (Figure 5.4 A), during the $2 \mathrm{~Hz}$ cued (C2), the alpha and beta band show a slightly positive TRP in the dorsolateral prefrontal, intermediate frontal, middle frontal cortex and the pars opercularis. In the gamma band a positive TRP is found around the pars opercularis, premotor and posterior transverse temporal cortex. The $2 \mathrm{~Hz}$ non-cued task (NC2) activity patterns were similar with a slightly more positive TRP seen in the gamma band at the pars opercularis. During the $4 \mathrm{~Hz}$ tapping task with cue (C4) an increase in TRP is again seen in the posterior transverse temporal cortex in all frequency bands. In the beta and, even more so, gamma band, additional activity is found around the pars opercularis. Cortical activity recorded during the non-cued $4 \mathrm{~Hz}$ tapping task (NC4) shows a similar pattern compared to the $\mathrm{C} 4$ task, but with a higher TRP, especially around the anterior transverse temporal cortex in the beta and gamma band. No significant intra-group differences were found. 
In the ET group (Figure $5.4 \mathrm{~B}$ ), a positive TRP was found in all three frequency bands during both tapping tasks. During the $\mathrm{C} 2$ and NC2 task, the frontal areas around dorsolateral prefrontal, intermediate frontal and the premotor cortex are activated in the beta and gamma band. In the alpha band additional activation of the primary auditory cortex was found in the ET group during the $\mathrm{C} 2$ task. The $\mathrm{C} 4$ task results in a positive TRP around the primary somatosensory cortex, angular gyrus and somatosensory association cortex in the alpha and beta band. In the gamma band activation of the supramarginal gyrus is seen. During the NC4 task, activation of the somatosensory association cortex is also found in all three frequency band. Additional activation in all three bands is found around the primary somatosensory and anterior transverse temporal cortex. Furthermore, activation of the dorsolateral prefrontal, intermediate frontal and the premotor cortex is found in the beta and gamma band, but to a lesser extend compared to the $\mathrm{C} 2$ and $\mathrm{NC} 2$ task. Intra-group differences were only found between the $\mathrm{C} 2$ and NC2 task in the alpha band in the frontal area, and in the gamma band in the posterior area, with a higher TRP during the $\mathrm{C} 2$ task.

In the PD group (Figure $5.4 \mathrm{C}$ ) activity patterns in the $\mathrm{C} 2$ and $\mathrm{NC} 2$ are almost the same. The alpha band shows slight activation of the dorsolateral prefrontal cortex. In the beta and gamma band activation of the dorsolateral prefrontal cortex increases compared to the alpha band contralateral to the dominant hand. Additional activation of the premotor cortex is found in both frequency bands. During the C4 task, activation of the dorsolateral prefrontal cortex is also found. Furthermore, activation of the primary auditory cortex is found in the beta and gamma band. During the NC4 task similar activation of the dorsolateral prefrontal cortex is seen. Additionally, activation of the angular gyrus is found, highest in the beta band. The only significant intra-groups difference was found in the posterior area between C4 and NC4 in the alpha band, with a higher TRP during the NC4 task.

The results of the inter-group analysis are displayed in Table 5.3. Significant differences were most frequently found in the frontal (F), central (C) and posterior (P) areas. Furthermore, the NC4 task resulted in the largest differences between the two patient groups and the HC group. However, significantly different results were not found between the two patient groups. 

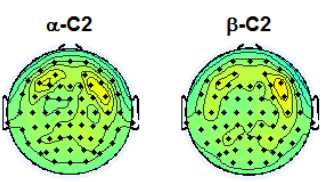

\section{A) Healthy controls}
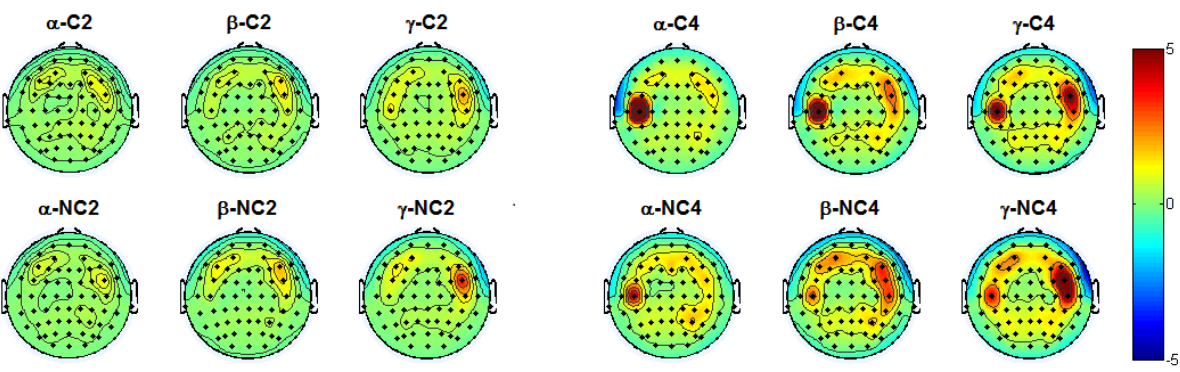

\section{B) Essential Tremor}
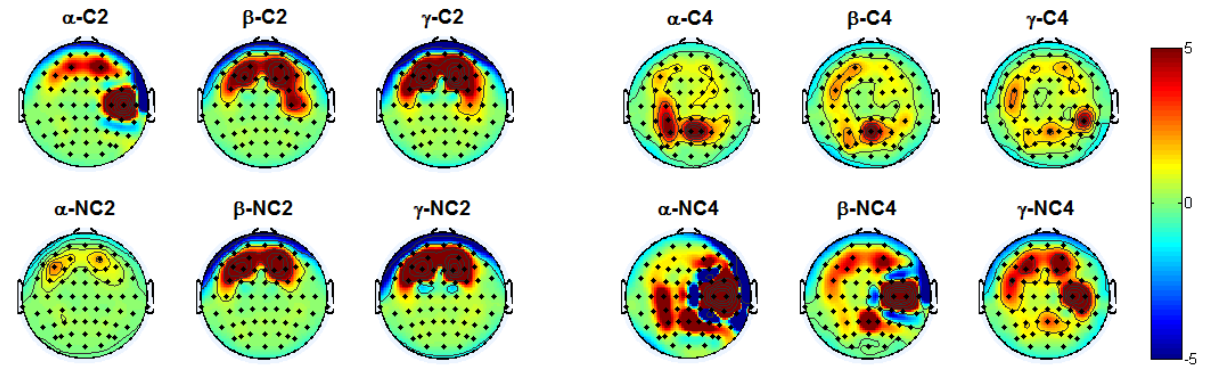

\section{C) Parkinson's Disease}
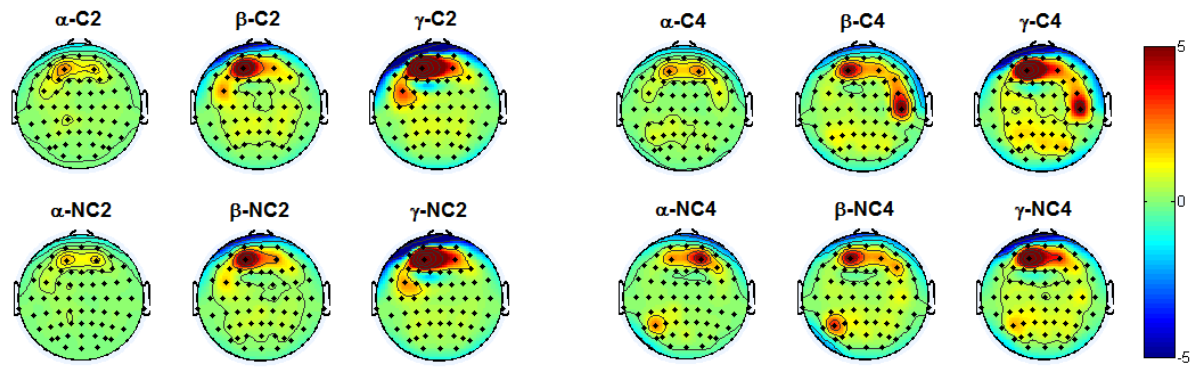

Figure 5.4. Mean group results of the HC (A), ET (B) and PD (C) group. TRP in the narrow alpha, narrow beta and gamma band during the two tapping tasks with both tapping conditions. Green areas indicate areas with no changes in power between the task and rest; yellow and red indicate an increase in power during the tapping task and blue indicates a decrease in power during the tapping task compared to rest. $\mathrm{C} 2$ = cued tapping task at $2 \mathrm{~Hz} ; \mathrm{NC} 2=$ non-cued tapping task at $2 \mathrm{~Hz} ; \mathrm{C} 4=$ cued tapping task at $4 \mathrm{~Hz}$; NC4 $=$ non-cued tapping task at $4 \mathrm{~Hz}$. 
Table 5.3. Inter-group differences

\begin{tabular}{|c|c|c|c|c|}
\hline & & \multicolumn{3}{|c|}{ Frequency band } \\
\hline Task & Area & alpha & beta & gamma \\
\hline \multirow{5}{*}{$\mathrm{C} 2$} & $\mathrm{~F}$ & - & - & - \\
\hline & $\mathrm{CL}$ & - & $0.004^{2}$ & - \\
\hline & $\mathrm{C}$ & - & $0.019^{2}$ & - \\
\hline & CR & - & - & - \\
\hline & $\mathrm{P}$ & $<0.001^{1}$ & $0.015^{2}$ & $<0.001^{3}$ \\
\hline \multirow{5}{*}{ NC2 } & $\mathrm{F}$ & - & - & - \\
\hline & $\mathrm{CL}$ & - & $0.039^{2}$ & - \\
\hline & $\mathrm{C}$ & $0.013^{4}$ & - & - \\
\hline & CR & - & - & - \\
\hline & $P$ & $<0.001^{1}$ & - & - \\
\hline \multirow{5}{*}{$\mathrm{C} 4$} & $\mathrm{~F}$ & $<0.001^{1}$ & $<0.001^{1}$ & $<0.001^{1}$ \\
\hline & CL & - & - & - \\
\hline & $\mathrm{C}$ & $0.012^{4}$ & - & - \\
\hline & CR & - & - & - \\
\hline & $P$ & $<0.001^{1}$ & $0.003^{2}$ & $<0.001^{3}$ \\
\hline \multirow{5}{*}{ NC4 } & F & $<0.001^{1}$ & $<0.001^{1}$ & $<0.001^{1}$ \\
\hline & CL & - & - & - \\
\hline & $\mathrm{C}$ & $0.017^{4}$ & - & - \\
\hline & CR & - & - & - \\
\hline & $\mathrm{P}$ & $<0.001^{4}$ & $0.003^{2}$ & $<0.001^{3}$ \\
\hline
\end{tabular}

Superscripts indicate which groups show significant differences. ${ }^{1} \mathrm{HC}$ higher TRP than ET and PD; ${ }^{2}$ ET higher TRP than HC; ${ }^{3} \mathrm{PD}$ and ET higher TRP than HC; ${ }^{4} \mathrm{HC}$ higher TRP than ET; $\mathrm{C} 2$ = cued tapping task at $2 \mathrm{~Hz}$; NC2 = non-cued tapping task at $2 \mathrm{~Hz}$; $\mathrm{C} 4=$ cued tapping task at $4 \mathrm{~Hz}$; NC4 = non-cued tapping task at $4 \mathrm{~Hz}$. F = frontal, $\mathrm{CL}=$ central left, $\mathrm{C}=$ central, $\mathrm{CR}=$ central right $\mathrm{P}=$ posterior.

\subsection{Discussion}

PD and ET are degenerative neurological disorders involving different parts of the brain. The overlapping symptom, tremor, and identifying differences in tremor characteristics have been the focus of many studies $[27,28,95,96]$. The overall goal of this study was to determine different cortical activation patterns during a bimanual tapping task at 2 and $4 \mathrm{~Hz}$, performed with and without an auditory cue. Significantly different activation patterns were found between the HC group compared to both patient groups and between the HC group and the ET group. Even though, 
no statistically significant differences were found between the two patient groups, the results suggest that different activity patterns are involved during cued and non-cued movements in ET and PD and HC.

\subsubsection{Tapping accuracy and kinetic tremor}

The tapping accuracy was calculated to determine the ability of the subjects to perform the task correctly. The only significant difference between the groups was found during the NC2 task indicating that under all other conditions all subjects were able to perform the task in a comparable manner. It also shows that PD patients benefit from an auditory cue, as to being able to perform the task more accurately with cue than without an external cue.

Kinetic tremor was detected in both groups. The duration of the tremor during a task varied per subject and task. Overall, kinetic tremor was recorded more often and for a longer period of time in the ET group compared to the PD group. This was to be expected as ET is characterized by a postural and/or kinetic tremor. However, we also see a clear task dependency of tremor occurrence in both groups.

\subsubsection{Task related power}

Significant differences in activation patterns were found mainly in the frontal, central and posterior area.

\section{Healthy controls}

The frontal area is mainly responsible for motor planning, organization and regulation and is involved in initiation, maintenance, coordination and planning of complex sequences of movements. In most cases the HC group had a significantly higher TRP in this region indicating that these areas are important for a high tapping accuracy and low variability in movement [89]. The primary motor cortex, areas responsible for selective attention to rhythm and the somatosensory association cortex lay within the central region. This area showed a significantly lower TRP in the ET group than in the HC group in the alpha band during the NC2, C4 and NC4 task. This is in accordance with our hypothesis that the hyperactivity of the cerebellum results in less activation of the motor cortex. In the posterior area, areas responsible for combining somatosensory, auditory and visual information 
and also areas that are involved in motor learning and bimanual manipulation are located. In the gamma band both patient groups had a higher TRP than the HC group. This might indicate that both PD and ET patients have to make use of more than one peripheral feedback mechanism to initiate and maintain a sequential movement. In the HC group a positive TRP was found in the area of motor planning, organization and regulation during the $\mathrm{C} 2$ and NC2 task in the alpha and beta band. Furthermore, areas involved in initiation, continuation and coordination of movements were active. In the gamma band areas responsible for selective attention to rhythm and processing auditory stimuli were active. Additional activations were found in the areas of motor response inhibition and bilateral object manipulation during the $\mathrm{C} 4$ and NC4 task. Contralateral to the dominant hand, activation of areas responsible for movement organization was found. A study by Walsh et. al [97] suggests that the dominant hemisphere initiates the activity responsible for bimanual movement. Likewise, we only found an increase of the primary motor cortex on the contralateral side of the dominant hand during the $4 \mathrm{~Hz}$ tapping task.

Other areas were found in the patient groups indicating pathological or compensatory activation of cortical areas in order to perform the desired task.

\section{Essential tremor}

In the ET group, an increased TRP was found in areas involved in motor planning, movement initiation, maintenance, coordination and planning of complex sequences during the $\mathrm{C} 2$ and $\mathrm{NC} 2$ task. These findings suggest that, in contrast to $\mathrm{HC}$, patients with ET need to plan and monitor simple bilateral hand movements more closely than $\mathrm{HC}$ to be able to execute them correctly. Furthermore, in the C4 task, areas responsible for combining somatosensory, auditory and visual information were activated, indicating that ET subjects need more feedback from the periphery to maintain rhythmic movements. That visual information is important in cerebellar disorders has been shown in other studies as well [98]. In the NC4 task, additional activation of areas involved in movement organization, learning motor sequences and the control of rhythmic motor tasks was found, which is in contrast to our hypothesis. ET patients may need more control over rhythmic motor tasks than HC. As we only record cortical activity we are not 
able to determine which underlying activity causes the increased primary motor cortex activity we recorded. This will be investigated in a future study.

\section{Parkinson's disease}

In the beta and gamma bands a positive TRP was found in the PD group in areas responsible for motor planning, organization and regulation, contralateral to the dominant hand during the $\mathrm{C} 2$ and NC2 task. Activation of the frontal areas might indicate a compensatory mechanism of PD to perform a movement task by relying more on motor planning compared to HC. During the C4 task, a positive TRP is seen in areas responsible for motor response inhibition, auditory priming and basic processing of auditory stimuli. As in the ET group, the area involved in combining somatosensory, visual and auditory information was activated in the NC4 task indicating that PD patients need more peripheral feedback to perform the task than HC.

There could be several reasons why there was no difference in TRP between the groups. First of all the group size was rather small. Furthermore, tremor occurred in several subjects in both patient groups (Table 5.2). Kinetic tremor in ET and in PD may have at least some common pathways resulting in similar cortical activity during these tremor episodes. In addition to this, freezing or hastening could have occurred in some subjects adding to the heterogeneity within the groups.

\subsubsection{Used methodology}

In this study, the TRP was calculated using the difference in cortical activity of each subject with respect to his or her own resting activity. Other studies showed that differences in resting activity between HC and PD [99] and HC and ET [100] exist. These differences in activity during rest could also be part of the findings we showed in this study. From literature it is known that PD and ET subjects show pathological changes in cortical resting activity [100-102] compared to HC. This could also have led to the lack in activation of the lateral motor areas in PD with our method as these might already have been pathologically activated during rest. However, the increase in TRP found in this study was related to movement, auditory or sensory processing which is to be expected when executing a movement 
task under different auditory conditions. Therefore, we conclude that the determined changes are task related and not based on differences in underlying resting activity.

Another limitation is the use of frequencies equal or larger than $2 \mathrm{~Hz}$. Stegemöller et al [103] showed that the tapping ability in PD patients was not significantly different from $\mathrm{HC}$ below $2 \mathrm{~Hz}$. The idea behind this phenomenon is that below $2 \mathrm{~Hz}$ the cerebellum is mainly involved in movement control and above $2 \mathrm{~Hz}$ the basal ganglia. Therefore, using frequencies below $2 \mathrm{~Hz}$ could result in even greater differences between PD and ET and it is suggested to use frequencies below and above $2 \mathrm{~Hz}$ in future studies. Furthermore, this could also explain why we did not find increased lateral activation in the PD group and why we did not find significant differences between patient groups.

\subsection{Conclusion}

The results of this study show significant differences in activation patterns during a bimanual tapping task in patients with PD and ET compared to a group of HC. Using TRP did not reveal the exact pathological networks involved in movement generation in ET and PD, but revealed distinct activation patterns during a bimanual tapping task. In contrast to our hypothesis, primarily the frontal regions were activated during the tapping task in PD. Therefore, we reject our hypothesis concerning PD. Furthermore, reduced activation of the motor cortex was found in the ET group compared to the HC group. Therefore, the hypothesis concerning reduced activation of the motor cortex due to hyperactivity of the cerebellum is confirmed. Even though no significant differences were found between the two groups, the results suggest that including a simple tapping task during clinical decision making could be a valuable tool. The beta band during the $\mathrm{C} 2$ task and the alpha band in the NC4 task showed significant differences between ET and HC but not HC and PD. Therefore, an activation pattern similar to the HC group during clinical decision making is a more likely indicator for PD than ET. Therefore, including a cued/non-cued tapping task seems to provide a promising tool to an objective diagnostic protocol. 


\section{Networks during cueing5}

\section{ABSTRACT}

Patients with either essential tremor and Parkinson's disease have deficits in movement accuracy and continuation and tremor. Determining objective parameters to support clinical decision making has been the aim of many studies. Analysis of cortical activity using EEG showed that providing external cues during voluntary movement results in distinct differences in activation patterns between PD and ET patients. The aim of this study is to determine differences in activation patterns in deeper lying brain structures.

Scans, obtained using functional magnetic imaging, of 11 ET, 14 PD and 17 healthy controls were included in this study. A Philips 3T Magnetic Resonance scanner (Philips, Eindhoven, The Netherlands) with a standard head receive coil was used and hand movement was recorded using 3Daccelerometer binders. Subjects had to perform a bimanual tapping task, consisting of 6 blocks. Each block started with one minute of rest followed by a minute of tapping at $2 \mathrm{~Hz}$. A visual cue, a blinking dot, was presented for half a minute each time (rest and tapping) and subjects were asked to synchronize their movement with the cue during the tapping phase.

The results of this study showed large differences in activity patterns between patients with PD and ET and between the patient groups and HC. The contrast between cued movement and non-cued movement revealed the most notable differences between the groups. In ET, cueing seemed to have almost no effect on activation, whereas in the PD group crossmodelling between different areas seemed to occur. Furthermore, reduced activation of the motor cortex was found in the ET group compared to the HC group.

The results suggest that a bimanual tapping task with and without a cue could be useful during clinical decision making and might be a valuable tool in an objective diagnostic protocol.

\footnotetext{
${ }^{5}$ To be submitted as:

Luft, F., Sharifi, S., Mugge, W., Schouten, A. C., van Rootselaar, A. F., Veltink, P. H., Heida, T. "Mapping brain activation in movement disorders and healthy controls during a bimanual tapping task"
} 


\subsection{Introduction}

The cerebellum and the basal ganglia are commonly affected in movement disorders and are involved in two important circuits, the basal ganglia-thalamo-cortical circuit (BGTC) and the cerebellar-thalamo-cortical circuit (CTC). These circuits play a crucial role in movement initiation, accuracy, timing, continuation and automaticity of movement. Essential tremor involves hyperactivity in the cerebellum [12] and Parkinson's disease is known to be caused by pathological changes in the BGTC. Additionally, pathological activity within the CTC is thought to be involved in tremor generation in PD [6]. It is probably these overlaps in pathological networks that cause similar symptoms, such as difficulties in movement accuracy and continuation and tremor, leading to misdiagnoses of $10 \%$ and higher $[104,105]$.

Previous studies showed that cueing, an external temporal or spatial stimulus [106], results in distinct differences in PD and ET [89] (Chapter 5). Luft et al [89] showed that PD and ET patients tapped significantly less accurately and more variably than healthy controls (HC). Most interestingly, the tapping accuracy improved in PD patients when kinetic tremor was recorded with EMG during the task, but not in ET [89]. Additionally, differences in cortical activity were found during tapping (Chapter 5). ET patients showed a significantly lower task related power (TRP) in the primary motor cortex than HC. In the area responsible for combining somatosensory, auditory and visual information, both patient groups had a higher TRP than the HC group (Chapter 5). Other studies showed that when providing PD patients with an external cue or sufficient training, task performance is similar to healthy subjects [106, 107]. Wu et al. [107] showed that hand movements can be performed automatically by healthy subjects resulting in overall reduced brain activation after initial training without cue. In PD patients, increased activity was recorded in the cerebellum, premotor area, parietal cortex, precuneus and prefrontal cortex compared to healthy subjects while performing the same task. The underlying theory is that these external cues allow movement to be mediated less by automatic processes and more by attentional motor control processes [107]. Another theory is that cueing activates the lateral system (including premotor and parietal cortex as well 
as, the cerebellum) to bypass the medial system, including the basal ganglia [106]. In ET, reduced activation of the cerebellum, parietal and frontal cortex, inferior olive nuclei and the left dentate nucleus was found during a cued tapping task [108].

Studies have been done comparing both patient groups with HC. However, comparing the patient groups with each other while performing the same task might provide insight into the involved networks and, even more important, provide differences in activity in these networks. The aim of this study is to determine the effect of cues on brain activation in ET and PD. We hypothesis that PD patients will have increased activity in the lateral system during cued movement compared to non-cued movement. In the ET group we expect to find reduced activation of the motor cortex (Chapter 5) and fewer differences between cued and non-cued movement compared to the PD group.

\subsection{Methods}

\subsubsection{Subjects}

Scans of 14 ET ( $62 \pm 17$ years) (mean \pm std), 13 PD ( $65 \pm 11$ years) and 15 HC ( $56 \pm 13$ years) were included in this study. Table 6.1 shows an overview of the patient details. Subjects were right-handed according to the Edinburgh Handedness Inventory [56] and patients temporarily interrupted tremor suppressing medication according to individualized schemes prior to the experiment. PD patients were diagnosed according to the UK Brain Bank criteria for PD [57] and showed neither major fluctuations in symptoms due to medication nor suffered from severe dyskinesia. ET patients fulfilled the criteria defined by the Tremor Investigation Group and the recently revised Consensus criteria for classifying tremor disorder $[58,75]$, were propranolol-sensitive and had a positive family history of ET. Healthy subjects had no record of a neurological, psychiatric or other disorder/disease affecting the motor system. Exclusion criteria were pregnancy, age younger than 18 years, neurological or psychiatric co-morbidities and other contra indications for MRI research [109]. The study was conducted in accordance to the 1964 Declaration of Helsinki. 
All subjects signed written informed consent prior to the experiment and the study was approved by the local medical ethics committee in Amsterdam, The Netherlands.

Table 6.1. Overview patient details

\begin{tabular}{|c|c|c|c|c|}
\hline Group & Gender & Age [years] & Duration [years] & Medication \\
\hline ET & M & 50 & Birth & - \\
\hline ET & $\mathrm{F}$ & 81 & 21 & - \\
\hline ET & M & 85 & Unknown & Propranolol \\
\hline ET & M & 66 & 46 & - \\
\hline ET & M & 49 & 9 & Propranolol \\
\hline ET & M & 54 & 38 & - \\
\hline ET & M & 70 & Unknown & - \\
\hline ET & M & 64 & Unknown & - \\
\hline ET & M & 55 & Childhood & - \\
\hline ET & M & 27 & Birth & - \\
\hline ET & $\mathrm{F}$ & 81 & 61 & - \\
\hline PD & M & 58 & 8 & Levodopa, Trihexyphenidyl \\
\hline PD & M & 72 & 15 & - \\
\hline PD & M & 67 & 4 & Trihexyphenidyl \\
\hline PD & $\mathrm{F}$ & 81 & 5 & Levodopa, carbidopa, metoprolol \\
\hline PD & $\mathrm{F}$ & 62 & 2 & Levodopa \\
\hline PD & M & 49 & 2 & Levodopa, carbidopa, ropinirole \\
\hline PD & M & 71 & 2 & - \\
\hline PD & $\mathrm{F}$ & 43 & 3 & Ropinirol \\
\hline PD & M & 68 & 14 & - \\
\hline PD & M & 73 & 3 & - \\
\hline PD & M & 78 & 2 & $\begin{array}{c}\text { Levodopa, carbidopa, rasagiline, } \\
\text { perindopril }\end{array}$ \\
\hline PD & $\mathrm{F}$ & 73 & Unknown & - \\
\hline PD & $\mathrm{F}$ & 56 & 5 & Levodopa, ropinirole \\
\hline PD & M & 64 & 7 & - \\
\hline
\end{tabular}

$\mathrm{PD}=$ Parkinson's disease, $\mathrm{ET}=$ essential tremor; $\mathrm{M}=$ Male; $\mathrm{F}=$ Female 


\subsubsection{Materials and experimental setup}

A Philips 3T Magnetic Resonance scanner (Philips, Eindhoven, The Netherlands) with a standard head receive coil was used. Prior to the bimanual tapping task, a structural T1 contrast scan was obtained with a repetition time (TR) of $9 \mathrm{~ms}$, an echo time (TE) of $3.53 \mathrm{~ms}$ and a voxel size (VS) of $1 \mathrm{~mm}^{3}$. The total acquisition time of the $\mathrm{T} 1$ contrast scan was 4 minutes. The experimental protocol is described in detail below. Blood oxygenation level-dependent (BOLD) function images were obtained using a gradient echoplanar T2*-weighted imaging (EPI) sequence (TR: $30 \mathrm{~ms}$; TE: 2000ms; VS: $3.5 \mathrm{~mm}^{3}$ ). Thirty-nine axial slices for a total of 180 volumes were obtained to cover the whole brain and the cerebellum. Head movement was minimized using foam padding inside the head coil.

Hand movement was recorded using 3D-accelerometer binders (TMSi, Oldenzaal, The Netherlands) attached with adhesive tape to the back of each hand, approximately in the middle of the third metacarpal bone. Accelerometers were connected to a Porti 32-channel system (TMSi, Oldenzaal, The Netherlands), which was placed in a custom-made cage of Faraday to minimize scanner artefacts. The Porti was connected to a computer outside the scanner via an optical cable and data was synchronized with the EPIs using an trigger signal. Data acquisition was done using a custom-written program written in LabVIEW (National Instruments, Austin, Texas, USA) with a sampling frequency of 2,048 Hz. Figure 6.1 shows the experimental setup.

\subsubsection{Experimental protocol}

Subjects had to perform a bimanual tapping task, consisting of 6 blocks. Instructions were visible on a screen placed behind the scanner via a mirror mounted on the head coil (see Figure 6.1). Each block started with one minute of rest. This minute was split into two 30-second epochs with two visual conditions. During the first 30 seconds subjects only saw a white screen with the instruction to rest. In the following 30 seconds, subjects were presented with a visual cue, a blue dot blinking at a rate of $2 \mathrm{~Hz}$. The minute of rest was followed by one minute of tapping with both hands simultaneously. This was also done under two visual conditions. During the first 30 seconds the visual cue, already presented during rest, was presented and subjects were asked to synchronize their hand movements 
with the $2 \mathrm{~Hz}$ tempo of the cue (cued movement). Subsequently the cue was withdrawn (non-cued movement) and subjects were asked to continue the tapping at $2 \mathrm{~Hz}$ for 30 seconds as accurately as possible (see Figure 6.2 for a schematic overview of the blocks). Correct task performance was assessed by inspection of the accelerometer signals and visual monitoring during the task. The order of the tasks was not randomized.
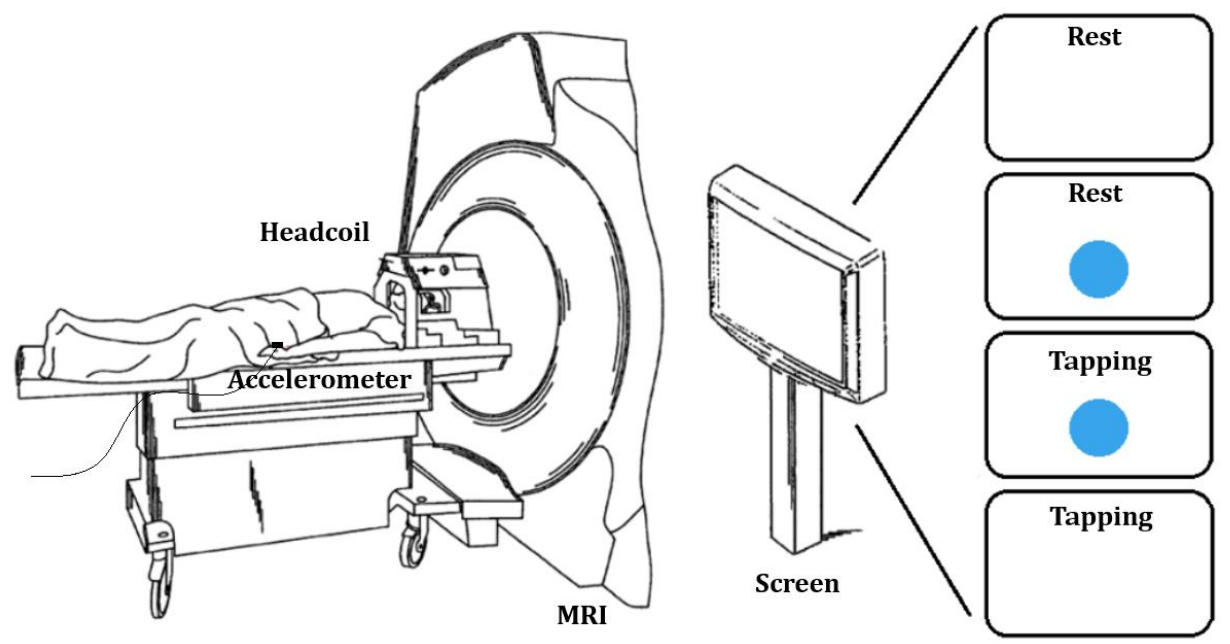

Figure 6.1. Schematic representation of the experimental setup. The screen shots show the screen as presented to the subjects during the task. At the top of the screen the task was given in writing and below the written instruction the cue was either shown (blinking rate $2 \mathrm{~Hz}$ ) or not, for 30 seconds.

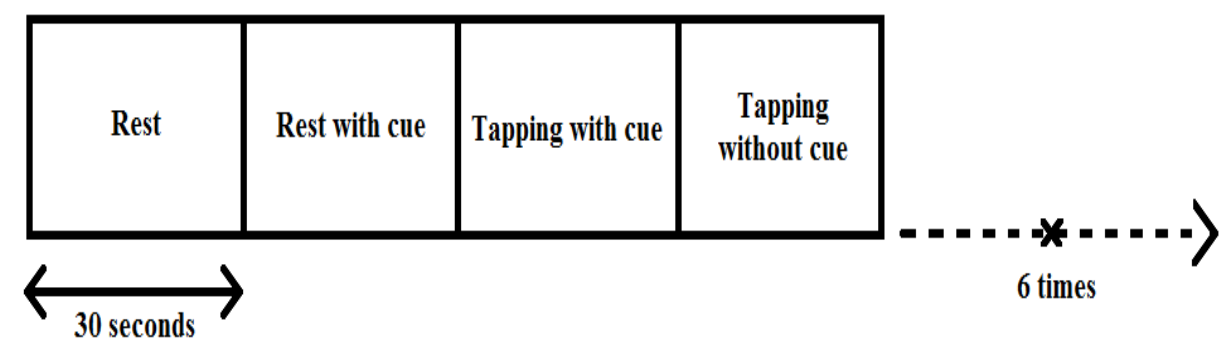

Figure 6.2. Schematic representation of one block. The block was repeated 6 times. Total duration of the task was 12 minutes. 


\subsubsection{Data pre-processing and analysis}

The norm of the accelerometer vectors was calculated, giving one acceleration signal for each hand. The acceleration signal for each hand was filtered off-line (non-causal, zero-phase, $0.25-15 \mathrm{~Hz}$ bandpass, $4^{\text {th }}$ order Butterworth filter).

Pre-processing and analysis of the data was done using SPM8 (Wellcome Trust Centre of Neuroimaging, UCL, London, United Kingdom) implemented in MATLAB R2013a (Mathworks, Natick, Massachusetts, USA). Pre-processing included first level single subject analysis, EPI image realignment to the first image, applying motion correction, and coregistration to the T1-weighted anatomical image.

\subsubsection{Data analysis}

Second-level intra-group analysis was performed. The following contrasts were calculated:

1) Cued movement versus rest with cue

2) Non-cued movement versus rest without cue

3) Cued movement versus non-cued movement

To determine statistically significant activity in the contrasts the tstatistic maps were used. For the intra-group analysis a familywise error (FWE) rate of $p<0.001$, a voxel threshold of 10 voxels and no mask were used.

\subsection{Results}

$3 \mathrm{HC}$ and $1 \mathrm{ET}$ subject were excluded due to technical failure, $1 \mathrm{HC}$ and 1 PD subject were excluded due to low image quality, leaving $13 \mathrm{HC}, 12 \mathrm{PD}$ and 10 ET subjects for analysis.

Figure 6.3 shows the intra-group results and contrasts. Areas of t-values $(p<0.001)$ calculated per 10 voxels are displayed. In each group, several significant areas were found. Therefore, we focus on the regions with the highest t-value in each group.

In the HC group (Figure 6.3 A), the primary somatosensory cortex bilaterally, primary motor cortex bilaterally and temporal lobe showed an increased BOLD response during the cued movement task compared to the resting task with cue. During the non-cued movement task, an increased 
BOLD response was found in the primary somatosensory and motor cortex and the supplementary motor area. An increase in BOLD was seen during cued movement compared to non-cued movement in the visual cortex, primary motor cortex, the middle frontal and supramarginal gyrus.

In the ET group (Figure $6.3 \mathrm{~B}$ ), the primary somatosensory and primary motor cortex, and the pars opercularis showed an increased BOLD response during the cued movement task compared to the resting task with cue. The non-cued movement task activated the primary motor and visual cortex and the cuneus. Only few differences were found between cued and non-cued movement. An increased BOLD response was seen in the middle occipital gyrus and the superior frontal gyrus.

In the PD group (Figure $6.3 \mathrm{C}$ ), the primary auditory, motor and somatosensory cortex and the angular gyrus showed an increased BOLD response during the cued movement task compared to the resting task with cue. During the non-cued movement task, an increased BOLD response was found in the primary auditory, middle occipital gyrus, cingulate gyrus. An increase in BOLD response was seen during cued compared to non-cued movement in the pars orbitalis, primary auditory cortex, olfactory cortex and the primary somatosensory cortex. 


\section{A) Healthy controls}

Tap with cue - Rest with cue
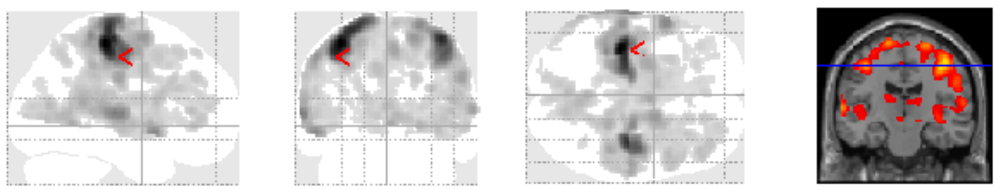

Tap without cue - Rest without cue
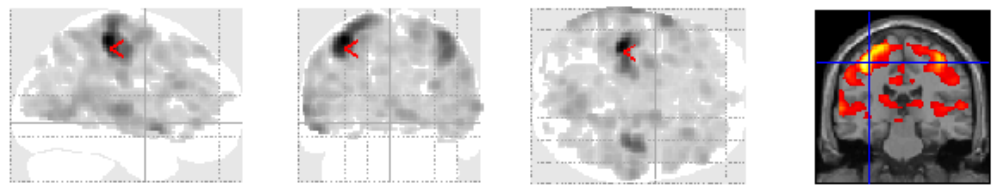

Tap with cue - Tap without cue
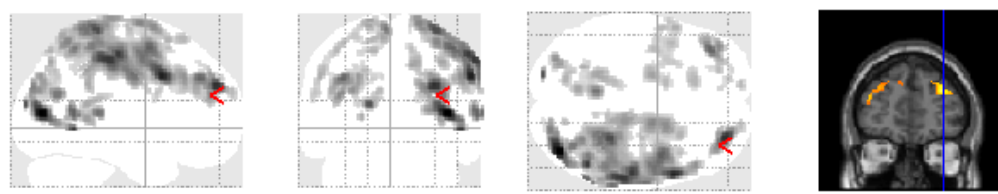

\section{B) Essential tremor}

Tap with cue - Rest with cue
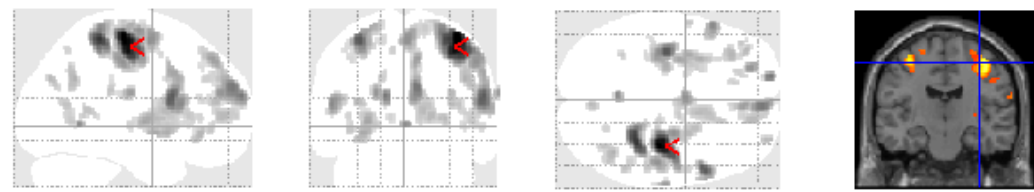

Tap without cue - Rest without cue
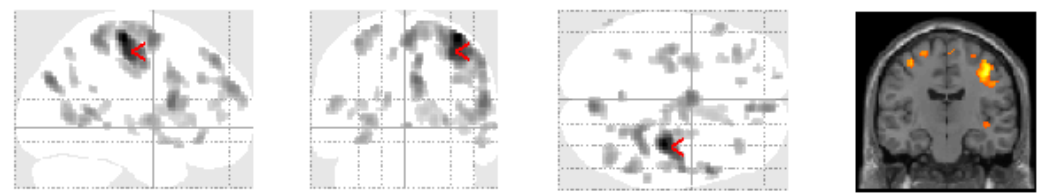

Tap with cue - Tap without cue
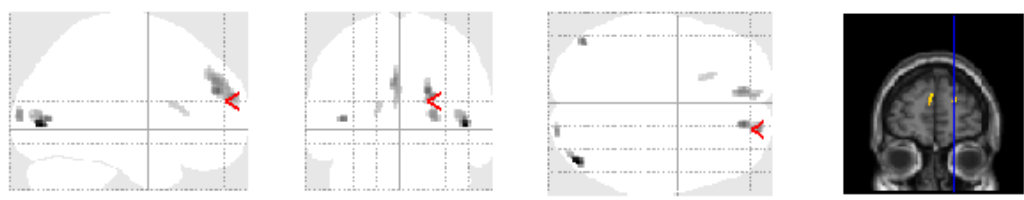

(Continued on the following page) 


\section{C) Parkinson's Disease}

Tap with cue - rest with cue
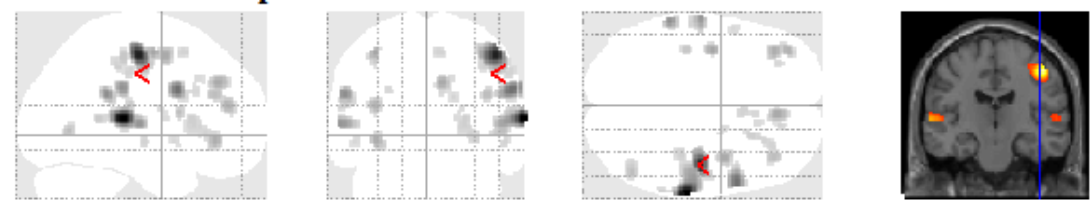

Tap without cue - rest without cue
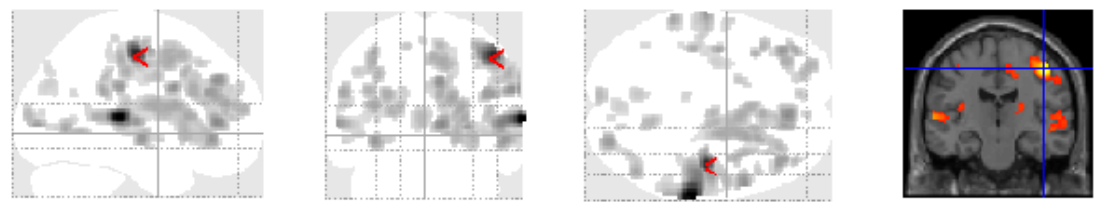

Tap with cue - Tap without cue
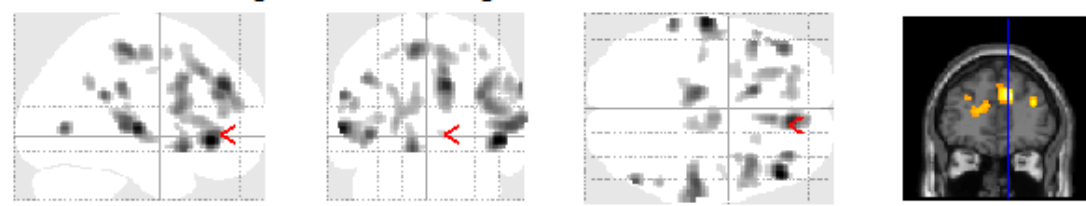

Figure 6.3. Intra-group results. The first three images in each row display the significant areas within the glass brain and the fourth image the results in the coronal plane through the point indicated by the red arrow in the glass brains. A) Results of the healthy control group; B) Results of the essential tremor group. C) Results of the Parkinson's disease group.

\subsection{Discussion}

In the HC group (almost) symmetric activation of the somatosensory and motor cortex was found during the cued movement task as would be expected during a bimanual tapping task. The BOLD response during the cued movement task was larger compared to the non-cued movement task. This could be a result of movement automation during non-cued movement resulting in decreased activity of the motor cortex [110]. The middle frontal gyrus which is responsible for motor planning, organization and regulation showed a higher BOLD response in cued compared to non-cued movement. This may be due to a more automatic performance of the task during noncued movement. Differences in the visual cortex are due to the absence of the visual cue during non-cued movement. The same is true for the differences found in the supramarginal gyrus, which is responsible for controlling movements guided by visuospatial information. 
In the ET group, activation of the motor cortex is primarily ipsilateral to the dominant hand and differences between cued and non-cued movement are minimal. Furthermore, the area involved is smaller compared to the HC group. This is in accordance with the findings of Chapter 5 that the motor cortex is significantly less active during a bimanual tapping task compared to HC subjects. Differences between cued and non-cued movement in the middle occipital gyrus, which is responsible for visual processing, is the result of the removal of the visual stimulus during non-cued movement.

The most interesting findings were detected in the PD group. Activation of the primary auditory cortex cannot be explained by the presence of the MRI scanner noise, as this is also present during the resting task. Studies in healthy subjects $[111,112]$ have shown that visual stimuli also activate the auditory cortex during lip-reading and visual language processing. It is known that cues can improve gait and rhythmic cyclic movements in patients with PD, but the exact underlying mechanism remains unclear $[113,114]$. The findings in this study suggest that PD patients make a broader use of external cues by activating more areas involved in processing external signals. This is also supported by the activation of the olfactory cortex. Wesson and Wilson [115] suggested a cross-modelling between the olfactory and auditory cortex. Additionally, the activated angular gyrus during cued movement, which is involved in combining somatosensory, auditory and visual information, is an indication for a broader use of external input compared to the other two groups. Activation of the pars orbitalis during cued movement could also be part of a compensatory mechanism activated by the visual cue [116]. It may be that cued movement is additionally facilitated by inhibition of unwanted or involuntary movement. Another explanation for the activation of the auditory and olfactory cortex could be loss of functional segregation [117].

\subsection{Conclusion}

The results of this study show large differences in activated areas during a bimanual tapping task in patients with PD and ET and between the patient groups and HC. The contrast cued movement versus non-cued movement revealed the most notable differences between groups. In ET, cueing seemed to have almost no effect on activation, while in the PD group crossmodelling between different areas seems to occur. Furthermore, reduced 
activation of the motor cortex was found in the ET group compared to the HC group. Therefore, the hypothesis concerning reduced activation of the motor cortex is confirmed. The results suggest that a cueing task in combination with fMRI could be used in an objective diagnostic protocol in patients that are difficult to diagnose. 


\section{General discussion and conclusion}

Movement disorders affect approximately $28 \%$ of the general population older than 50 years of age [8]. Two of the most common movement disorders are discussed in this thesis, essential tremor (ET) and Parkinson's disease (PD). Diagnosis is often based on medical and family history, visible symptoms and neurological and physical examination. However, due to overlapping symptoms, such as tremor and deficits in movement initiation and execution, initial misdiagnosis is up to $20-37 \%$ [15-17]. New diagnostic tools are approaching, such as SPECT with dopamine transporter labeling [10], but these tests are often invasive, expensive and not widely available. Small, lightweight, and affordable sensors are readily available these days, enabling objective and quantitative recording of movement [118]. Therefore, objective, non-invasive quantification of symptoms for a faster and more accurate diagnosis, could become a reality soon. In this thesis we used accelerometers, EMG, EEG and fMRI to evaluate and quantify four simple movement tasks. Our results suggest that accelerometers and EMG data can provide useful, objective information about tremor and other movement parameters, and EEG and FMRI can be used to investigate the underlying pathological networks in the brain that are involved in abnormal movement performance.

The overall goal of this thesis was to determine the potential of quantitative methods in aiding the diagnostic process of movement disorders. The first research objective, quantifying tremor occurrence in ET and PD subjects and identifying corresponding cortical activity, was the topic of chapters 2 and 3. The second research objective, quantifying the timing ability of ET and PD subjects during cued and non-cued repetitive hand movements and identifying corresponding neuronal networks, was the topic of chapters 4 through 6 . Additionally, healthy control (HC) subjects were included for comparison between parameters found in the patient groups and the HC group. In the remainder of this chapter, specific aspects of each research objective and future direction as well as associated research topics are discussed. 


\subsection{Quantification of tremor severity and intermittency}

As tremor is the most common symptom in movement disorders, many classification schemes exist. However, tremor still complicates diagnosis of movement disorders, because it can be caused by a variety of, some probably still unknown, pathological changes in the central and peripheral nervous system [119]. In chapter 2 and 3 a general method to split accelerometer, EMG [51], and EEG (Chapter 2) data into tremor (TW) and non-tremor windows (NTW) was introduced. The method reliably detects pathological tremor, independent of the underlying cause or task. This is especially useful in the early phase of the diagnostic process when quantitative, objective assessment of a patient is needed. Bove et al. [120] showed that using five diagnostic criteria of tremor recordings can yield good differential diagnostic support. Splitting data into TW and NTW [51] prior to the analysis performed by Bove et al. [120] could result in an even higher sensitivity and specificity.

Pathological changes in the central nervous system have been identified for PD as well as ET. However, the exact underlying mechanisms and involved networks are still not fully understood. Therefore, studies combining peripheral tremor recording with EEG or fMRI are important for understanding and treating tremor, which might be the most peculiar symptom in movement disorders. In Parkinson's disease, it correlates only poorly with the dopaminergic deficit in the substantia nigra [121], in contrast to bradykinesia and other parkinsonian (hypokinetic) symptoms. Furthermore, deep brain stimulation (DBS) targets to improve motor functions are different for tremor (Vim DBS) and bradykinesia and akinesia (STN and GPi) [122]. But even with the most suitable target the effect of DBS on tremor suppression diminishes over time and with disease progression [122]. Helmich et al. introduced the dimmer-switch theory for parkinsonian resting tremor suggesting that the basal ganglia are acting as a switch for tremor and that the cerebello-thalamico-cortical circuit acts as a dimmer on tremor amplitude. This theory is supported by Duval et al. [123] who found evidence that tremor in PD is induced by abnormal BG firing, generated by the thalamus and modulated by the cerebellum. A recent study of Dirkx et al. [124] showed that the basal ganglia influences the cerebello-thalamocortical circuit through the motor cortex. These studies show that there 
might be other target sites in PD for successful tremor suppression than the STN. Our studies showed that studying these networks in the presence and absence of peripheral tremor could result in new insight into the intermittent phenomenon, and in several cases task dependency, of tremor. Changes in cortical activity due to tremor presence or absence during a short task are best recorded using EEG and DBS due to the high temporal resolution. A disadvantage of EEG is that only superficial activity is measured and activity changes in deeper brain structures cannot be localized very accurately. High-density EEG could reduce the spatial resolution limitations to some extend [125]. Due to its invasive nature DBS cannot be studied in healthy subjects for comparison. Furthermore, recordings are only possible from very limited regions and not the entire network. In patients with a clear task dependent tremor fMRI could be used to visualize the whole network instead of single nuclei.

Detecting tremor and other symptoms, reliably and objectively is not only important for diagnostic purposes but, if integrated for example into wearables or clothing, could be used to monitor, provide feedback to the patient and evaluate therapeutic interventions [126].

\subsection{Quantification of timing ability}

Patients with PD and ET experience difficulties with movement initiation and continuation. A well-known phenomenon in PD is freezing of gait [127]. That the timing ability in these patient groups is disturbed has been demonstrated in several studies $[39,45,46]$. However, studies often focus on a specific patient group. We showed that deficits in tapping accuracy (TA) and variability (TV) exist in PD and ET patients [89]. For this purpose patients performed a bimanual tapping task at two different cue frequencies, 2 and $4 \mathrm{~Hz}$ (see Figure 3.1 for a schematic task overview). The cue frequencies were presented using a digital metronome, which was alternately turned on and off. The results suggest that the addition of a straight forward bimanual tapping task with little equipment has the potential to be used in clinical practice to support clinical decision making during the diagnostic procedures of movement disorders. Especially, the combination of TA/TV and the occurrence of kinetic tremor resulted in interesting findings. Kinetic tremor seemed to have no influence in TA in PD patients, but resulted in worsening of the TA in ET patients [89]. This will 
have to be evaluated in a larger population, but seems to have potential in differentiating kinetic tremor in PD from kinetic tremor in ET.

Additionally, we have looked at cortical and subcortical activity patterns during the bimanual tapping task to identify pathological changes in neural activity in ET and PD. The network involved in timing motor tasks consists of the cerebellum, basal ganglia, supplementary motor area and rightinferior frontal and parietal cortical areas [128]. The cerebellum projects to the primary motor and premotor areas and is thought to be mainly involved in synchronization tasks [128]. Our findings in the HC group during the cued (synchronization) tapping task are in accordance with that. However, similar activation patterns were found during the non-cued (continuation) task. A possible explanation is that $\mathrm{HC}$ were able to perform the tasks automatically or at least that automaticity increased in the course of the task. Balsters et al. [129] showed that the cerebellar activity decreases with increasing automation of movement. In PD primarily the frontal areas were activated during both cued and non-cued movements. As the cerebellar activity is increased during synchronization tasks and projections from the cerebellum to the prefrontal cortex exist [130], it could be a compensatory mechanism in PD patients. Furthermore, this would also explain the wide area of activation seen in the ET group during the $2 \mathrm{~Hz}$ tapping task. Hyperactivity of the cerebellum is thought to be the underlying cause of ET, and a further increase of the activity of the cerebellum due to a motor task could result in hyper-activation of the frontal areas. One of the things we have not looked into in the second study, due to the limited population size, is a possible difference in the cortical activity pattern in patients with and without kinetic tremor. Further dividing each task into TW and NTW would be of interest, but requires a larger population. This could lead to more insight into the pathological nature of kinetic tremor and its influence on movement accuracy in PD and ET.

In chapter 6, patients performed the bimanual tapping task in the MRI scanner. In contrast to the EEG study, the cue $(2 \mathrm{~Hz})$ was presented visually instead of auditory because of the noise produced by the MRI scanner. Furthermore, the task design was slightly different. The block design of the task consisted of 1 minute of rest, 30 seconds without cue and 30 seconds with cue and 1 minute of continuous tapping, the first 30 seconds with cue followed by 30 seconds without cue (see Figure 6.2). Even with the adapted 
task design, less activation of the motor cortex was found in the ET group compared to the HC group. This supports the findings of the EEG study (Chapter 5). The contrast of cued movement versus non-cued movement showed the most notable differences between groups. In ET, cueing seemed to have almost no effect on activation patterns, but in the PD group crossmodelling between different sensory areas seemed to occur (Chapter 6). The cross-modelling seen in the PD group could be part of the underlying neural mechanism that facilitates movement initiation and continuation in this patient group when an external cue is presented.

In this thesis PD and ET subjects were included, who were diagnosed with PD or ET, respectively according to the current clinical diagnostic process. As mentioned before the rate of misdiagnosis could result in a potential bias of the outcomes of the studies included in this thesis. Only post mortem studies can give $100 \%$ certainty of the correct diagnosis. To minimize the changes of such a bias all subjects were included by an experienced movement specialist who was not involved in the diagnostic process. Also videos for rating the MDS-UPDRS and TRS were evaluated by a third specialist.

\subsection{Outlook}

The aim of this thesis was not so much determining underlying pathological networks and exact pathological mechanisms in PD and ET, as determining objective parameters that are different between these two groups. The overall idea behind this study was to develop an objective diagnostic system for movement disorders. A complete diagnostic system has not been established, but we showed that unique, objective parameters and patterns for specific movement disorders exist. New diagnostic, therapeutic and monitoring methods, such as machine learning [126, 131, 132], closed-loop DBS [133-135], other home-based monitoring systems [136] and ambulatory systems could make use of some of these objective parameters and patterns. Possible applications of our findings will be discussed briefly below.

Machine learning algorithms using kinetic parameters are often used in gait analysis [137, 138] for diagnostic purposes and monitoring of disease progression during medical interventions. Furthermore, machine learning 
algorithms for tremor evaluation are being developed [139]. Tremor parameters in the frequency domain used for machine learning are amplitude, power distribution, frequency dispersion and median frequency [139]. Our method to split data into TW and NTW could be used prior to feature extraction for machine learning. Parameters such as the tapping variability and accuracy could be used as new parameters for machine learning algorithms.

DBS is a treatment option for patients without significant cognitive or psychiatric problems who suffer from severe motor fluctuations due to medication or severe tremor which is non-responsive to medication [140]. It involves uni- or bilateral placement of electrodes in the brain, with the STN being the most effective and most commonly used target site. Postsurgical programming of the DBS can take 3 to 6 months for optimal results [140]. Re-programming can be done, but it does not happen automatically, based on for example symptom (re-)occurrence. Closed-loop DBS systems are still in the experimental stage. The idea is that they can measure electrophysiological signals of PD motor symptoms and automatically adapt the stimulation [141]. The introduced method for tremor detection is not suitable in its current form for closed-loop DBS. However, we showed that cortical patterns are different during tremor windows compared to non-tremor windows. The next step could be to determine cortical activity patterns prior to tremor onset allowing to prevent tremor to occur. If a reliable pattern can be found, this could be used for closed-loop DBS. Additionally EMG and accelerometer data could be reevaluated with respect to finding distinct changes in, for example, the power distribution of a signal prior to tremor onset or during a tremor episode. In case of finding such patterns, these could be used for adaptation of DBS stimulation. Such patterns could be used as input for machine learning algorithms in closed-loop DBS.

Another treatment option for movement disorders is lesion therapy [142]. It is one of the oldest treatments in movement disorders, but has run out of favor with the upcoming of DBS. Due to the irreversible nature of lesion therapy, DBS seemed the better solution for some time. However, with the emergence of magnetic resonance-guided high-intensity focused ultrasound it has once more captured the attention of researchers and clinicians. Using this method highly precise lesions can be induced without 
the need for open brain surgery. Its effectiveness has been shown in ET and PD when applied unilaterally. Long-term effects are yet to be looked at, but, as it is an incisionless approach with fewer risks of hemorrhaging, it seems to become an interesting treatment option once again. [142]. To determine the exact underlying pathological networks is of special interest, as possible new target sites may be found that are more easily accessible.

Data collected from home monitoring systems are often analyzed offline and after tasks have been performed. In such a setting our method for tremor detection could be used, for example for evaluating ON- and OFFtimes of Parkinson's disease patients, as it detects tremor during multiple tasks. Furthermore, we showed that cortical activity is different for TW and NTW. The same technique could be used to investigate other symptoms and in case of successful symptom reduction it could be used to determine whether a specific intervention results in more normal/healthy activity or in activation of compensatory pathways. Ambulatory systems are often used for symptom monitoring [143-145]. However, with the emerging technology of, for example, augmented and virtual reality, ambulatory systems for therapeutic interventions are becoming more and more interesting. Smart-glasses have been used to provide external auditory and visual cues to patients with Parkinson's disease $[145,146]$. The findings of our studies show that cueing has an effect on the movement abilities and cortical and subcortical activation patterns in PD but not so much in ET. These patterns, in addition to the TA and TV could be used to investigate the optimal cue for a system such as smart glasses to provide non-invasive therapeutic treatment for patients with PD, especially to support performing daily activities.

The cortical and subcortical activation patterns found in this thesis contribute to a better understanding of the underlying pathophysiology of PD and ET patients. Furthermore, we have found several quantitative and objective parameters that could be used to support clinical decision making during the diagnostic process of patients with movement disorders. To establish and determine these parameters (chapters 2 through 5) straight forward experimental setups were used. The equipment used in these studies is widely available and does not require specially trained personal, with exception of the MRI scanner. This is important, because establishing 
new diagnostic parameters with equipment that is hardly available, time consuming, expensive or only useable by highly trained personal, will not likely result in clinical usage.

\subsection{Conclusion}

At the beginning of this thesis two objectives were formulated. In chapters 2 and 3 the first objective, quantifying tremor occurrence in ET and PD subjects and identifying corresponding cortical activity, was discussed. The method introduced in chapter 2 to detect tremor in accelerometer and EMG data, is able to detect tremor occurrence in both data streams and during different motor task. Using this method, we were able to quantify tremor occurrence in PD and ET patients. This method provides a good basis for a more complete quantification of tremor and not just the occurrence. The next step should be to test this method in other patient groups and to recalculate more tremor parameters, other than the TSI for the detected tremor and non-tremor windows. The results of chapter 3 support the usefulness of splitting data into tremor and non-tremor epochs prior to any further analysis. The cortical activation patterns suggest a distinct difference in the underlying pathophysiology of parkinsonian and essential tremor. Therefore, it can be stated that the first objective has been met.

The second objective, quantifying the timing deficits of ET and PD subjects during voluntary movement under different conditions and identifying corresponding neuronal networks, was discussed in chapters 4 through 6 . The main finding was that auditory and visual cues effect patients with ET and PD differently. In chapter 4 we showed that the movement parameters TA and TV did not result in clear differences between the groups, but the co-occurrence of kinetic tremor effected the groups differently. In future studies, that focus on kinematic parameters, this effect should be analyzed in more depth. Chapters 5 and 6 showed that the differences in cortical and subcortical activity patterns are much clearer compared to the kinematic parameters alone. For future studies, we suggest to analyze whether the presence of tremor causes the differences found in the cortical and subcortical structures, or the presence and absence of the cue. Concluding, it can be said that objective 2 has been met, but that our findings also give cause for future studies. 


\section{Bibliography}

1. Helmich RC, Toni I, Deuschl G, Bloem BR: The pathophysiology of essential tremor and Parkinson's tremor. Curr Neurol Neurosci Rep 2013, 13(9):378.

2. Parkinson J: An essay on the shaking palsy. 1817. J Neuropsychiatry Clin Neurosci 2002, 14(2):223-236; discussion 222.

3. Gironell A, Kulisevsky J: Diagnosis and management of essential tremor and dystonic tremor. Ther Adv Neurol Disord 2009, 2(4):215222.

4. Davie CA: A review of Parkinson's disease. Br Med Bull 2008, 86:109-127.

5. Hirsch EC, Mouatt A, Faucheux B, Bonnet AM, Javoy-Agid F, Graybiel AM, Agid Y: Dopamine, tremor, and Parkinson's disease. Lancet 1992, 340(8811):125-126.

6. Helmich RC, Hallett M, Deuschl G, Toni I, Bloem BR: Cerebral causes and consequences of parkinsonian resting tremor: a tale of two circuits? Brain 2012, 135(Pt 11):3206-3226.

7. Mure H, Hirano S, Tang CC, Isaias IU, Antonini A, Ma Y, Dhawan V, Eidelberg D: Parkinson's disease tremor-related metabolic network: characterization, progression, and treatment effects. Neuroimage 2011, 54(2):1244-1253.

8. Wenning GK, Kiechl S, Seppi K, Muller J, Hogl B, Saletu M, Rungger G, Gasperi A, Willeit J, Poewe W: Prevalence of movement disorders in men and women aged 50-89 years (Bruneck Study cohort): a population-based study. Lancet Neurol 2005, 4(12):815-820.

9. Bares M, Husarova I, Lungu OV: Essential tremor, the cerebellum, and motor timing: towards integrating them into one complex entity. Tremor Other Hyperkinet Mov (N Y) 2012, 2.

10. Elble R, Deuschl G: Milestones in tremor research. Mov Disord 2011, 26(6):1096-1105.

11. Klaming R, Annese J: Functional anatomy of essential tremor: lessons from neuroimaging. AJNR Am J Neuroradiol 2014, 35(8):1450-1457.

12. Sharifi S, Nederveen AJ, Booij J, van Rootselaar AF: Neuroimaging essentials in essential tremor: a systematic review. Neuroimage Clin 2014, 5:217-231.

13. Raethjen J, Deuschl G: The oscillating central network of Essential tremor. Clin Neurophysiol 2012, 123(1):61-64.

14. Postuma RB, Berg D, Stern M, Poewe W, Olanow CW, Oertel W, Obeso J, Marek K, Litvan I, Lang AE et al: MDS clinical diagnostic 
criteria for Parkinson's disease. Mov Disord 2015, 30(12):15911601.

15. Post B, Merkus MP, de Bie RM, de Haan RJ, Speelman JD: Unified Parkinson's disease rating scale motor examination: are ratings of nurses, residents in neurology, and movement disorders specialists interchangeable? Mov Disord 2005, 20(12):1577-1584.

16. Rizzo G, Copetti M, Arcuti S, Martino D, Fontana A, Logroscino G: Accuracy of clinical diagnosis of Parkinson disease: A systematic review and meta-analysis. Neurology 2016, 86(6):566-576.

17. Jain S, Lo SE, Louis ED: Common misdiagnosis of a common neurological disorder: how are we misdiagnosing essential tremor? Arch Neurol 2006, 63(8):1100-1104.

18. Pagano G, Niccolini F, Politis M: Imaging in Parkinson's disease. Clin Med (Lond) 2016, 16(4):371-375.

19. de la Fuente-Fernandez R: Role of DaTSCAN and clinical diagnosis in Parkinson disease. Neurology 2012, 78(10):696-701.

20. Mansur PH, Cury LK, Andrade AO, Pereira AA, Miotto GA, Soares AB, Naves EL: A review on techniques for tremor recording and quantification. Crit Rev Biomed Eng 2007, 35(5):343-362.

21. Deuschl G, Lauk M, Timmer J: Tremor classification and tremor time series analysis. Chaos 1995, 5(1):48-51.

22. Timmer J, Gantert C, Deuschl G, Honerkamp J: Characteristics of hand tremor time series. Biol Cybern 1993, 70(1):75-80.

23. Hellwig B, Mund P, Schelter B, Guschlbauer B, Timmer J, Lucking CH: A longitudinal study of tremor frequencies in Parkinson's disease and essential tremor. Clin Neurophysiol 2009, 120(2):431-435.

24. Gao JB: Analysis of amplitude and frequency variations of essential and Parkinsonian tremors. Med Biol Eng Comput 2004, 42(3):345349.

25. Keijsers NL, Horstink MW, Gielen SC: Ambulatory motor assessment in Parkinson's disease. Mov Disord 2006, 21(1):34-44.

26. Spieker S, Boose A, Breit S, Dichgans J: Long-term measurement of tremor. Mov Disord 1998, 13 Suppl 3:81-84.

27. Breit S, Spieker S, Schulz JB, Gasser T: Long-term EMG recordings differentiate between parkinsonian and essential tremor. J Neurol 2008, 255(1):103-111.

28. di Biase L, Brittain JS, Shah SA, Pedrosa DJ, Cagnan H, Mathy A, Chen CC, Martin-Rodriguez JF, Mir P, Timmerman L et al: Tremor stability index: a new tool for differential diagnosis in tremor syndromes. Brain 2017, 140(7):1977-1986.

29. Sarma SV, Cheng ML, et al: The effect of cues on neurons in the basal ganglia in Parkinson's disease. Frontiers in Integrative Neuroscience 2012, 6 (40). 
30. Shibasaki H: Cortical activities associated with voluntary movements and involuntary movements. Clin Neurophysiol 2012, 123(2):229-243.

31. Wang SY, Aziz TZ, Stein JF, Liu X: Time-frequency analysis of transient neuromuscular events: dynamic changes in activity of the subthalamic nucleus and forearm muscles related to the intermittent resting tremor.J Neurosci Methods 2005, 145(1-2):151158.

32. Lalo E, Thobois S, Sharott A, Polo G, Mertens P, Pogosyan A, Brown P: Patterns of bidirectional communication between cortex and basal ganglia during movement in patients with Parkinson disease. J Neurosci 2008, 28(12):3008-3016.

33. Brown P: Oscillatory nature of human basal ganglia activity: relationship to the pathophysiology of Parkinson's disease. Mov Disord 2003, 18(4):357-363.

34. Little S, Brown P: The functional role of beta oscillations in Parkinson's disease. Parkinsonism Relat Disord 2014, 20 Suppl 1:S44-48.

35. Beudel M, Little S, Pogosyan A, Ashkan K, Foltynie T, Limousin P, Zrinzo L, Hariz M, Bogdanovic M, Cheeran B et al: Tremor Reduction by Deep Brain Stimulation Is Associated With Gamma Power Suppression in Parkinson's Disease. Neuromodulation 2015, 18(5):349-354.

36. Hirschmann J, Hartmann CJ, Butz M, Hoogenboom N, Ozkurt TE, Elben S, Vesper J, Wojtecki L, Schnitzler A: A direct relationship between oscillatory subthalamic nucleus-cortex coupling and rest tremor in Parkinson's disease. Brain 2013, 136(Pt 12):3659-3670.

37. Yahalom G, Simon ES, Thorne R, Peretz C, Giladi N: Hand rhythmic tapping and timing in Parkinson's disease. Parkinsonism Relat Disord 2004, 10(3):143-148.

38. Rubinstein TC, Giladi N, Hausdorff JM: The power of cueing to circumvent dopamine deficits: a review of physical therapy treatment of gait disturbances in Parkinson's disease. Mov Disord 2002, 17(6):1148-1160.

39. Freeman JS, Cody FW, Schady W: The influence of external timing cues upon the rhythm of voluntary movements in Parkinson's disease. J Neurol Neurosurg Psychiatry 1993, 56(10):1078-1084.

40. Willems AM, Nieuwboer A, Chavret F, Desloovere K, Dom R, Rochester L, Jones D, Kwakkel G, Van Wegen E: The use of rhythmic auditory cues to influence gait in patients with Parkinson's disease, the differential effect for freezers and non-freezers, an explorative study. Disabil Rehabil 2006, 28(11):721-728. 
41. Suteerawattananon M, Morris GS, Etnyre BR, Jankovic J, Protas EJ: Effects of visual and auditory cues on gait in individuals with Parkinson's disease. J Neurol Sci 2004, 219(1-2):63-69.

42. Espay AJ, Beaton DE, Morgante F, Gunraj CA, Lang AE, Chen R: Impairments of speed and amplitude of movement in Parkinson's disease: a pilot study. Mov Disord 2009, 24(7):1001-1008.

43. Cerasa A, Hagberg GE, Peppe A, Bianciardi M, Gioia MC, Costa A, Castriota-Scanderbeg A, Caltagirone C, Sabatini U: Functional changes in the activity of cerebellum and frontostriatal regions during externally and internally timed movement in Parkinson's disease. Brain Res Bull 2006, 71(1-3):259-269.

44. Samuel M, Ceballos-Baumann AO, Blin J, Uema T, Boecker H, Passingham RE, Brooks DJ: Evidence for lateral premotor and parietal overactivity in Parkinson's disease during sequential and bimanual movements. A PET study. Brain 1997, 120 ( Pt 6):963-976.

45. Farkas Z, Szirmai I, Kamondi A: Impaired rhythm generation in essential tremor. Mov Disord 2006, 21(8):1196-1199.

46. Avanzino L, Bove M, Tacchino A, Ruggeri P, Giannini A, Trompetto C, Abbruzzese G: Cerebellar involvement in timing accuracy of rhythmic finger movements in essential tremor. Eur J Neurosci 2009, 30(10):1971-1979.

47. Alty JE, Kempster PA: A practical guide to the differential diagnosis of tremor. Postgrad Med J 2011, 87(1031):623-629.

48. Jankovic J: Parkinson's disease: clinical features and diagnosis. $J$ Neurol Neurosurg Psychiatry 2008, 79(4):368-376.

49. Louis ED: Essential tremor. Lancet Neurol 2005, 4(2):100-110.

50. Thenganatt MA, Jankovic J: The relationship between essential tremor and Parkinson's disease. Parkinsonism Relat Disord 2016, 22 Suppl 1:S162-165.

51. Luft F, Sharifi S, Mugge W, Schouten AC, Bour LJ, van Rootselaar AF, Veltink PH, Heida T: A Power Spectral Density-Based Method to Detect Tremor and Tremor Intermittency in Movement Disorders. Sensors (Basel) 2019, 19(19).

52. Muthuraman M, Schnitzler A, Groppa S: [Pathophysiology of tremor]. Nervenarzt 2018, 89(4):408-415.

53. Kane A, Hutchison WD, Hodaie M, Lozano AM, Dostrovsky JO: Enhanced synchronization of thalamic theta band local field potentials in patients with essential tremor. Exp Neurol 2009, 217(1):171-176.

54. Melgari JM, Curcio G, Mastrolilli F, Salomone G, Trotta L, Tombini M, di Biase L, Scrascia F, Fini R, Fabrizio E et al: Alpha and beta EEG power reflects L-dopa acute administration in parkinsonian patients. Front Aging Neurosci 2014, 6:302. 
55. Air EL, Ryapolova-Webb E, de Hemptinne C, Ostrem JL, Galifianakis NB, Larson PS, Chang EF, Starr PA: Acute effects of thalamic deep brain stimulation and thalamotomy on sensorimotor cortex local field potentials in essential tremor. Clin Neurophysiol 2012, 123(11):2232-2238.

56. Oldfield RC: The assessment and analysis of handedness: the Edinburgh inventory. Neuropsychologia 1971, 9(1):97-113.

57. Gelb DJ, Oliver E, Gilman S: Diagnostic criteria for Parkinson disease. Arch Neurol 1999, 56(1):33-39.

58. Chouinard S, Louis ED, Fahn S: Agreement among movement disorder specialists on the clinical diagnosis of essential tremor. Mov Disord 1997, 12(6):973-976.

59. Nunez PL, Srinivasan R, Westdorp AF, Wijesinghe RS, Tucker DM, Silberstein RB, Cadusch PJ: EEG coherency. I: Statistics, reference electrode, volume conduction, Laplacians, cortical imaging, and interpretation at multiple scales. Electroencephalography and clinical neurophysiology 1997, 103(5):499-515.

60. Holmes A, Illowsky, B., Dean, S.: Introductory Business Statistics. In. Edited by OSCRiceUniversity; 2015: 1 .

61. Louis ED, Hernandez N, Michalec M: Prevalence and correlates of rest tremor in essential tremor: cross-sectional survey of 831 patients across four distinct cohorts. Eur J Neurol 2015, 22(6):927932.

62. Cohen O, Pullman S, Jurewicz E, Watner D, Louis ED: Rest tremor in patients with essential tremor: prevalence, clinical correlates, and electrophysiologic characteristics. Arch Neurol 2003, 60(3):405410.

63. Raethjen J, Govindan RB, Kopper F, Muthuraman M, Deuschl G: Cortical involvement in the generation of essential tremor. $J$ Neurophysiol 2007, 97(5):3219-3228.

64. Archer DB, Coombes SA, Chu WT, Chung JW, Burciu RG, Okun MS, Wagle Shukla A, Vaillancourt DE: A widespread visually-sensitive functional network relates to symptoms in essential tremor. Brain 2018, 141(2):472-485.

65. Hallett M: Parkinson's disease tremor: pathophysiology. Parkinsonism Relat Disord 2012, 18 Suppl 1:S85-86.

66. Sharifi S, Luft F, Verhagen R, Heida T, Speelman JD, Bour LJ, van Rootselaar AF: Intermittent cortical involvement in the preservation of tremor in essential tremor. J Neurophysiol 2017, 118(5):2628-2635.

67. Synofzik M, Lindner A, Thier P: The cerebellum updates predictions about the visual consequences of one's behavior. Curr Biol 2008, 18(11):814-818. 
68. Nantel J, McDonald JC, Tan S, Bronte-Stewart H: Deficits in visuospatial processing contribute to quantitative measures of freezing of gait in Parkinson's disease. Neuroscience 2012, 221:151156.

69. Deuschl G, Elble R: Essential tremor--neurodegenerative or nondegenerative disease towards a working definition of ET. Mov Disord 2009, 24(14):2033-2041.

70. Louis ED, Ferreira JJ: How common is the most common adult movement disorder? Update on the worldwide prevalence of essential tremor. Mov Disord 2010, 25(5):534-541.

71. Pringsheim T, Jette N, Frolkis A, Steeves TD: The prevalence of Parkinson's disease: a systematic review and meta-analysis. Mov Disord 2014, 29(13):1583-1590.

72. Parker KL, Lamichhane D, Caetano MS, Narayanan NS: Executive dysfunction in Parkinson's disease and timing deficits. Frontiers in integrative neuroscience 2013, 7:75.

73. Elble RJ: Essential tremor is a monosymptomatic disorder. Mov Disord 2002, 17(4):633-637.

74. Espay AJ, Lang AE, Erro R, Merola A, Fasano A, Berardelli A, Bhatia KP: Essential pitfalls in "essential" tremor. Mov Disord 2017.

75. Bhatia KP, Bain P, Bajaj N, Elble RJ, Hallett M, Louis ED, Raethjen J, Stamelou M, Testa CM, Deuschl G et al: Consensus Statement on the classification of tremors. from the task force on tremor of the International Parkinson and Movement Disorder Society. Mov Disord 2018, 33(1):75-87.

76. Shahed J, Jankovic J: Exploring the relationship between essential tremor and Parkinson's disease. Parkinsonism Relat Disord 2007, 13(2):67-76.

77. Salzman B: Gait and balance disorders in older adults. American family physician 2010, 82(1):61-68.

78. de Lau LM, Breteler MM: Epidemiology of Parkinson's disease. Lancet Neurol 2006, 5(6):525-535.

79. Hopfner F, Ahlf A, Lorenz D, Klebe S, Zeuner KE, Kuhlenbaumer G, Deuschl G: Early- and late-onset essential tremor patients represent clinically distinct subgroups. Mov Disord 2016, 31(10):1560-1566.

80. Hess CW, Pullman SL: Tremor: clinical phenomenology and assessment techniques. Tremor Other Hyperkinet Mov (N Y) 2012, 2.

81. Elble RJ: What is essential tremor? Curr Neurol Neurosci Rep 2013, 13(6):353.

82. Tolleson CM, Dobolyi DG, Roman OC, Kanoff K, Barton S, Wylie SA, Kubovy M, Claassen DO: Dysrhythmia of timed movements in Parkinson's disease and freezing of gait. Brain Res 2015, 1624:222231. 
83. Carboncini MC, Manzoni D, Strambi S, Bonuccelli U, Pavese N, Andre P, Rossi B: The relation between EMG activity and kinematic parameters strongly supports a role of the action tremor in parkinsonian bradykinesia. Mov Disord 2001, 16(1):47-57.

84. Franz EA, Ivry RB, Helmuth LL: Reduced Timing Variability in Patients with Unilateral Cerebellar Lesions during Bimanual Movements. J Cogn Neurosci 1996, 8(2):107-118.

85. Teravainen H, Calne DB: Action tremor in Parkinson's disease. $J$ Neurol Neurosurg Psychiatry 1980, 43(3):257-263.

86. Gijsberts A, Caputo B: Exploiting accelerometers to improve movement classification for prosthetics. IEEE International Conference on Rehabilitation Robotics : [proceedings] 2013, 2013:6650476.

87. Ziv I, Avraham M, Michaelov Y, Djaldetti R, Dressler R, Zoldan J, Melamed E: Enhanced fatigue during motor performance in patients with Parkinson's disease. Neurology 1998, 51(6):1583-1586.

88. Heida T, Wentink EC, Marani E: Power spectral density analysis of physiological, rest and action tremor in Parkinson's disease patients treated with deep brain stimulation. Journal of neuroengineering and rehabilitation 2013, 10:70.

89. Luft F, Sharifi S, Mugge W, Schouten AC, Bour LJ, van Rootselaar AF, Veltink PH, Heida T: Deficits in tapping accuracy and variability in tremor patients. Journal of neuroengineering and rehabilitation 2019, 16(1):54.

90. Gerloff C, Richard J, Hadley J, Schulman AE, Honda M, Hallett M: Functional coupling and regional activation of human cortical motor areas during simple, internally paced and externally paced finger movements. Brain 1998, 121 ( Pt 8):1513-1531.

91. Jia X, Kohn A: Gamma rhythms in the brain. PLoS Biol 2011, 9(4):e1001045.

92. Wooten GF, Currie LJ, Bovbjerg VE, Lee JK, Patrie J: Are men at greater risk for Parkinson's disease than women? J Neurol Neurosurg Psychiatry 2004, 75(4):637-639.

93. Hubble JP, Busenbark KL, Pahwa R, Lyons K, Koller WC: Clinical expression of essential tremor: effects of gender and age. Mov Disord 1997, 12(6):969-972.

94. Hirsch L, Jette N, Frolkis A, Steeves T, Pringsheim T: The Incidence of Parkinson's Disease: A Systematic Review and Meta-Analysis. Neuroepidemiology 2016, 46(4):292-300.

95. O'Suilleabhain PE, Matsumoto JY: Time-frequency analysis of tremors. Brain 1998, 121 ( Pt 11):2127-2134.

96. Wile DJ, Ranawaya R, Kiss ZH: Smart watch accelerometry for analysis and diagnosis of tremor. J Neurosci Methods 2014, 230:1-4. 
97. Walsh RR, Small SL, Chen EE, Solodkin A: Network activation during bimanual movements in humans. Neuroimage 2008, 43(3):540-553.

98. Bronstein AM, Hood JD, Gresty MA, Panagi C: Visual control of balance in cerebellar and parkinsonian syndromes. Brain 1990, 113 (Pt 3):767-779.

99. Chen HM, Wang ZJ, Fang JP, Gao LY, Ma LY, Wu T, Hou YN, Zhang JR, Feng T: Different patterns of spontaneous brain activity between tremor-dominant and postural instability/gait difficulty subtypes of Parkinson's disease: a resting-state fMRI study. CNS Neurosci Ther 2015, 21(10):855-866.

100. Benito-Leon J, Louis ED, Romero JP, Hernandez-Tamames JA, Manzanedo E, Alvarez-Linera J, Bermejo-Pareja F, Posada I, Rocon E: Altered Functional Connectivity in Essential Tremor: A RestingState fMRI Study. Medicine (Baltimore) 2015, 94(49):e1936.

101. Wu T, Wang L, Chen Y, Zhao C, Li K, Chan P: Changes of functional connectivity of the motor network in the resting state in Parkinson's disease. Neurosci Lett 2009, 460(1):6-10.

102. Baudrexel S, Witte T, Seifried C, von Wegner F, Beissner F, Klein JC, Steinmetz H, Deichmann R, Roeper J, Hilker R: Resting state fMRI reveals increased subthalamic nucleus-motor cortex connectivity in Parkinson's disease. Neuroimage 2011, 55(4):1728-1738.

103. Stegemoller EL, Simuni T, MacKinnon C: Effect of movement frequency on repetitive finger movements in patients with Parkinson's disease. Mov Disord 2009, 24(8):1162-1169.

104. Espay AJ, Lang AE, Erro R, Merola A, Fasano A, Berardelli A, Bhatia KP: Essential pitfalls in "essential" tremor. Mov Disord 2017, 32(3):325-331.

105. Costa J, Gonzalez HA, Valldeoriola F, Gaig C, Tolosa E, Valls-Sole J: Nonlinear dynamic analysis of oscillatory repetitive movements in Parkinson's disease and essential tremor. Mov Disord 2010, 25(15):2577-2586.

106. Heremans E, Nieuwboer A, Feys P, Vercruysse S, Vandenberghe W, Sharma N, Helsen WF: External cueing improves motor imagery quality in patients with Parkinson disease. Neurorehabil Neural Repair 2012, 26(1):27-35.

107. Wu T, Hallett M: A functional MRI study of automatic movements in patients with Parkinson's disease. Brain 2005, 128(Pt 10):22502259.

108. Buijink AW, Broersma M, van der Stouwe AM, van Wingen GA, Groot PF, Speelman JD, Maurits NM, van Rootselaar AF: Rhythmic finger tapping reveals cerebellar dysfunction in essential tremor. Parkinsonism Relat Disord 2015, 21(4):383-388. 
109. Ghadimi M, Sapra A, Magnetic Resonance Imaging (MRI), Contraindications, 2019

110. Floyer-Lea A, Matthews PM: Changing brain networks for visuomotor control with increased movement automaticity. $J$ Neurophysiol 2004, 92(4):2405-2412.

111. Pekkola J, Ojanen V, Autti T, Jaaskelainen IP, Mottonen R, Tarkiainen A, Sams M: Primary auditory cortex activation by visual speech: an fMRI study at 3 T. Neuroreport 2005, 16(2):125-128.

112. Calvert GA, Bullmore ET, Brammer MJ, Campbell R, Williams SC, McGuire PK, Woodruff PW, Iversen SD, David AS: Activation of auditory cortex during silent lipreading. Science 1997, 276(5312):593-596.

113. Lim I, van Wegen E, de Goede C, Deutekom M, Nieuwboer A, Willems A, Jones D, Rochester L, Kwakkel G: Effects of external rhythmical cueing on gait in patients with Parkinson's disease: a systematic review. Clin Rehabil 2005, 19(7):695-713.

114. Schaefer RS: Auditory rhythmic cueing in movement rehabilitation: findings and possible mechanisms. Philos Trans R Soc Lond B Biol Sci 2014, 369(1658):20130402.

115. Wesson DW, Wilson DA: Smelling sounds: olfactory-auditory sensory convergence in the olfactory tubercle. J Neurosci 2010, 30(8):3013-3021.

116. Aron AR, Robbins TW, Poldrack RA: Inhibition and the right inferior frontal cortex. Trends Cogn Sci 2004, 8(4):170-177.

117. Kaasinen V, Rinne JO: Functional imaging studies of dopamine system and cognition in normal aging and Parkinson's disease. Neurosci Biobehav Rev 2002, 26(7):785-793.

118. FitzGerald JJ, Lu Z, Jareonsettasin P, Antoniades CA: Quantifying Motor Impairment in Movement Disorders. Front Neurosci 2018, 12:202.

119. Fahn S: Classification of movement disorders. Mov Disord 2011, 26(6):947-957.

120. Bove F, Di Lazzaro G, Mulas D, Cocciolillo F, Di Giuda D, Bentivoglio AR: A role for accelerometry in the differential diagnosis of tremor syndromes. Funct Neurol 2018, 33(1):45-49.

121. Carr J: Tremor in Parkinson's disease. Parkinsonism Relat Disord 2002, 8(4):223-234.

122. Fasano A, Daniele A, Albanese A: Treatment of motor and non-motor features of Parkinson's disease with deep brain stimulation. Lancet Neurol 2012, 11(5):429-442.

123. Duval C, Daneault JF, Hutchison WD, Sadikot AF: A brain network model explaining tremor in Parkinson's disease. Neurobiol Dis 2016, 85:49-59. 
124. Dirkx MF, den Ouden H, Aarts E, Timmer M, Bloem BR, Toni I, Helmich RC: The Cerebral Network of Parkinson's Tremor: An Effective Connectivity fMRI Study. J Neurosci 2016, 36(19):53625372.

125. Klamer S, Elshahabi A, Lerche H, Braun C, Erb M, Scheffler K, Focke NK: Differences between MEG and high-density EEG source localizations using a distributed source model in comparison to fMRI. Brain Topogr 2015, 28(1):87-94.

126. Kubota KJ, Chen JA, Little MA: Machine learning for large-scale wearable sensor data in Parkinson's disease: Concepts, promises, pitfalls, and futures. Mov Disord 2016, 31(9):1314-1326.

127. Spildooren J, Vinken C, Van Baekel L, Nieuwboer A: Turning problems and freezing of gait in Parkinson's disease: a systematic review and meta-analysis. Disabil Rehabil 2018:1-11.

128. Avanzino L, Pelosin E, Vicario CM, Lagravinese G, Abbruzzese G, Martino D: Time Processing and Motor Control in Movement Disorders. Front Hum Neurosci 2016, 10:631.

129. Balsters JH, Ramnani N: Cerebellar plasticity and the automation of first-order rules. J Neurosci 2011, 31(6):2305-2312.

130. Glickstein M, Doron K: Cerebellum: connections and functions. Cerebellum 2008, 7(4):589-594.

131. Ahmadi Rastegar D, Ho N, Halliday GM, Dzamko N: Parkinson's progression prediction using machine learning and serum cytokines. NPJ Parkinsons Dis 2019, 5:14.

132. Salvatore C, Cerasa A, Castiglioni I, Gallivanone F, Augimeri A, Lopez M, Arabia G, Morelli M, Gilardi MC, Quattrone A: Machine learning on brain MRI data for differential diagnosis of Parkinson's disease and Progressive Supranuclear Palsy. J Neurosci Methods 2014, 222:230-237.

133. Rosin B, Slovik M, Mitelman R, Rivlin-Etzion M, Haber SN, Israel Z, Vaadia E, Bergman H: Closed-loop deep brain stimulation is superior in ameliorating parkinsonism. Neuron 2011, 72(2):370384.

134. Gorzelic P, Schiff SJ, Sinha A: Model-based rational feedback controller design for closed-loop deep brain stimulation of Parkinson's disease. J Neural Eng 2013, 10(2):026016.

135. Little S, Pogosyan A, Neal S, Zavala B, Zrinzo L, Hariz M, Foltynie T, Limousin P, Ashkan K, FitzGerald J et al: Adaptive deep brain stimulation in advanced Parkinson disease. Ann Neurol 2013, 74(3):449-457.

136. Patel S, Chen BR, Buckley T, Rednic R, McClure D, Tarsy D, Shih L, Dy J, Welsh M, Bonato P: Home monitoring of patients with Parkinson's 
disease via wearable technology and a web-based application. Conf Proc IEEE Eng Med Biol Soc 2010, 2010:4411-4414.

137. Figueiredo J, Santos CP, Moreno JC: Automatic recognition of gait patterns in human motor disorders using machine learning: A review. Med Eng Phys 2018, 53:1-12.

138. Begg R, Kamruzzaman J: A machine learning approach for automated recognition of movement patterns using basic, kinetic and kinematic gait data. J Biomech 2005, 38(3):401-408.

139. Dai H, Zhang P, Lueth TC: Quantitative Assessment of Parkinsonian Tremor Based on an Inertial Measurement Unit. Sensors (Basel) 2015, 15(10):25055-25071.

140. Bronstein JM, Tagliati M, Alterman RL, Lozano AM, Volkmann J, Stefani A, Horak FB, Okun MS, Foote KD, Krack P et al: Deep brain stimulation for Parkinson disease: an expert consensus and review of key issues. Arch Neurol 2011, 68(2):165.

141. Bouthour W, Megevand P, Donoghue J, Luscher C, Birbaumer N, Krack P: Biomarkers for closed-loop deep brain stimulation in Parkinson disease and beyond. Nat Rev Neurol 2019, 15(6):343-352.

142. Walters H, Shah BB: Focused Ultrasound and Other Lesioning Therapies in Movement Disorders. Curr Neurol Neurosci Rep 2019, 19(9):66.

143. Godinho C, Domingos J, Cunha G, Santos AT, Fernandes RM, Abreu D, Goncalves N, Matthews H, Isaacs T, Duffen J et al: A systematic review of the characteristics and validity of monitoring technologies to assess Parkinson's disease. Journal of neuroengineering and rehabilitation 2016, 13:24.

144. Salarian A, Russmann H, Vingerhoets FJ, Dehollain C, Blanc Y, Burkhard PR, Aminian K: Gait assessment in Parkinson's disease: toward an ambulatory system for long-term monitoring. IEEE Trans Biomed Eng 2004, 51(8):1434-1443.

145. Zwartjes DG, Heida T, van Vugt JP, Geelen JA, Veltink PH: Ambulatory monitoring of activities and motor symptoms in Parkinson's disease. IEEE Trans Biomed Eng 2010, 57(11).

146. Zhao Y, Nonnekes J, Storcken EJ, Janssen S, van Wegen EE, Bloem BR, Dorresteijn LD, van Vugt JP, Heida T, van Wezel RJ: Feasibility of external rhythmic cueing with the Google Glass for improving gait in people with Parkinson's disease. J Neurol 2016, 263(6):1156-1165. 


\section{List of journal publications}

1. Luft F, Fynne L, Gregersen H, Lundager F, Buntzen S, Lundby L, Laurberg S, Krogh K., Functional luminal imaging probe: a new technique for dynamic evaluation of mechanical properties of the anal canal. Tech Coloproctol. 2012 Dec;16(6):451-7. doi: 10.1007/s10151-012-0871-0. Epub 2012 Aug 31.

2. Fynne L, Luft F, Gregersen H, Buntzen S, Lundby L, Lundager F, Laurberg S, Krogh K., Distensibility of the anal canal in patients with systemic sclerosis: a study with the functional lumen imaging probe. Colorectal Dis. 2013 Jan;15(1):e40-7. doi: 10.1111/codi.12063.

3. Witteveen HJ., Luft F., Rietman JS., Veltink PH., Stiffness Feedback for Myoelectric Forearm Prostheses Using Vibrotactile Stimulation. IEEE Trans Neural System Rehabilitaion Eng. 2014 Jan;22(1):53-61. doi: 10.1109/ TNSRE.2013.2267394.

4. Sharifi, S., Mugge, W., Luft, F., Schouten, A. C., Heida, T. H., Bour, L. J., \& van Rootselaar, A. F. (2013). Differentiation of tremor disorders with fMRI: A novel quantitative approach. Movement disorders, 28(Suppl. 1), 157. DOI: $10.1002 / \mathrm{mds} .25605$

5. Sharifi S., Luft F., Verhagen R., Heida T., Speelman JD., Bour LJ., van Rootselaar AF., Intermittent cortical involvement in the preservation of tremor in essential tremor. Journal of Neurophysiology. 2017 Nov 1;118(5):2628-2635. doi: 10.1152/ jn.00848.2016.

6. S. Sharifi, F. Luft, S. Potgieter, T. Heida, W.Mugge, N.M. Maurits, A. C. Schouten, L.J. Bour, A.F. van Rootselaar. Directionality of corticomuscular coupling in essential tremor and cortical myoclonic tremor-it is all about the rhythm. Neurolmage

7. Luft F., Sharifi S., Mugge W., Schouten A. C., Bour L. J., van Rootselaar A. F., Veltink P. H., Heida T., Deficits in tapping accuracy and variability in tremor patient. Journal of NeuroEngineering and Rehabilitation, Volume 16, Article number: 54 (2019)

8. Luft, F., Sharifi S., Mugge W., Schouten A. C., Bour L. J., van Rootselaar A. F., Veltink P. H., Heida T., A Power Spectral Density-Based Method to Detect Tremor and Tremor Intermittency in Movement Disorders. Sensors (Basel), 2019. 19(19). 
9. Luft, F., Sharifi S., Mugge W., Schouten A. C., Bour L. J., van Rootselaar A. F., Veltink P. H., Heida T., Distinct cortical activity patterns in Parkinson's disease and Essential tremor during a bimanual tapping task, Journal of NeuroEngineering and Rehabilitation.

\section{Submitted journal publications}

1. Luft, F., Sharifi S., Mugge W., Schouten A. C., Bour L. J., van Rootselaar A. F., Veltink P. H., Heida T., Identifying tremor patterns in EEG of patients with Parkinson's disease and essential tremor; Journal of Clinical Neurophysiology.

2. Sharifi S., Luft F., Potgieter S., Heida T., Mugge W., Schouten A.C., Bour L.J., van Rootselaar A.F., Directionality of corticomuscular coupling in essential tremor and cortical myoclonic tremor-it is all about the rhythm 


\section{List of conference contributions}

1. Luft F., Sharifi S., Mugge W., Schouten A.C., Bour L., van Rootselaar A.F., Veltink P.H., Heida T. (2015). Automatic detection of tremor and nontremor windows in movement disorders. $5^{\text {th }}$ Dutch Bip-Medical Engineering Conference. January 2015.

2. Sharifi S., Mugge W., Luft F., Schouten A.C., Bour L., Heida T., van Rootselaar A.F. (2014). Manipulation of the sensorimotorloop with a novel quantitative fMRI approach reveals motor networks in essential

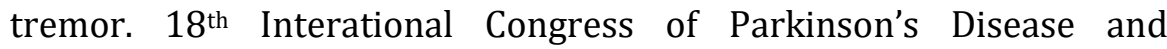
Movement Disorders. Stockholm, Sweden 2014.

3. Luft F., Sharifi S., Mugge W., Schouten A.C., Bour L., van Rootselaar A.F., Veltink P.H., Heida T. (2014). Differentiation between movement disorders by cortical activity. 18 ${ }^{\text {th }}$ Interational Congress of Parkinson's Disease and Movement Disorders. Stockholm, Sweden 2014.

4. Sharifi S., Mugge W., Luft F., Schouten A.C., Bour L., Heida T., van Rootselaar A.F. (2017). Unraveling essential tremor - manipulation of the sensorimotor loop with a novel quantitative fMRI approach. $3^{\text {rd }}$ Congress of the European Academy of Neurology. Amsterdam, The Netherlands 2017.

5. Sharifi S., Mugge W., Luft F., Schouten A.C., Bour L., Heida T., van Rootselaar A.F. (2015). The role of the motor cortex in essential tremor. XXI World Congress of Parkinson's Disease and Related Disorders.

6. Sharifi S., Luft F., van Scheepen J.A.M., Mugge W., Schouten A.C., Heida T., van Rootselaar A.F. (2014). Corticomuscular coherence in essential tremor during motor and cognitive tasks. Abstract from Clinical Neurophysiology.

7. Luft F., Sharifi S., Mugge W., Schouten A.C., Bour L., van Rootselaar A.F., Veltink P.H., Heida T. (2015). Error correction in essential tremor patients and healthy subjects during a constant torque task. $7^{\text {th }}$ International IEEE EMBS Conference on Neural Engineering. 


\section{Acknowledgement}

So, finally, I start writing the last piece of my thesis, the acknowledgements. Over the past $71 / 2$ years I have had the honor to meet a lot of people, who in the end, contributed to a bigger or smaller extend to this work. The list would be endless but I do want to mention a couple of people by name. Before I started writing I debated for a while whether to write it in English, Dutch or German or maybe a combination of it all depending on whom I am thanking. Sitting in the car, driving to Utrecht, I decided to write (most of) it in English and also on trying to not making it to cheesy. In case I forget to mention anybody, please don't feel offended! You have definitely contributed to the person I am today.

In 2010 I started looking for an internship. I knew I wanted to do something with neurostimulation and was send to Peter because he had contacts at Medtronic. Peter, since then you have been my supervisor and during the last weeks of writing my master thesis you offered me this $\mathrm{PhD}$ position in the MDS-project. Thank you for all the time and energy you invested in me and for the opportunities you provided me with!

Ciska, thank you for all the hours you helped me during these past years! Having you as my daily supervisor is what made this thesis possible in the end. All our countless talks about the data and the analysis, but also about everything else is what brought us here today. Trips to Amsterdam and especially to Montpellier will always be remembered.

None of this would have been possible without the MDS-project group. Sarvi, thank you for the countless hours we spend together getting the whole experimental setup ready, performing the experiments together, and of course for the trip to Stockholm to present our results at the Movement Disorder conference. Without you it would not have been the same (and I would have had to run a couple of extra miles throughout the AMC to get our MRI equipment to where it needed to be). Fleur, Winfred, Alfred and Lo, thank you for all the valuable feedback you gave me and all the questions you answered concerning physiology, methodology, analysis techniques and so many more. Working together with you on this project has taught me a lot! 
Wies and Sandra, without your help throughout this PhD journey I would have gotten lost about 100 times, my account would have been blocked and I would not have known where to begin in the first place. Thank you for all your help! A big thank you to the rest of the "old" BSS group, Heidi, Lamia, Wendy, Ainara, Hendrik, Marcel, Ed, Bert-Jan, Jan, Gerco, Betty and a special thanks to the Edinburgh/Whisk(e)y group, Kees, Frederiek, Fokke, Dirk, Hoessein, Thijs, and Robert-Jan, and to anyone I might have forgotten to mention by name. All of you made it four fun years at BSS with great Christmas parties, BSS uitjes, borrels, whiskey tastings and other activities! I also had the pleasure to mentor a couple of bachelor and master students during my time at BSS. To all of you a big "thank you" for all the work you have done. All of you have contributed to this thesis!

After spending 4 years at BSS I entered a "new world". The IT-world. I felt, and actually still feel, like I had to learn a new language. A big thank you to my "old" app team, Astrid, Niels, Nelis, Bas, Roald, Arnout, Roberto, Casper, Michiel, Willem and Bram. Living on our onbewoond eiland has been so much fun! Everything I learned from and with you, including the Dutch spelling, I can now use to be a better F...rauke for my new team Joost, Frank, Keoma, Carl, Hugo, Laurenz, Edwin and Paul. Thanks to Aniek and Jan for giving me the great opportunity to work for Ecare and thanks to all the other colleagues I did not mention by name!

Another group of people I need to thank is my friends and family. Thank you for all the great memories about trips to Croatia, Wales, New Year's Eve parties, nights out or with Magic Mike, Viking tours, boy group concerts, walks home (through snow or barefoot accompanied by slugs) or just sitting on the balcony talking all night long.

They always say choose your paranymphs wisely. Kees, after spending 4 years in the same office, drinking liters of coffee together and sharing some overlap in the topic around PD and tremor I hope you can take over in case I go into labor today. Vanessa, we share so many memories it would take a book of its own to name them all. For today, in case I go into labor I hope, as a pediatrician, you can get Junior out safely. Thank you both for standing by my side today! 
I want to thank my family. Mum and dad, thank you for always having my back, for always supporting me and for your unconditional love. I think if the worst thing you can say about your parents is "They made me watch Ronja Räubertochter" you got damn lucking in this world! Thank you, not only for being the best parents I could have asked for, but also for being wonderful grandparents to our Hannah. Maike and Niels, what can I say. I'll keep it short: an Tagen wie diesen the only thing we need to do is drink more wine. David and Tascha (and of course Bela and Lia, but those two did not really have a choice) thank you for putting up with our crazy family. Gerrie, Tonnie, Anke, Koen (and Krisse and Steffie), the moment Henk told me all of you could sing along with Marmor, Stein und Eisen bricht I knew I found the perfect match. A little crazy but always there for each other. Wednesday evenings would not be the same without you. I am very happy and thankful to be able to call you family.

Henk, my love, there are not enough words in this world to thank you! Working together at BSS has brought us so much more than we both ever expected. Thank you for taking a chance on me! These past years have been a kind of magic and I love the beautiful war we fight every night trying to put Hannah into bed and soon our son, too. I thank you for everything you do for me and our little family and I cannot wait to see what the future holds for us. I love you!

Hannah and Junior, don't worry you already have a name but we won't tell until you arrive, being a mum to you put everything in a different perspective. You show me what unconditional love truly means. I will love you always and forever! 